\title{
Pilzstudien in Finnland II
}

\author{
Otto von Schulmann
}

\section{Erste Fortsetzung: Das Jahr I 955}

Ausser der in Karstenia III aufgezählten Lit. standen 1955 zur Verfügung:

A. S. B o n d a r z e w. Trutovyie griby. 1953.

P. A. Karsten. Discomycetes. 1870 .

J. A. N a n n feldt. Studien über die Morphologie und Systematik der nichtlichenisierten inoperculaten Discomyceten. 1932.

A. A. P e a r s o n. The genus Russula. Revised ed. 1950.

A. Thesleff. Studier öfver basidsvampfloran i sydöstra Finnland. 1919.

Sehr verdienstvolle Werke, von denen jedoch nur das erstgenannte für die speziellen Zwecke dieser Arbeit benutzt werden konnte. Die Stärke des Bondarzewschen Buches liegt in der ungewöhnlich genauen und zuverlässigen Beschreibung der einzelnen Arten, während das Urteil über die zugrunde gelegte Systematik des Verfassers und R. Singers verschieden ausfallen kann. Ihre Anwendung in der vorliegenden Arbeit kam schon darum nicht in Frage, weil sie umfangreiche Erklärungen des sehr komplizierten Systems zur Voraussetzung gehabt hätte, durch welche der Rahmen dieser Arbeit völlig gesprengt worden wäre.

$\mathrm{Zu}$ obigen Werken gesellten sich zum Schluss der Pilzsaison:

R. H e i m. Le Genre Inocybe 1931.

J. S c h a e ffer. Russula-Monographie. 2. Auflage 1952.

In beide Werke konnte vorläufig nur oberflächlich Einblick genommen werden. Die Erfahrung wird erst zeigen in welchem Masse Heims Buch bei Bestimmung der finnländischen Arten von Nutzen ist. Mein vorläufiger Eindruck ist der, dass Heim, wie die meisten franz. Autoren, sich in der Hauptsache auf westeuropäische Arten beschränkt und die nördlichen Arten verhältnissmässig wenig beachtet. Schaeffers allgemein anerkannte Arbeit ist in den neuesten Publikationen der Mykologen aller Länder bereits so gründlich ausgenutzt worden, dass sie beim praktischen Bestimmen beinahe beiseite gelegt werden kann.

\section{Lohja 13-15. 5.}

Ein kurzer Besuch daselbst führte u.a. zu ff. Funden:

\section{Clitocybe vermiularis Fr.}

C. rhizophora (Vel.) Joss. Ich führe diese zwei Arten nur an, um zu betonen, dass diese nahe verwandten Pilze, die ich - wenn ich mich nicht irre als erster in Finnland feststellen konnte, keineswegs so selten sind, wie ich früher annahm. Ich fand sie am 19. 5. 55 auch auf Eckerö (Åland). Übrigens ist C. rhizophora garnicht und C. vermicularis nur kaum merklich hygrophan. Moser befindet sich hier in einem Irrtum, der die Benutzer der ersten Auflage seines guten Büchleins leicht in die Irre führen kann.

Pseudohiatula tenacella Fr. Métrod

Plectania (Sarcosypha) protracta Fr. $=P$, hiemalis (Nees et Bernst.) Seaver - 13. 5. - H. bis 1 breit, zuerst glockig, dann trichterförmig und schliesslich ausgebreitet und einreissend. Scheibe innen zinnober, aussen rötlich und schwach mehlig. F. bis $2 \times 2$, weisslich-zottig. Sp. $33-40 \times 14-$ 18, glatt, dickwandig, mit einem grossen Öltropfen. Vor einer Villa, auf dem Erdboden, meist in Grüppchen. 


\section{Eckerö 19. 5. - 6. 6 .}

Zweck dieses Besuches war mir Einblick zu verschaffen in die Pilzflora Ålands im Frühjahr. Das Resultat blieb hinter den Erwartungen zurück, da der Frühling sehr ungünstig war. Bis zum 20. 5. war es so nass, dass weite Strecken in Wald, Wiese und Weide unter Wasser standen. Ausserdem hatten wir bis zum 31.5. anhaltende Kälte (In der Nacht zum 25.5. gab es an einigen Stellen angeblich -5 Grad). Ich konnte nur 52 Arten feststellen. Nachstehend die Liste der Pilze, die ich bei früheren Besuchen Alands nicht hatte beobachten können:

\section{BASIDIOMYCETES.}

Clitocybe rhizophora Vel. Bres. - 19. 5.

C. vermicularis Fr. - 19. 5 .

Pseudohiatula tenacella (Pers.) Fr. Schröter, Favre 31. 5.

P. stephanocystis K. et Rom. - 19. 5.

P. tenacella (Fr.) Métrod, ss. Tuom. - 21. 5.

Rhodophyllus (Entoloma) aprilis (Britz.) Rom. f. typica - 19. 5. - F. graubraun.

R. aprilis f. majus Rom. (majalis Lange) - 24. 5 . - Heller und mit kleineren Sp. als f. typica.

$R$. hirtipes Schum. Lange - 21. 5 .

Tubaria pallidispora Lange ss. Kühn. Rom. - 30. 5. T. pellucida Bull. ss. Rom. - 3. 6 .

Pholiota carbonaria Fr. - 24. 5.

Psathyrella spintrigera Fr. ss. K. et Rom. - 4. 6. H. bis 6 breit, jung kastanienbraun, alt crème, event. mit violettlichem Schimmer, feinstens punktiert, Rand ausgesprochen gerieft und meist nicht behangen. F. bis $6 \times 6$, verbogen, hohl, aber relativ fest, faserstreifig, besonders oben, strohfarben, unten und oben heller. Basis verdickt. Ring nur im Jugendstadium. L. ziemlich breit (bis $8 \mathrm{~mm}$ ), bräunlich, dann dauernd violettlich. Sp. etwa eiförmig, oval, 6. 5-7. $5 \times$ $4.5-5.25$, purp. Im Walde, unter verfaulten Holzstücken. - Identisch mit Langes Stropharia spintrigera.

Calvatia saccata Vahl var. pistilliformis (Bon.) Holl. 22. 5. - Ein altes, aber sehr charakteristisches
Ex. dieser Var. F. nicht faltigrunzelig. Sp. 5-6 im Diam., mit Stielchen, warzig.

Geaster coronatus Schff. - 23. 5. - Gut erhaltene alte Pilze.

Lenzites quercina L. - 30. 5 .

Phellinus salicinus Pers. - 31. 5.

\section{ASCOMYCETES}

Morchella conica Pers. - 30. 5. - Der Pilz hat einen schmalen, vom F. abstehenden Rand, einen längsfurchigen $\mathrm{F}$. und $16-21$ breite, keulige Cystiden. Nach der neueren deutschen Lit. ist $M$. conica ganz ohne freien Rand und hat einen glatten F. und $9 \mathrm{~mm}$ breite Cystiden. Unklarer Fall. Freie Stelle im Mischwald, überwiegend Laubhölzer.

Gyromitra gigas Krombh. - 27. 5. - Exs. dem Forstwissenschaftlichen Inst. in Hels. übergeben.

Discina venosa Pers. - 27. 5. - Nur ein junges Ex. Scheibe $15 \mathrm{~mm}$ breit, innen braun, Mitte faltiggrubig, aussen heller, weisskleiig. F. ganz kurz und breit, durch Rippen aderig. Keine Sp. Nadelwald. Erdboden.

Sclerotinia tuberosa Hedw. - 22. 5. - Keineswegs immer auf Rhizomen der Anemone nemorosa.

Ciboria amentacea (Balbis) Fuckel - 25. 5. - H. bis 1 im Diam., kelchförmig, ausbreitend, kahl, hellbraun. F. dunkler braun, bis $3 \times 2$. Sp. 9-11 $1 \times 4-4.75$, ellipt., ziemlich farblos, Öltropfen. Sklerotium - wie nicht selten bei den Ciboria-Arten - nicht nachweisbar und Wirt nicht mehr feststellbar. Sehr gute Übereinstimmung mit Abbildungen und Text bei Seaver (»The North American Cup-fungi, Inoperculates»).

Elaphomyces cervinus L. - 19. 5. - Nur ein unreifes Ex. Frk. kugelig, haselnussgross. Schalenartige äussere Hülle starr und derb. Sie besteht aus krustenartiger, gelblicher Rinde, die mit runden, körnigen Warzen dicht besetzt ist, und einer weicheren inneren Schicht, die rötlich wird. Aussenrinde und Innenschicht untrennbar. Fruchtmasse nicht untersucht, da unreif-amorph und undifferenziert. Geruch nicht angenehm. Nur schlecht sichtbar auf einem aufgewühlten Waldwege im Nadelwalde. Im Normalfalle vielleicht ganz unterirdisch. Exs. im Forstwissenschaftlichen Inst. in Hels.

\section{Lohja 9. 6.}

Ich fand hier auf demselben toten Pflaumenstamm wie schon 1952 (Karstenia III., S. 53) denselben Pilz, den ich damals als Melanopus elegans Bull. bestimmte. Heute, nach Einsichtnahme in Bondarzews Werk, bin ich in der Lage diese Bestimmung zu vertiefen und in gewisser Hinsicht $\mathrm{zu}$ modifizieren. Es handelt sich hier um die Form squamigerus Pil. des Melanopus elegans ss. Pil., besser $M$. varius Pers. f. squamigerus Pil.

\section{Kasuri im Kirchspiel Parikkala 15. 6.- 3. 10.}

Den Sommer, beginnend mit dem 15. 6 . verbrachte ich im Gebiete Kasuri in Ostfinnland, in der nächsten Nähe der russischen
Grenze. Eingeschaltet wurden einige Besuche am Pyhäjärvi (etwas nördlicher, dicht an der Grenze), ferner im Gebiete südlich Vuori- 
niemi (Provinz Mikkeli) und vor allen Dingen in Punkaharju (bezeichnet mit »P.» in der folgenden Liste). Das Resultat war anfangs ein ganz schwaches. Während ich in den Jahren 1952-1954 bis Anf. Sept. alljährlich etwa 500 Arten und Varietäten feststellen und bestimmen konnte, erreichte ich hier nur knapp die Hälfte, wobei die Arten häufig durch vereinzelte, meistschlecht erhaltene Ex. vertreten waren. In Laienkreisen ist man leicht geneigt das schlechte Pilzjahr auf die 1955 herrschende Dürre zurückzuführen. Diese Erklärung mag im Allgemeinen nicht unrichtig sein, für den von mir untersuchten Teil Ostfinnlands gilt sie jedoch wenn überhaupt nur innerhalb recht bescheidener Grenzen. Wir hatten starke Niederschläge am 16 und 17 Juni, am 3 und 16 Juli und am 3 August. Ausserdem gab es mittlere Regen am 20 Juni, am 18, 20 und 22 Juli und am 4 August. Gewiss hätte es auch mehr regnen können, doch waren die Niederschläge doch soweit genügend, dass eine merkliche Schädigung der Landwirtschaft im Sommer nicht festgestellt werden konnte. Erst Ende August begannen Kartoffel- und Rübenfelder und Viehweiden besorgnisserregend auszusehen bis in der Nacht vom 30 auf den 31 August reichliche Herbstniederschläge eintraten, die dann bei relativ hohen Temperaturen bis in den Spätherbst hinein anhielten. Nun machte sich eine radikale Verbesserung der landwirtschaftlichen Lage geltend. Wenn die Ernte schliesslich recht mittelmässig ausfiel, so ist dies nur darauf zurückzuführen, dass Herbstgetreide und Klee schlecht überwintert hatten (zu nasser Herbst 1954, grosse Schneemassen auf schlecht oder garnicht gefrorenem Boden) resp. durch ein zu langes und zu kaltes Frühjahr geschädigt worden waren. Etwas ähnliches mag sich auf dem Gebiete der Pilzflora zugetragen haben. Es unterliegt schwerlich einem Zweifel, dass der nasse Winter und das kalte Frühjahr der Entwicklung der Myzelien wenig förderlich gewesen sind und die Entstehung von Fruchtkörpern im Sommer im grossen verhindert haben. In der Hoffnung auf einen nassen und warmen Herbst mit verspäteter Entwicklung von Fruchtkörpern beschloss ich meine Untersuchungen bis Anf. Oktober auszudehnen, mit ausgezeichnetem Resultat, denn als ich am 3 Oktober Kasuri verliess, hatte ich in summa wieder etwa 500
Arten festgestellt, wie in den vergangenen guten Pilzjahren. Um sich ein Bild von der eingetretenen Verspätung zu machen genügt der Hinweis auf einen Massenpilz dieser Gegend, Leccinum testaceo-scabrum Secr. Ich sah denselben zum ersten Mal im J. 1952 am 15. 6, im J. 1953 am 24. 6, im J. 1954 am 18. 7 und 1955 erst am 14. 9!

\section{BASIDIOMYCETES.}

Suillus elegans Schum. - 14. 9. - Am selben Tage auch P.

S. luteus L. - 7. 9.

S. bovinus L. - 13. 9 .

S. variegatus Sow. - 12. 9.

S. piperatus Bull. - 14. 9. - P

Leccinum aurantiacum Bull. - 14. 9. - P.

L. holopus Rostk. - 2. 10. - Ein grosser Pilz mit langem F. Sieht L. leucophaeum Gilb. ähnlich, ist aber überall weiss, nur mit leichtem grünem Anflug (z. B. auf der Röhrenschicht). Unter Birken.

L. leucophaeum Gilb. - 3. 7.

Boletus versicolor Rostk. (Vielleicht besser Xerocomus) - 21. 9.

B. edulis Bull. - 2. 9.

Tylopilus felleus Bull. - 8. 8.

Xerocomus badius Fr. - 14. 9. - $\mathrm{P}$.

$X$. subtomentosus L. -8.8 .

Paxillus involutus Batsch - 14. 7.

P. atrotomentosus Batsch - 9.8.

P. filamentosus Fr. - 10. 8 .

Hygrophoropsis aurantiaca Wulf. - 12. 9.

H. aurantiaca Wulf. f. pallida Cooke - 20. 9.

Gomphidius glutinosus Schff. - 9. 9.

G. roseus Fr. - 12. 9 .

G. viscidus L. - 15. 9.

Hygrophorus olivaceoalbus Fr. - 24. 9. - P.

H. agathosmus Fr. - 24. 9. - P.

Hygrocybe nigrescens Quel. - 22. 9.

H. conica Scop. - 22. 9.

Lyophyllum palustre (Peck) Sing. (clusilis Fr. ss. Schroet.; leucomyosotis Lange) - 5. 7. - H. bis 1.5 breit, konvex, nass dunkelolivbraun, trocken graubräunlich, durchscheinend gerieft. F. sehr gebrechlich, bis $5 \times 1$, braun, glatt. L. weisslichgrau, stark ausgebuchtet, beinahe frei, breit. Sp. $6.25-7 \times 4-4.5$, nicht warzig, aber mit granuliertem Inhalt. Keine Cyst. bemerkt. Auf Sphagnum.

L. erosum Fr. (plexipes Fr. f. typicum. K. et Rom.) - 2. 10. - H. bis 2 breit, bräunlich, nass gerieft, trocken nur radialfaserig. F. bis $3 \times 2$, bräunlich, weisslich überfasert. L. bauchig, tief ausgebuchtet. Sp. stachelig, $6-7 \times 5-6$ etc. Die Pilze dieser Gruppe werden bisweilen unter Collybia behandelt. S. Karstenia III, C. tesquorum, erosa und tylicolor auf S. 44 und 63.

Calocybe ionides Bull. - 19. 9. - H. 1-2 breit, lila, purpurn. Rand bereift. F. violettlich, $3 \times$ $2-3$. Basis weissfilzig. L. weiss. Sp. $6 \times 3$. Büschelig. Nasser Mischwald.

Clitocybe odora Bull. - 14. 9. 
C. odora Bull. var. alba Lange (C. Trogii Fr. ss. Cooke) - 23. 9.

Clitocybe clavipes Pers. - 29. 9. - Sp. bis $8 \times 4$ !

C. costata K. et Rom. - 16. 9. - Nur ein Ex. H. 7 breit, lederbraun, mit gekerbtem Rand, trichterförmig, beinahe kahl. F. $7 \times 7$, etwas blasser als der H. L. blass mit gelbem Ton, weit herablaufend. Sp. c. $7-7.5 \times 5$. Nasser Wald.

C. infundibuliformis Schff. - 6. 8.

C. sinopica Fr. - 10. 8

C. phyllophila Fr. -25.9.

C. cerussata Fr. f. ss. Langei (C. catinus Fr.?) 28. 9.

C. dealbata Sow. - 22. 9.

C. rivulosa Pers. - 21.8.-Normale und langstielige Formen.

C. candicans Pers. f. phyllophila - 19. 9.

C. olorina (Fr.) Gill. - 28. 9. - Im Gegensatz zu C. candicans Pers.: F. mehlig, voll, nie mit geknieter Basis den Blättern aufsitzend. L. fast bogig. Sp. wie bei C. candicans. Laubwald. Fragliche Art.

C. obsoleta Batsch - 17. 9. - Ohne gerieften Rand. Büschelig.

C. fragrans Sow. - 17. 9 .

C. suaveolens Schum. - 18. 9.

C. pinetorum Vel. - 24. 9. - P. - H. bis 2.5 bréit, honigfarben mit rötlichem Ton. Eingebogener Rand. Trocken blass, lederfleischfarben. F. bis $6 \times 8$, heller als der H., hohl. L. blass, schwach herablaufend. Sp. $4-5 \times 2.5-2.75$. Auf Nadeln.

C. dicolor Pers. - 30. 9.

Laccaria amethystina Bolt. - 22. 8.

L. laccata Scop. - 6. 8.

L. proxima Boud. - 29.8.

L. echinospora Speg. - 13. 8.

Tricholomopsis platyphylla Pers. - 28. 6. - Am 13. 7. auf Kieferwurzel.

T. rutilans Schff. -2.9

T. decora Fr. - 9. 8.

T. ornata Fr. - 18. 9. - Der Gesamteindruck dieses Pilzes ist ausgesprochen »oliv», keine Spur von rot. H. bis 10 breit, gewölbt, beinahe gebuckelt, gelb mit braunen Schüppchen besetzt. Rand eingebogen. F. exzentrisch, bis $12 \times$ mehr als 10, gleichdick, resp. nach oben verdickt, gelbbraun, faserig, oben mehlig. L. gelb, sehr breit, schwach herablaufend. Fl. gelblich. Sp. $6.5-8 \times 5-5.5$, weisslich. Cyst. am Rande zahlreich, von verschiedener Dicke (sichtbarer Teil bis 22 breit). Der Pilz, der nicht von mir gefunden wurde, wuchs nicht auf einem Baumstumpf, sondern unter Holzresten auf dem Erdboden im gemischten Walde, vielleicht auf einer Wurzel (meine Annahme). Kein Mehlgeschmack.

Die Lit, über die verwandten Pilze $T$. ornata und $T$. decora ist voller Widersprüche. Mein $\mathrm{Pilz}$ ist jedenfalls nicht identisch mit dem Pilz, den ich 53 und 54 und am 9.8.55 in Kasuri fand und der von mir als $T$. decora bestimmt wurde.

Collybia cirrhata Schum. var. typica Maire - 12. 9.

C. tuberosa Bull. - 19. 9.

C. dryophila Bull. - 21. 7.

C. dryophila Bull. var. funicularis Fr. - 9. 9.

C. aquosa Bull. - 23. 9.
C. butyracea Bull. - 19. 9.

C. asema Fr. - 8. 8.

C. maculata Alb. et Schw. - 14. 9. - P.

Omphalina umbellifera L. - 22. 6. - H. 1 breit, hellhonigfarben, genabelt, durchscheinend gerieft, schwach seidig. Rand eingebogen. F. $2.5 \times 3$, Farbe des H., oben schwach violettlich (siehe K. et Rom.). L. weit herablaufend, ziemlich entfernt, am Rande teilweise gegabelt, Farbe des H. Sp. 6.75--8 $\times 5.5-5.75$. Auf Sphagnum im Torfmoor.

O. umbellifera L. f. albida - 8. 7. - Gefunden im Walde s. Vuoriniemi.

O. rustica Fr. ss. Langei - 30. 6. - Einleitend sei bemerkt, dass dieser Pilz nicht identisch ist mit dem Pilze, den ich am 12. 9. 54 auf Eckerö fand (s. Karstenia III, Seite 63). H. bis 1.25 breit, dunkelgrau, hygrophan, durchscheinend gerieft, Rand beinahe gekerbt, tief genabelt. F. bis $1.5 \times 1$, dunkelgrau, oben dicker. Basis weissfilzig. L. grau, entfernt, dreieckig, nicht auffallend gegabelt am Rande, Randcystiden sehr klein, daher von Lange wohl übersehen. Sp. $6-7 \times 4.75-5.5$. Schnallen konnten nicht festgestellt werden. Auf sandigem Moorboden.

O. obscurata Kühn. (reclinis Fr.? oder rustica Pers.?) - 29. 7. - H. bis 0.8 breit, konvex, nicht genabelt, braun, Rand gerieft (wenn nass). F.bis $3 \times$ unter 1 , zäh, dunkel, schwach wurzelnd. L. graubraun, herablaufend, um 20 Stück, ziemlich breit. Sp. undeutlich amyloid, 11$13.5 \times 6-7.5$. Keine Cyst. gefunden. Waldweg. Meist Kiefer. Keine absolut sichere Bestimmung, da die Lit. nicht ausreicht. Sollte es sich herausstellen, dass der Pilz Bürstencyst. hat, dann handelt es sich wohl um O. (Mycena) pseudopicta Lange.

O. griseopallida (Desm.) Fr. - 22. 6. - H. bis 2 breit, nur schwach genabelt, Rand niedergebeugt und gefurcht. F. bis $2 \times 3$. L. breit, hinten besonders breit, buchtig herablaufend, normal entfernt, am Rande häufig gegabelt. Bas. meist zweisporig. Sp. verschieden gross, die zweisporigen offenbar grösser, $8-11 \times 5-6.75$. Cyst. nicht bemerkt. Feldrand, nasses Terrain.

Der Pilz wechselt auffallend in der Farbe. Als ich ihn nach 2 trockenen Tagen zuerst sah, erschien mir der $\mathrm{H}$. schmutzig gelbbraun und F. und L. was man unter »holzfarben» versteht. In Wasser getaucht wurde der H. olivgraulich, etwa wie $O$. umbellifera bei Lange Tab. $60 \mathrm{~J}$. Getrocknet wurden $\mathrm{H}$. und F. weiss infolge einer so gefärbten Filzschicht, besonders auf dem $\mathrm{H}$. Die L. wurden dagegen mit dem Rande beginnend braun. Allem Anscheine nach handelt es sich hier um den Pilz von K. et Rom. In der Lit. finden sich sehr abweichende Beschreibungen.

O. oniscus Fr. - 19. 8. - H. 2 breit, graubraun, tief genabelt, beinahe bis zur Mitte gefurcht. F. $4 \times 2$, Farbe des H., breitgedrückt, hell gepudert. L. stark herablaufend, Farbe des H. Sp. $6-8 \times 4-5.5$, bisweilen $9 \times 5.5$, nicht amyloid, nicht warzig oder stachelig, aber mit granuliertem Inhalt. Eine genaue Untersuchung des Pilzes am 29. 9. zeigte, dass Cyst. auf der Schneide eindeutig vorhanden sind. Geht man davon aus, dann führt die Bestimmung nach K. et Rom. zu den Gruppen Sect. E. und F. 
(Seite 125-127). Hier ist der Pilz aber nicht zu finden. Da er hier sehr gewöhnlich zu sein scheint, möchte ich davon Abstand nehmen von einer neuen Art zu reden. Viel wahrscheinlicher ist, dass $K$. et Rom. bei Untersuchung ihres $O$. oniscus die Cyst. nicht bemerkt haben. Geht man von dieser Annahme aus, dann deckt sich die Beschreibung der zwei franz. Gelehrten genau mit den hier gefundenen Pilzen.

Armillariella mellea Vahl - 2. 9.

Tricholoma flavobrunneum Fr. - 26. 9.

T. imbricatum Fr. - 1. 9.

Cantharellula umbonata Wulf. - 26. 9.

Melanoleuca strictipes Karst. - 28. 6.

M. evenosa (Sacc.) Konr. - 7. 8. - Nur ein Ex. Nicht identisch mit $M$. strictipes Karst. H. 6 breit, weiss-crème. F. $11 \times 8$, weisslich. L. schwach herablaufend, weiss, dicht. Sp. 9-11x $4.5-5.25$, viel länger und schmäler als bei $M$. strictipes. Die schwarzen Verfärbungen auf dem H. und auf den L. des Exs. sind beim Trocknen entstanden.

M. melaleuca Pers. - 18. 9.

M. cognata Fr. ss. Konr. et M. - 19. 9. - H. bis 6 breit, rehbraun, mindestens am Rande fein gerieft, stumpf gebuckelt, schwach hygrophan. F. bis $10 \times 8$, glatt, graulich, wurzelnd. L. ausgebuchtet, mit Zahn angewachsen, weisslich, später ockerrötlich, ungefähr 45 lang. Sp. amyloid und warzig, 8.5-9 $\times 5.5-6$. Keine Gyst. auf der Schneide bemerkt. Angenehmer süsslicher Geruch. Mischwald.

Pleurotus salignus Pers. - 5. 8. - H. bis 12 breit, violettlichgrau, horizontal, kahl, glatt. F. kurz, seitlich, unten weissfilzig. L. weiss, hinten nicht anastomisierend. Sp. $7-11 \times 3-4.5$. Cyst. mit freiem Teil, der c. 5 breit ist und oben bisweilen einen kleinen Kopf hat. Auf Eller.

Anm. Der am 23. 10. 49 in Mustila gefundene Pilz (siehe Karstenia III S. 26) war jedenfalls nicht $P$. salignus Pers. $\mathrm{Zu}$ langer $\mathrm{F}$. und $\mathrm{zu}$ grosse Sp.

P. pulmonarius Fr. - 30. 9. - Ziemlich klein, löffelresp. nierenförmig, braun. Seitlicher zottiger F. L. gelblich, herablaufend. Sp. $7-8 \times 4$, weiss. Auf Birkenast. Wird heute vielfach als Var. von $P$. ostreatus angesehen.

Panellus mitis Pers. - 2. 10.

Panus conchatus Fr. - 9. 8.

Lentinus lepideus Bull. - 25. 6.

Flammulina velutipes Curt. - 5. 9.

Micromphale perforans Hoffm. - 9. 9. - P.

Pseudohiatula conigena Pers. ex Fr. - 15. 6.

P. sp. - 15. 6. - H. grau. F. oben schneeweiss, unten rotbraun. L. weiss. Sp. $5.5-6 \times 2.75-3$, einseitig abgeplattet. Cyst. spitz und stumpf. Mild. Das Exs. hat nur einen halben H. Die andere Hälfte diente als Grundlage für die Untersuchung. Der Pilz wurde mir von einem Knaben aus einem Kieferwalde (mit wenigen Fichten) zugetragen.

Marasmius scorodonius Fr. - 24. 8.

M. oreades Bolt. - 15. 9.

M. androsaceus L. - 9. 8.

M. epiphyllus Fr. - 21. 9.

M. tremulae Vel. - 18. 9. - H. nur wenige mm breit, halbkugelig, dann konvex, weiss. F. $1 \times 0.3$, feinborstig. L. circa 8 Stück, aderförmig. Sp.-Grösse konnte nicht festgestellt werden. Cyst. schopfig. Auf Blättern von Populus tremula.

Xeromphalina campanella Batsch - 8. 7. - Südl. Vuoriniemi, Fichtenwald.

Delicatula integrella Pers. - 15. 7.- H. bis $7 \mathrm{~mm}$ breit, weiss, runzelig. F. bis $1.5 \times$ unter 0.5 , oben weiss, glasig, unten bräunlich. Basis etwas verdickt. L. flach, verzweigt, weiss, kaum herablaufend. Sp. etwa $7 \times 4.5$, amyloid. Auf einer Wurzel. Die dunkle Färbung des Exs. ist auf Jod zurückzuführen.

Fayodia sp. - 5. 8. - Vielleicht = lacerata Lasch. Nur ein Ex. H. $6 \mathrm{~mm}$ breit, graubraun, gerieft, breit genabelt. F. $2 \times 1$, oben weiss gepudert, nach unten zu dunkler (rötlich braun), ganz unten weissfilzig. L. mit Zahn angewachsen, schmutzig. Sp. citronförmig, dickwandig, amyloid, mit Perispor, innen ornamentiert, $6.5-7.2 \times 5.2-5.8$ (Vergrösserung mal 1350). Auf einem Ast.

Hydropus marginellus (Pers. ex Fr.). Sing. (Clitocybe umbrinomarginata Britz. = Omphalia philonotis Lasch ss. Karst?) - 19. 9. - H. bis 2 breit, graurussig, ausblassend. Trocken unter der Lupe flockig. Nass nur undeutlich am Rande gerieft. Trocken ungerieft. F. bis $3 \times 2$, grau, bereift. L. etwas heller als der H. Sp. amyloid 5.5-7 ×3-4. Cyst. aufder Schneide zahlreich. Daher häufig Verdunkelung der Schneide. Mischwald.

Mycena sanguinolenta Schw. - 14. 9. - P. - H. 1 breit, blassrötlich, mit blutrotem Rand, gerieft, glockig. F. $6 \times 0.5$, purpurbräunlich, gebrochen einen wässerigen, rötlichen Saft absondernd. L. weisslich mit rotbrauner Schneide, entfernt, ziemlich frei. Sp. um $8 \times 5$.

M. haematopoda Pers. - 15. 9.

M. galopoda Pers. f. typica. - 13. 9.

M. galopoda Pers. var. nigra. - 13. 9.

M. vitilis Fr. (iodiolens Lund.) - 11. 9.

M. galericulata Scop. - 20. 7.

M. rugosa Fr. - 29. 9. - Form von M. galericulata.

M. megaspora Kauffm. (permixta Britz.) - 30. 8. H. bis 3.5 breit, weit gerieft, dunkel graubraun bis schwarzbraun. F. bis $5 \times 4$, graubraun, oben heller. L. dicklich, grau. Sp. in der viersporigen Form $11-12 \times 7$ (unter den Exs. das grosse Ex.) und in der zweisporigen From $13-15 \times 6.5-8$. Torfmoor, auf Holzstückchen oder auf dem Torfboden. - Nordamerikanische Art, die vor nicht langer Zeit von Favre auch im trockenen Torfmoor der Fr. Jura gefunden wurde.

M. epipterygia Scop. - 23. 9.

M. viscosa Maire - 11. 9. — Ähnlich $M$. epipterygia Scop. H. graubraun bis gelblich. F. $10 \times 0.5$, gelb, mir schleimiger, dehnbarer Haur, wurzelnd. L. weisslich, mic Zahn angewachsen. Sp. $9-11 \times 6-7.5$, amyloid, erheblich breiter als die Sp. von $M$. epipterygia. Mischwald.

M. rubromarginata Fr. - 25. 9 .

M. rosella Fr. - 29. 9.

M. purpureofusca Peck - 27. 8.

M. pura Pers. f. typica - 18. 8.

$M$. pseudopura Cke non ss. Kühn. - 26. 9. - H. nur bis 2.5 breir, bräunlichlila. L. horizontal angewachsen, mit Zahn herablaufend. Sp. $6-7.5 \times 3.5-4.5$, schwach amyloid. Cyst. auf der L.fläche vorhanden. Grösse z.B. $112 \times 40$ und $68 \times 31$. Der Pilz steht also zwischen Kühners Arten pura und pseudopura. 
M. laevigata Lasch -2.10 .

M. polygramma Bull. f. pumila Lange - 29. 6. $\mathrm{H}$. bis 1.5 breit, dunkelbraun, stark gerieft. F. bis $3 \times 2$, etwas heller als der H., oben faserstreifig und schwach weiss gepudert, kaum richtig wurzelnd (nur schwach behaart), zäh. L. weissgrau. Sp. amyloid, etwa $10 \times 6$. Cyst. nicht bürstig, klein, nur 3-5 breit. Birkenstumpf.

$M$. leptocephala Fr. ( $M$. alcalina Fr, var. chlorinella Lange) - 18. 8.

$M$. vitilis (Fr.) Quel. ( $M$. filopes Bull. ss. Kühn.) - 23. 6. - Rhizoiden an der F.-Basis. Sp. bis $11 \times 17$. Winzige Cystiden, z.B. $10 \times 2.5$.

M. Jacobi Maire (pseudogalericulata Lange) - 5. 9. Nur ein Ex. Sehr ähnlich $M$. galericulata. H. 2.5 breit, grau, ausblassend bis beinahe weiss, gerieft-rinnig. F. $8 \times 2$, grau, dann weiss, röhrig, nicht so zäh wie bei $M$. galericulata. L. entfernt, schmal, mit Zahn angewachsen, nicht rötend. Sp. $9-10 \times 6-7$. Cyst. nicht bürstig, sondern glatt. Auf Birke.

M. alcalina Fr. - 4. 7.

M. flavoalba Fr. - 7. 9.

M. phaeophylla Kühn. - 11. 9. - M. speirea Fr. ss. Rick. sehr nahestehend. Nur ein Ex. H. 0.8 breit, graubraun, niedergedrückt, bis beinahe zur Mirte gerieft. F. $4 \times 1$, kahl, oben verdickt, heller als der H., zäh. L. angewachsen bis deutlich herablaufend, graulich (nicht weiss). Sp. 8-9.5 ×5.5-6.5, nicht amyloid. Auf Holzstückchen.

M. fibula Bull. - 4. 8.

M. Swartzii Fr. Sing. (Omphalia setipes Rick.) 22. 9. - Wie M. fibula Bull. H. braun, dunkler gerieft. Mitte schwärzlich. F. fädig, bräunlich, nach oben zu blauend. Sp. $5 \times 3$ etc. Im Moose.

M. ignobilis Joss. - 6. 7. - Nur ein schlechtes Ex. H. $3 \mathrm{~mm}$ breit, kahl, weiss. F. 1 lang, nur Bruchteil eines $\mathrm{mm}$ breit, weiss. L. weit herablaufend, nur wenige, sehr flach. Sp. $7-8 \times 4.25-5$. Auf einem Waldweg.

Baeospora myosura Fr. - 15. 8.

Lepista sordida Fr. - 1. 10.

Clitopilus prunulus Scop. - 14. 9. - P.

G. Giovanellae Bres. (Omphalia, Hexajuga) 28. 6. - H. einige mm breit, gewölbt, später schwach genabelt und ausgebreiter, graulichhoniggelb, weiss bereift, am Rande gerieft. F. $1-1.5$ lang und höchstens $1 \mathrm{~mm}$ breit, oben weisslich und bereift, unten glasartig, Farbe des H., ganz unten weissfilzig. L. herablaufend, etwa 16 gut ausgebildete ganze und ebensoviele kurze, weisslich, werden braunrandig. Sp. $5.75-6.5 \times 4$ mit kaum sichtbaren Längsfurchen (Ölimmersion!). Gyst. scheinbar nicht vorhanden. Hyphen ohne Schnallen. Im Moose, auf sandigmoorigem Seeufer.

Rhodophyllus turbidus Fr. ss. Rick. - 24. 9. - P. H. bis 7 breit, kegeligglockig, konvex-gebuckelt, olivbraun, trocken grau, durchscheinend gerieft. F. bis $8 \times 7$, hohl, gebrechlich, silbergraulich, gerieft, unten aufgeblasen und weiss. L. lange grau, fast frei. Sp. $8 \times 7$ etc. Ohne Geruch. Fichtenanpflanzung.

R. politus Pers. - 1. 10. - Ein Ex. H. 5 breit, hornbraun, trocken lederfarben, tief genabelt, trichterförmig. F. $10 \times 6$, faserstreifig, blass, oben weiss gepudert, unten weissfilzig. L. dicht, herablaufend, bleich (rötlich). Sp. sehr unregelmässig, $8 \times 7,7 \times 6, \max .9 \times 7$. Im Moose. Laubwald.

R. nidorosus Fr. - 17. 9.

R. rhodopolius Fr. - 14. 9. - P.

$R$. staurosporus (Bres.) Lange var. typicus - 5. 9.

R. Rickeni Romagn. - 5. 9. - Ein Ex. H. 1.5 breit, braungrau, wenig hygrophan, durchscheinend gerieft. F. weisslich, $3 \times 2$, unten verdickt, aber ohne richtige Knolle. L. ausgebuchtet. Sp. kreuzförmig. Grösse sehr verschieden, 9-11 $\times 8-9$. Sumpf.

$R$. hirtipes Schum. Lange var. typicus K. et Rom. - 17. 6. - Mit meist länglichen Sp. z.B. $11-17 \times 7-8$

R. hirtipes Schum. var. - 15. 6. - H. bis 4 breit, zugespitzt (schwach konisch), nass durchscheinend gerieft, trocken nur seidig, dunkel honigbraun, trocken ausblassend, aber nicht auffallend. F. bis $10 \times 6$, stark gerieft, etwa Farbe des $\mathrm{H}$. L. weisslich-bräunlich, schliesslich rötlichbraun, mit Randcyst. Sp. 4-5-eckig, bisweilen beinahe kreuzförmig, jedenfalls sich etwas denjenigen von $R$. staurosporus nähernd. Meist 7-9 im Durchmesser. Es kommen aber auch längliche Sp. vor. Hüte gebrechlich. Ziemlich geruch- und geschmacklos. Nasser Birkenwald.

Nicht die gewöhnliche Form von $R$. hirtipes mit länglichen $\mathrm{Sp}$. Aber auch nicht $R$. mammosus Fr. ss. K. et Maubl. mit schwachem Mehlgeruch und Mehlgeschmack.

R. mammosus Fr. ex L. ss. Boud. Rick. var. sericoides Kühn. 20. 6. - Fraglich ob als Var. aufrechtzuerhalten.

R. hebes Romagn. - 2. 10. - H. 1. 5-3 breit, braun, glänzend, schnell ausgebreitet, wenig entwickelte Papille. Trocken nur wenig verfärbt. F. $3-4 \times 2$, graubraun, weisslich gestreift. L. schmal und ziemlich dicht, Sp. $8-9.5 \times 6-7$. Mehlgeruch und Mehlgeschmack.

$R$. sericeus Bull. - 15. 8 .

R. junceus Fr. - 4. 9 .

R. griseorubellus Lasch ss. Karst. - 1. 9.

R. anatinus Lasch - 13. 9. - H. bis 3 breit, graubraun (nicht blau), mit dunklem, breitem Buckel, stumpf glockig, feinfaserig, auch riefelig, bisweilen rissig. F. dunkelblau (blau häufig gegen schwarz zurücktretend), $4 \times 2$. L. aufsteigend, breit, bauchig, zuerst weisslich, dann rötlich. Sp. sehr gross und unregelmässig, $10-14 \times 8-10$. Sumpfwald, überwiegend Birke.

$R$. asprellus Fr. ss. Quél. - 20. 9.

R. serrulatus Pers. - 17. 9.

$R$. caelestinus Fr. ss. Langei - 29. 9. - Ein Ex. H. 1 breit, graublau, gerieft. F. $3 \times 1$, stahlblau. L. rötend. Sp. rundlich, 8 im Diam. Nasser Laubwald.

R. rhodocylix Lasch - 28. 8.

R. parkensis Fr. - 23. 9. - H. bis 1.5 breit, honigbraun, trocken beinahe schwarz, stark genabelt, kahl, Rand gerieft. F. bis $3 \times 1.5$, braungrau. L. weisslich, dicht, herablaufend. Sp. $8-9.5 \times$ 6-7. Birkenwald. Von $R$. rusticoides Gill. schwer zu trennen. Lit. widerspruchsvoll.

R. nigrellus Quél. ss. Langei - 21. 9. - Ein Ex. H. 1 breit, dunkel graubraun, bis zum tiefen Nabel gerieft. F. $2.5 \times 1$, braun, unten weiss gepudert, Basis weissfilzig. L. rötlichbraun, weit 
herablaufend, ziemlich dicht. Sp. beinahe weiss, von sehr verschiedener Form, je nach dem von welcher Seite betrachtet, z. B. $5 \times 5$ (rund), $6 \times 3$ (oval), $12 \times 8$ (völlig unregelmässig) etc.

Pluteus petasatus Fr. - 7. 8. - Olivbraun.

P. patricius Schulz. (pellitus Pers. ss. Rick.) - 20 . 7. - Ein Ex. H. 9 breit, weiss, seidig, Mitte leicht braunschuppig. F. $12 \times 10-15$ (unten), ohne Knolle, unten grubig, weiss, sehr zäh. L. breit, frei. Sp. 6-7.5 $\times 4.5-5.5$. Cyst. ziemlich spärlich, mit oder ohne Haken. Auf Birkenstamm.

P. hispidulus Fr. - 28. 8. - Nur ein Ex. H. 1 breit, mit schwarzgrauen Faserschuppen dicht besetzt, Rand zart gerieft. Huthaut hyphisch. F. $1.5 \times 0.5$, sehr hell-bräunlich, oben verdickt und gepudert. Sp. 5.5-6.75 $\times 5-6$. Keine Hakencyst. Auf Birke. Vielleicht nicht identisch mit Langes Pilz.

P. pseudo-Roberti Moser (P. Roberti ss. Rick.) - 7. 7. - Huthaut hyphisch. H. bis 3 breit, crème, bräunend, faserig gestreift. F. bis $3 \times 2$ (oben)4 (unten), weiss, wird gelbbraun, faserstreifig, schwach mehlig. Unten leicht knollig. L. dicht, weisslich, werden rötlich, breit, aufsteigend. Sp. etwa $7 \times 5.5$ etc. Hakencyst., ziemlich kurz und dick, z. B. $43 \times 16$. Der Pilz ist ziemlich weich. Auf Birkenstamm.

P. murinus Pers. - 4. 8.

P. salicinus Pers. forma - 26. 7. - Nur ein Ex. H. 2.5 breit, halbkugelig, bräunlichgrau, Mitte dunkler, aber nicht schuppig, schwach klebrig, schwach radialfaserig. F. $4 \times 4$ (oben) -8 (unten), spindelig wurzelnd, zäh, faserstreifig, grauweisslich. L. aufsteigend, frei, weiss, sehr dicht, breit. Sp. $5.5-6.5 \times 4-4.75$. Es kommen aber ausnahmsweise auch solche von $8 \times 5.5$ vor. Sehr blass. Cyst. zahlreich, hakig. Grösse z. B. $68 \times 7$ (oben, unter den Haken) -16 (unten). Im Kieferwalde aut einem Stumpf, vermutlich Birke, keinesfalls Weide.

Wenn die Bestimmung mich nicht voll befriedigt, so ist dies darauf zurückzuführen, dass die Pluteus-Arten nicht genügend untersucht und beschrieben sind. Mein Pilz weist nicht die grünblauen Töne auf, die $P$. salicinus in der Lit. meist nachgesagt werden. Ausserdem wuchs er nicht auf Salix. Eigentlich hätte die Bestimmung leicht sein müssen, da der Pilz einwandfrei der Gruppe Coronati Lange angehört, die nur aus 6-7 Arten besteht:

$P$. cervinus Schff. allg. bekannt.

$P$. nigroflocculosus Schulz, allg. bekannt, eine Art, die ich mit $P$. petasatus ss. Karst. identifizierte (s. Karstenia III s. 64).

P. patricius Schulz. Gross, weiss. Siehe oben.

$P$. pellitus Pers. Mittelgross, weiss. Siehe Karstenia III, Seite 35.

P. pseudo-Roberti Moser. Siehe oben.

$P$. salicinus Pers. Grau, klein.

Von diesen Arten passt die letzte weitaus am besten. Die Bestimmung der Pluteus-Arten ist dadurch stark erschwert, dass sie - mit Ausnahme von $P$. cervinus - selten sind und immer nur in vereinzelten Ex. auftreten.

P. cervinus Schff. - 19. 6 .

P. roseipes v. Hoehn. (carneipes Kühn.) - 13. 8. Nur ein schlechtes Ex. H. 2.5 breit, feinschuppig- körnig, braun. Haut hyphisch. F. $3 \times 1-2$, Basis verdickt, faserstreifig, unten ausgesprochen rot-violett. L. rosa, breit. Sp. $6-8 \times 5-7$. Cystiden ohne Haken, keulig, z. B. $70 \times 16$. Auf Birke.

P. sp. - 18. 9. - Wohl nur eine Form von $P$. roseipes v. Hoehn. Ein Ex. H. 3 breit, kastanienbraun. Haut nicht hymeniform. F. $4 \times 7$, hohl, oben hell, unten ausgesprochen bräunlich-rot. L. ausgebuchtet. Sp. $6.5-8 \times 5-5.5$. Cyst, spitz zulaufend, ohne Haken. Auf Birke.

P. atromarginatus Konr. - 29. 8.

P. phlebophorus Ditm. - 27. 8. - Nur ein Ex. H. 3 breit, russbraun, netzartig gerunzelt. Cellen der Huthaut um 25-50 breit. F. faserstreifig, $4 \times 2$, hell, unten dunkler (graubraun). Sp. $6 \times 5$ etc. Cyst. farblos. Auf Birke.

Volvaria speciosa Fr. - 19. 8.

Amanita vaginata Bull. f. typica (fr. »grisette») - 19. 8.

A. vaginata Bull. f. badia - 7. 8 .

A. crocea Quél. - 9. 8.

A. vaginata Bull. var. fulva - 16. 8.

A. vaginata Bull. var. lutescens Boud. - 1. 9.

A. muscaria L. - 30. 8.

A. porphyria A. et S. - 1. 9 .

A. rubescens Fr. -26.9 .

Macrolepiota procera Scop. - 23. 9.

$M$. rhacodes Vitt. - 25. 9.

Leucoagaricus excoriatus Schff. - 17. 9.

Lepiota clypeolaria Bull. - 24. 9. - P.

Agaricus edulis Vitt. - 14. 9. - P. - Nur ein Ex. Der Pilz verfaulte bevor er getrocknet werden konnte. H. weiss, ohne Schuppen. Rötend. Doppelring. Kurze Sp. z.B. $5.5-6.5 \times 4-5$. Cyst. spärlich und nicht auffallend.

A. subperonatus (Lange) Sing.-14. 9.- P. - H. bis 6 breit, bräunlich, schwach beschuppt. Rand mit Velumresten bedeckt. F. meist kurz, gleichdick, mit 1 oder mehreren weissen ringförmigen Zonen. Sp. 6-7.25 $\times 5-5.25$. Cyst. schmal, nie ballonförmig, nie nach oben keulig verdickt. Schnell röcend. Kieferwald, am Wege.

A. campestris L. f. typica - 16. 9 .

A. campestris L. var. equestris Møller - 18. 9. Kahl, bei Berührung gilbend.

A. nivescens Møller - 30. 9. - Ein junges Ex. H. 4 breir, glatt. F. $6 \times 10-15$, cylindrisch. Ring einfach. Sp. 5.5-6.5 $\times 4-4.5$. Viehweide.

A. rusiophyllus Lasch -2.10.

Cystoderma carcharias Pers. - 1. 10.

C. amianthinum Scop. - 24. 9. - P.

C. cinnabarinum Schw. - 26. 9.

Pleurotellus pubescens Sow. (septicus Fr. ss. Konr. et M.) - 14. 9. - P. - H. bis $8 \mathrm{~mm}$ breit, meist resupinat, muschel- bis nierenförmig, fein flaumig. Ohne F. L. dicht, weisslich. Sp. spulenförmig, weisslich, $8 \times 3$. Auf Pflanzenresten.

Crepidotus mollis Schff. - 14. 9. - P.-Sp. meist $8 \times 5$. C. variabilis Pers. - 12. 8. - H. bis $3 \times 2$, nierenförmig, mit Scheitel angeheftet, gelblich-weiss. Basis weisszottig. L. gelblich- bis rötlichweiss. Sp.Staub beinahe weiss, nur mit leichtem rötlichem Schimmer. Sp. 5.5-7.5 ×3-4, sub immersione feinwarzig. Auf Erlenast.

Ripartites albido-incarnatus (Britz.) Métr. - 22. 9. 
Tubaria pallidispora Lange ss. K. et Rom. - 3. 8. T. pellucida Bull. ss. Romagn. - 5. 9.

T. conspersa Pers. - 20. 6.

T. trigonophylla Lasch - 7. 9. - H. bis 1.5 breit, hygrophan, nass honigfarben, trocken crème. F. $2 \times 1$. oben garz weiss, nach unten stark zugespitzt. Sp. höchstens 6.5-4.5, meist kleiner, ziemlich dunkel und grobwandig. Cyst. cylindrisch, nicht selten mit deutlichem Kopf. Sumpfiger Łaubwald.

T. ferruginea Maire - 28. 9. - H. bis 2.5 breit, rotbraun, überall dicht mit Flocken bedeckt, flach trichterförmig, Rand gekerbt, eingebogen, durchscheinend gerieft. Trocken weisslich mit rötlichem Ton, ungerieft. F. gleichfarbig, bis $3 \times 2$, bisweilen excentrisch, nach unten verschmälernd und filzig. L. herablaufend, Farbe des H. Sp. ellipt. 6-7 $\times 4.5-5$, gelb. Laubwald.

Rozites caperata Pers. - 25. 9.

Hebeloma strophosum Fr. - 15. 9. - Glatte $8 \times 5$ Sporen.

H. mesophaeum Fr. - 17. 9.

H. hiemale Bres. - 1. 10. - Nur ein Ex. H. 3 breit, lederbraun, Mitte dunkler. F. $4 \times 4$, oben weisskleiig, unten beinahe rostfarben, hohl, mit ganz kleiner Knolle. L. zimtbraun, nicht tränend. Sp. $11-12 \times 6.5-7$. Kein Rettichgeruch. Auf dem F. meines Exs. konnten kaum sichtbare Schleierreste bemerkt werden. Moser behandelt den Pilz unter den schwach beschleierten, Kühn. unter den Denudata. Entsprechend ist eine völlig einwandfreie Bestimmung kaum möglich. Es ist $H$. hiemale Bres. ss. Moseri.

H. testaceum Batsch - 30. 8 .

H. firmum $\mathrm{Fr}$ - 21. 9. - H. 3 breit, rotbraun, Rand heller. Halbkugelig-glockig. F. $5 \times 5$ weisslich, Basis bräunend. Gleichdick, Basis häufig spitz auslaufend. L. tonbraun, Schneide weisslich, (wie gesägt, Cyst!). Sp. 9.5-10×5.5, deutlich warzig. Geruch sehr schwach nach Rettich.

H. rlariceps Fr. - 20. 9. - H. 2-3 breit, gewölbt, mit lange eingebogenem Rand, falb, Mitte rötlich, mit seidigem Rand, klebrig. F. $3-8 \times$ 5-7, mit bräunender Knolle. F. weiss, flockigmehlig. L. tonbraun mit weissflockiger Schneide. Sp. ziemlich glatt, $9.5-11 \times 5.5-6$. Rettichgeruch. Mischwald. Vornehmlich Birke und Eller.

H. pumilum Lange - 16. 9.

H. spoliatum Fr. - 11. 9. - H. 2.5 breit, tonbraun, Rand heller, schmierig, kahl, glockig, dann verflacht. F. $5 \times 3$, blass, wird hohl, wurzelnd. L. blass, bisweilen fleckig, aber nicht tränend, dicht. Sp. warzig, 9-10 $\times 5.5-6$, mandelförmig. Rettichgeruch. Mischwald.

H. crustuliniforme Bull. - 23. 9 .

H. pusillum Lange - 3. 9.

Inocybe scabra O. F. Müll. - 21. 9. - H. bis 5 breit, konvex, schwach gebuckelt, in der Mitte cigarrbraun, am Rande heller und strahlig-rissig. F. $4.5-7 \times 7-8$, weisslich bis bräunlich. Basis weissstriegelig. L. ausgebuchtet. Sp. $8 \times 5$ etc. Cyst. $40-78 \times 13-16$, schwach schopfig. Fl. rötend. Süsser aromatischer Geruch. Birkenwald.

I. obscura Pers. ss. OvS. - 29. 6. - Ohne violette Töne. Sp. spitze Eiform.

I. pusio Karst. - 14.7.
I. geophylla Sow. -30.9

I. hirsuta Lasch - 5. 9. - Ein sehr schlechtes Ex. H. 5 breit, braun (nicht dunkel), sparrigschuppig. F. $6 \times 5$, nicht sparrig, faserstreifig, Farbe des H., unten weissfilzig. L. sehr breit. Fl. schwach rötend. Sp. 10-13 $\times 5.5-7$. Cyst. $55 \times 15$ etc. Nasser Mischwald.

I. fastigiata Schff. -11.8 .

I. descissa Fr. var. brunneo-atra Lange - 22. 8. - H. bis 3 breit, rissig, braun, gebuckelt. F. bis $6 \times 5$, blass, verbogen, Basis weisslich. L. braun. Sp. $9-9.5 \times 5-6$. Cyst. $54-61 \times 14-23$.

I. abjecta Karst. - 28. 6. - Immer gebuckelt. Sp. $9-11 \times 5.5-6.25$.

I. flocculosa Berk. (gausapata Kühn.?) -7. 8.-Cyst. $49-57 \times 11-12$.

I. brunnea Quél. - 31. 8. - H. bis 2.5 breit, konvex, schwach gebuckelt, braun, schuppig. F. bis $3.5 \times 5$, grobfaserig, beinahe gerieft, bekommt Farbe des H. (bisweilen mit leichtem rotem Schimmer). Fl. im F. rötlich. Sp. $11-15 \times 5.5-7$, einseitig zugespitzt. Bas, viersporig. Cyst. $43 \times 13$ etc., also relativ klein (nur der sichtbare Teil gemessen), meist ohne Schopf, dickwandig. In einem Graben.

I. sp. - 1. 10. - Scheinbar I. brunnea nahestehend. H. 5 breit, kastanienbraun, dunkler beschuppt. F. $6 \times 6$, grobfaserig, beinahe gerieft, bekommt etwa Farbe des $\mathrm{H}$., vielleicht etwas ins Rötliche neigend. Sp. $12-13.5 \times 6-6.5$, einseitig zugespitzt. Gyst. dickwandig, meist mit Schopf und z.T. mit langem Hals, 57-64×12-21. Laubwald.

I. eutheles Berk. var. Quél. ss. Heim. - 31. 8. H. bis 4 breit, ockerbraun, meist stumpf gebuckelt, radialfaserig. $F$, heller, verbogen, $2 \times 4$, faserstreifig, ziemlich kahl. Sp. $11-13.5 \times 6-7$, an einem Ende zugespitzt. Cyst. dickwandig, 59$68 \times 14-20$, dickhalsig. Zweisporigkeit der Basidien konnte nicht festgestellt werden. In einem Graben.

Vielleicht identisch mit $I$. Langei Heim f. bispora.

I. posterula Britz. - 11. 8. - Gyst. $55 \times 8-16$.

I. lacera Fr. - 26. 6.

1. halophila Heim - 31. 7. - H. bis 2 breit, braun, faserig (etwa wie $I$. lacera), mit spitzem Buckel. F. bis $4 \times 3$, oben weissgepudert, überall (auch innen) mit rötlichem Schimmer, nach unten $z u$ dunkler, ganz unten weissfilzig. Sp. $11-13.5 \times$ 5-5.5, cylindrisch. Cyst. auf Schneide und Fläche dickwandig, mit oder ohne Kristalle. Grösse $65-73 \times 16-21$. Spermageruch. Im Mischwalde, auf Sandboden.

I. sp. - 7. 9. - H. bis 2 breit, braun, schuppig, wie $I$. lacera, beinahe sparrig, konisch, dann flach gebuckelt. F. $2 \times 2$, nur faserig, nie sparrig, bisweilen verdreht, oben gepudert. Farbe etwas heller als der H. Sp. 11.5-13.5 ×5.5-6.25, nur ausnahmsweise cylindrisch, meist zugespitzt. Es kommen auch Sp. $10.5 \times 5.5$ vor. Cyst. $49-80 \times 18-27$, also dick. Steriler Sandboden. Erinnert stark an $I$. lacera.

I. confusa Karst. - 6.8. - H. bis 3.5 breit, kegelig, dann glockig, ockerbraun, faserig-rissig. Fasern rotbraun. F. bis $5 \times 6$, faserstreifig, etwas blasser als der H. L. Farbe des H. Sp. spitze Eiform, 8 -11 $\times 5-7$. Cyst. 50-60×15-20. Laubgehölz. 
1. Langei Heim f. bispora - 6. 7 - Sp. 11-12x 6.5-7.25, spitze Eiform. Cyst. c. $50 \times 15$. Siehe oben $I$. eutheles Berk. var. Quél. ss. Heim.

I. trechispora Berk. (paludinella Peck.) - 12. 8. H. 1-1.5 breit, schwach gebuckelt, flach, weisslich (bräunlich), radialfaserig. F. $1-2 \times 1$, weiss, schwach gepudert, unten weissfilzig und verdickt. L. sehr dicht, ausgebuchtet angewachsen. Sp. flachwarzig, $7-8 \times 4-5$ (bei Lange sehr gut abgebildet). Cyst. schopfig, bis 16 breit. Unter Birken. Sumpf.

I. umbratica Quél. - 12. 8. - Wie I. trechispora. Nur konisch-glockig und kleinknollig. Sieht I. geophylla täuschend ähnlich. Riecht auch ebenso. Sumpfgebiet.

I. xanthomelas Kühn. (Bours.) Lange (salicis Kühn.) - 6. 8. - Cyst. 60-65 ×16 (oben 10).

I. praetervisa Quél. - 4.9.

I. napipes Lange - 5. 8.

I. umboninota Peck - 31.8.

I. umbrina Bres. - 30. 8 .

I. Boltoni Heim - 21. 9.

I. decipientoides Peck (globocystis Vel. und carpta ss. Rick.) - 19. 8. - H. bis 3.5 breit, ockerbraun, breit und dunkel gebuckelt, radialfaserig, im Alter ausgesprochen schuppig, aber nicht rissig. F. bis $4 \times 6$, schwach faserig, im Alter glatt, bräunlich, unten und oben weisslich, ohne Knolle. L. braunoliv, angewachsen. Sp. sehr schwach kantig, 8-9.5 $\times 5.5-6.5$, einseitig zugespitzt (bei K. et Rom. sehr gut abgebildet). Cyst. stets sehr dick, ohne Kristalle, 54-80 × 17-24 (5 Messungen). Bessere Beschreibung als Karstenia III S. 57 ,

I. pseudoasterospora Kühn. \& Bours. - 20. 8. - Nur ein Ex. H. 2.5 breit, braun, radialfaserig, schliesslich rissig. Gebuckelte Mitte dunkler. F. $6 \times 4$, ohne Knolle, rotbraun, unten dunkler, mit weisslichen Schleierresten. Sp. beinahe sternförmig, $10 \times 8$ etc. Cyst. dick, z. B. $46 \times 15,57 \times$ 19. Steht $I$, umboninota Peck sehr nahe.

I. putilla Bres. - 12. 8 .

Durch obige Zusammenstellung wird die InocybeFlora der Gebietes Kasuri nicht erschöpft. Insbesondere gibt es hier dunkelbraune, schuppige, nicht sparrige Arten, die der Gruppe Eu-Inocybe-Muricatae-Ovisporae-Ingratae (nach Lange) angehören, die mit Hilfe der modernen Lit. (Heim, Lange, Kühner, Moser) nicht bestimmt werden können.

Alnicola subconspersa Kühn. (conspersa Pers.) - 13. 9.

A. melinoides Fr. Kühn. (escharoides Lange. Konr. et M.) - 12. 9 .

A. phaea Kühn. Maire (Tubaria umbrina Maire und scolecina Fr. ss. Lange) - 10. 9. - H. bis 2 breit, braun, nass bis zur Hälfte schwach gerieft, trocken hellbraun. F. $3 \times 1$. Schleier nur schwach entwickelt. L. aufsteigend, hinten am breitesten. Sp. $10-13 \times 5-7$, warzig. Cyst. mit Schnabel. Unter Erlen.

A. submelinoides Kühn. - 12. 9.

Phaeomarasmius aridus Pers. (Naucoria erinacea Fr.) - 8. 9. - H. bis 1 breit, rostfarben, mit spitzen, aufgerichteten Schüppchen. F. ganz kurz, striegelig. L. dunkelocker. Sp. $10 \times 8$ etc. gelblich, citronförmig. Erlenast.

Galerina gibbosa Favre - 5. 9. - Zum Unterschiede von $G$. tibiicystis Atk.: L. breit angewachsen und mit einem Zahn herablaufend. Cyst. cylindrisch, sehr lang und ohne Köpfchen. Angeblich Mehlgeruch, was wegen Erkältung des Untersuchers nicht nachgeprüft werden konnte.

G. sphagnorum Pers. ss. restr. - 17. 9. - H. 2 breit, wachsgelb, grobgerieft. F. $10 \times 2$ etc. L. breit, horizontal angewachsen. Sp. $8-9 \times 5.5$, glatt. Cyst. meist cylindrisch, aber auch bauchig, z. B. $62 \times 16$. Kein Mehlgeschmack, nur etwas bitterlich. Sumpf. Die Exs. stehen zwischen G. sphagnorum ss. Atk. und G. gibbosa Favre. Hier wird in der Aufspaltung der Arten vermutlich viel zu weit gegangen.

G. tibiicystis Atk. - 16.8.

G. paludosa Fr. - 16.8.

G. mycenoides Fr. ss. Jaap - 10. 8. - Nur ein Ex. H. 1 breit, rotbraun, gestreift. F. rotbraun, glatt, $3 \times$ unter 1 . Sp. $11 \times 5.5$ bis $16 \times 7.5$, erstere spitzeiförmig, letztere spindelig, rauh. Kieferwald.

G. hypnorum Schrank ss. Rick. - 24. 6. - H. 1 breit, halbkugelig, grob gerieft, Grund ocker, Riefen braun. F. 3 lang, von unten bräunend, oben hell, weisse Rhizoiden an der Basis. Sp. $8-9.5 \times 5-5.5$, dickwandig. Cyst. cylindrisch, bauchig. Mehlgeschmack. Im Moose.

G. mycenopsis Fr. - 10.8.

G. triscopa Fr. - 7. 7. - Kommt auch auf Sphagnum vor.

G. marginala Batsch - 25. 6. - Von G. unicolor kaum zu trennen.

G. unicolor FI. Dan. - 19. 6.

G. ambigua Karst. - 24. 6. - H. bis 2.5 breit, gebuckelt, nass durchscheinend gerieft, trocken ungerieft, braun, trocken ocker. Haut nicht zellig. F. bis $8 \times 3$, schwarzbraun, faserstreifig, oben mit braunen Ringresten, unten weissfilzig. L. braun, sehr dicht, bis $3 \mathrm{~mm}$ breit, angewachsen. Sp. 6-6.8 $\times 4.2-4.7$, ziemlich hell, dickwandig, eiförmig, kaum warzig (bei Vergrösserung $\times 1350$ kaum wahrnehmbar). Cyst. haarförmig, oben 4, unten 7 breit. Kein Mehlgeruch und kein Mehlgeschmack. Direkt auf Moos und verfaulten Blättern im Sumpf. $G$. unicolor sehr nahestehend.

G. pumila Fr. var. subferruginea Møller et Lange 27. 8. - H. 0.8 breit, braun, hygrophan, trocken ocker. Rand undeutlich gerieft. F. $2.5 \times 0.5$, braun. L. breit und im Gegensatz zu Ph. filaris breit angewachsen bis herablaufend und sehr dicht. Sp. $9-11 \times 5.5-6$. Gyst. $60 \times 6$. In einem Graben. Moosiger Laubwald.

Phaeocollybia festiva Fr. ss. Karst. - 30. 9. - H. bis 3 breit, kastanienbraun (var.), kaum verfärbend, kahl. F. $3 \times 3$, violettlich, hohl, wurzelnd. L. ausgebuchtet, beinahe frei. Sp. mandelförmig, schwach warzig, $7-8 \times 4$, nicht amyloid. Cyst. haarförmig, meist mit Köpfchen (2-3 breit). Rettichgeruch.

Gymnopilus limulatus Fr. - 8. 8. - H. bis 2 breit, braunkörnig auf gelbem Grund. F. $2 \times 4$, verbogen, faserig, oben gelb, unten braun. L. ausgebuchtet angewachsen, goldgelb. Fl. gelb, kaum bitter. Sp. bohnenförmig, amyloid, sehr dickwandig (mit Perispor), 7.2-8.5 ×3.9-4.2. Cyst. keulenförmig $27 \times 8$, oval $20-40 \times 8-18$. Auf Ästchen.

G. sapineus Fr. - 13. 9 . 
G. hybridus Fr. - 9. 7.

G. penetrans Fr. - 16. 9 .

Dermocybe cinnamomea L. var. conformis Fr. f. crocea Schff. - 26. 9. - L. und F. safr.-orange. Jodgeruch.

D. cinnamomea L. var. conformis Fr. f. croceipolia Peck - 18. 9. - F. goldolivgelb. L. safr.-orange. Rettichgeruch.

D. cinnamomea L. var. lutescens Gill. -2.10 .

Cortinarius Kauffmanianus Hry - 16. 9. - Im Gegensatz zu C. alboviolaceus schwach hygrophan. F. nie gestiefelt, knollig. Sp. 8.5-9 $9 \times 6$. Sumpfwald.

C. albo:iolaceus Pers. - 1.9.

C. hircinus Fr. ss. Moseri, 2. Auflage-24.9.- $-\mathrm{P}:-\mathrm{H}$. bis 8 breit, lila, Mitte ockerlich verfärbend. F. bis $10 \times 20$, keulig, lila. L. lila, später rostgelb. Fl. blass, oben im F. violett, unten gelb. Sp. $11 \times 5.5$. Reaktion auf $\mathrm{KOH}$, Ammoniak und Phenol sehr gering (Fl. wird schmutzig), auf Phenolanilin rot. Im Gegensatz zu diesem Pilze hat G. camphoratus Fr. ss. Moser, 1. Auflage, okkerlichen Töne auf dem H., auch ist der F. weisslich und nur die Spitze violett.

C. pholideus Fr. - 11.9.

C. spilomeus Fr. -24 . 9. - $\mathrm{P}$.

C. anomalus Fr. var. Lebretonii Quél. (lepidopus Cooke) - 11.9-Gelbgegürtelt. Sp. $6 \times 5$.

C. raphanoides Fr. - 11.9.

C. melanotus Kalchbr. - 16.9. - H. 3-6 breit, braunoliv, mit dunklen sparrigen Schüppchen. F. olivbraun mit gleichfarbiger Ringzone, unter derselben braunfaserig. L. zimtoliv. Sp. $6-7.5 \times 5-5.5$. Kein Rettichgeruch. Nasser Laubwald.

C. arenatus Pers. ss. OvS. - 4.9. - Relativ junge Ex. H. bis 2 hoch und 2 breit, glockig, breitgebuckelt, feinkörnig, mit eingerolltem Rand. Schleier braun. F. $6 \times 7-12$ (Keule), verbogen, unten braunschuppig. L. dicht, angewachsen. Färbung des Pilzes überall braun, mit Olivton. Sp. $5.5-6.6 \times 4-4.75$. Laubwald mit vereinzelten Kiefern. Die Lit. über den Pilz sehr oberflächlich.

C. gentilis Fr. - 24.9. - P. - Subglobare Sp.

C. tophaceus Fr. ss. OvS. - 24. 9. - P. - H. 3 breit, fuchsiggelb, halbkugelig, feinschuppig. F. $5 \times 8$, Farbe des $H$., aber weissfaserig. Velum weiss. F. über dem Velum blass und kahl. L. tonfarben mit gelber, gekerbter Schneide. Sp. 5.5-6.5 $\times$ 4.5-5. Gyst. auf der Schneide der L. Fl. weiss, gilbend. Geruch und Geschmack unangenehm, rettichartig.

Hydrocybe armillata Fr. - 30. 8.

H. saniosa Fr. ss. Langei et Moseri - 24. 9. - P.

H. evernia Fr. - 13. 9.

H. castanea Búll. - 30.9.

H. erythrina Fr. ss. Langei - 9. 9. - P. - Hutrand mit weissen Schleierresten. L. Schneide gekerbt durch 6 breite sterile Zellen.

H. bulbosa Fr. non ss. Kühn. - 9. 9. - P.

H. laniger Fr. - 14.9. - P. - L. ziemlich breit. Sp. $8-11 \times 6-6.5$, schwach punktiert.

H. armeniaca Schff. - 9. 9. - P.

H. diluta Pers. ss. Rick. (saturata Lange) - 13.9.

H. pseudoduracina Hry - 12. 9.

H. bovina Fr. - 15.9.

H. brunnea Pers. - 14. 9. - P.
H. brunneofulva Fr. ss. OvS. - 24. 9. - P.

H. alnetorum Vel. - 11.9. - Sp. $9-11 \times 5-6$, warzig.

H. hemitricha Fr. $-24.9 .-\mathrm{P}$

H. incisa Pers. - 2. 10.

H. striaepilea Fav. - 16.9. - F. im Moose bis $13 \times 5$ !

H. flexipes Fr. - 18.9. - . Mit starken bis ganz schwachen violettlichen Tönen.

H. paleacea Fr. - 24. 9. - P.

H. angulosa Fr. -2 . 10. - H. bis 6 breit, rotbraun, ausbleichend, geschweift Ränd bisweilen eingeknickt. Velum blass. F. bis $8 \times 10$, ockerbraun, braun befasert, mit 20 breiter Knolle. L. undicht, kanelfarben. Sp. 6-7 $\times 4.5$. Moorwald.

H. balaustina Fr. ss. Rick. - 26.9.

H. subbalaustina Hry (balaustina Lange, non Fr.) - 11.9.

H. scandens Fr. $-24.9 .-\mathrm{P}$.

H. acuta Fr. ss. Favre - 2. 10. - Schwach warzige Sp. $6-7 \times 4-4.5$. Cyst. haarförmig, über 100 lang.

H. acuta Fr. ss. Henry - 29.9. - Sp. warzig, $11 \times 7$. Cyst. keulig, $45 \times 12$. etc. Phenolanilinreaktion negativ.

H. suilla Fr. ss. OvS. $-9.9-$ P. - Nur ein Ex. H. 3 breit, nass kastanienbraun mit violettlichem Ton, trocken schwach verblassend, glockig mit eingebogenem Rand. F. 5×7-15 (Knolle), schwach violettlich (deutlich nur oben), mit nur angedeutetem weissem Velum, wurzelnd. L. kanelfarben (nicht violett), breit, ausgebuchtet. Sp. 8.5-9 5 5-5.3, warzig, mit Perispor. Fichtenwald.

Myxacium stillatitium Fr. 11.9.

M. mucifluum Fr. - 1.9.

M. elatium Fr. - 12. 9.

M. pseudosalor Lange (mucifloides Hry) - 11.9. Wie $M$. stillatitium Fr., nur $L$. nie violettlich. Laubwald.

M. mucosum Bull. - 13. 9 .

Phlegmacium montanum Kauffm. ssp. europaeum Moser (scaurum ss. Bres.) - 24.9. - P. - Nur ein Ex. H. 4 breit, rötlichbraun mit grünlichem Rand. F. $5 \times 12.5-25$ (gerandete Knolle), oben bläulich. L. jung grün (mit schwachem Olivton), später ausgesprochen olivbraun. Cortina grünlich. Fl. mit Melzers Reagenz dunkel weinrot. Sp. 9-10 $\times 5-6$. Unter Fichten. Lit. ungenügend.

P. cyanopus Fr. ss. Rick. Lange (amoenolens Hry.) - 26. 9. - Ein gutes Ex. H. 5 breit, löwengelb, klebrig. F. $8 \times 10-15$, oben bläulich, unten gelbbraun. Knolle weisslich, 25 breit. L. bläulich schwach gesägt. Sp. sehr warzig, $11-12 \times 6-7$. Laubwald.

P. vespertinum Fr. ss. Moseri - 1.9. - Ein Ex. H. 5 breit, ocker-bis rotbraun, gewölbt, ganz glatt. F. $6 \times 10$, hellbraun, oben heller, faserstreifig. Knolle 25 breit, rund, nicht gerandet. L. gelbbraun, angewachsen, schwach gesägt. Sp. 7$8 \times 4.5-5.25$. Laubwald.

P. aurantiacum Moser - 11.9.

P. triumphans Fr. - 26. 9 .

$P$. validum Favre - 22.9. - H. bis 10 breit, rotbraun, zum Rande zu blasser. Rand eingewachsen faserig. F. bis $12 \times 20$, keulig, abwärts bräunlich mit reichlichen Cortinaresten. L. tonfarben, werden dunkler. Sp. $11 \times 6$, warzig. 
Fl. gelblich, durch Potasche sofort hell braunrot. Unangenehmer Geruch, der an $P$. olidum Lange erinnert. Birkenwald, moorig.

P. decoloratum Fr. ss. Lange - 11. 9. - Ohne viol. Töne.

P. decoloratum Fr. ss. OvS. - 3. 9. - Über wenige Pilze herrscht eine so grosse Unklarheit, wie über diesen. Hier handelt es sich um die Var. mit bläulichen Tönen. H. 3-4 breit, tonfalb bis bräunlich, bald trocken, dünnfleischig. F. $9 \times 6$, sehr hell mit schwachem gelblichem Tone unten. Oben anfangs bläulich. L. zuerst bläulich, dann zimtfalb, angewachsen. Velumreste am Rande des H. oder auf dem F. Sp. 5.5-6.75 $\times 4,7$ -5.75 , warzig. Laubwald. In sumpfiger Gegend. Die Verwandtschaft dieses Pilzes mit $P$. compar Fr. ss. Rick. ist nicht geklärt. Jedenfalls sehr nah.

P. porphyropus Schw. - 29. 9. - Sp. bis $9,5 \times 6$.

Conocybe lactea Lange (Métr.) (lateritia Fr.) - 17.9.

C. tenera Schff. f. subovalis Kühn. - 8.9. - Mit Knöllchen.

C. tenera Schff. f. typica - 9. 8 .

C. Rickeniana Sing. (spicula Rick.) - 8. 9. - H bis 2 breit, ockerbraun, lange gerieft, kegeligstumpf. F. $5 \times 1$, oben hell, unten rötlich ocker, gepudert, kleinknollig. Sp. 9-10×5.5-6. Ammoniakreaktion null. Im Grase.

Pholiotina blattaria Fr. ss. Moseri - 23.9. - H. bis 2 breit, Rand wenn nass gerieft, flaumig, gelbbraun, schwach hygrophan, Mitte dunkler. Haut zellig. F. bis $5 \times 3$, braun, weissfaserig, Basis weissfilzig. Hängender Ring oben am F. Sp. c. $8 \times 5$. Cyst. sehr verschieden: z. B. cyl. $70-80 \times 5-11$, flaschenförmig $60 \times 4-19$ (verdickte Basis). Birkenwald, auf dem Erdboden.

$P$. teneroides Lange ss. Kühn. - 8. 9. - Auf Ellerast.

Bolbitius vitellinus Pers. f. maxima - 11. 7. - Uukuniemi am Pyhäjärvi. Nur ein Ex. Ich hebe diese Form nur hervor, weil sie besonders üppig ist. H. wenn ausgebreitet c. 6 breit, gelbweiss, radialfaserig. F. $11 \times 8$, faserig gestreift, besonders oben, Farbe des H., hohl, innen gelb, unten weissfilzig. L. bis 8 breit, gelblich. Sp. 13-14 $\times 8$, gelb. Hinter einem Speicher, auf Dünger.

B. vitellinus Pers. var. titubans Bull. ex Fr. - 9. 8. Citrongelb. Sp. $14 \times 8$.

B. fragilis L. - 19. 7. - Kleine Sp. $11 \times 7.5$. Form von $B$. vitellinus.

Agrocybe praecox Pers. - 4. 7.

A. sphaleromorpha Bull. - 6. 8.

A. tabacina Cand. - 19.9. - H. bis 2 breit, kastanienbraun, trocken ocker. Huthaut - im Gegensatz zu Deconica crobula und inquilina - nicht schleimig-abtrennbar. Nass gerieft. Rand eingebogen. $\mathrm{F}$, bis $3 \times 2$, braun, Basis verschmälert und sehr dunkel, schuppig-faserig mit weissen Velumresten. L. braun, angewachsen. Sp. $7-8 \times 4-4.5$. Gyst. keulig. Der sichtbare Teil oben 5 breit. An einem Waldwege, auf und unter Holzstücken.

Pholiota flammans Fr. - 14. 9. - P.

P. tuberculosa Fr. - 16.9.

P. curvipes Fr. ss. OvS. - 17.8. - Nur ein Ex. H. 3 breit, gelbbraun, mit eingewachsenen Flocken, trocken, flach. F. $3 \times 3$, bis zum unvollständigen Ring feinschuppig und über dem
Ring weissflaumig, gelb, nach unten zu verschmälernd und rötlich-bräunlich werdend. L. gelblich-bräunlich, breit, dicht, etwas ausgebuchtet angewachsen. Sp. 5.5-6.1 $\times 3.9-4.7$ (Karst. 6-7 $\times 2-4$, Moser $6-7 \times 3-4$, K. et Rom. 6.5-9 $\times 4-5$ ) Cyst., die offenbar sehr unbedeutend sind (oben rundlich), konnten leider nicht isoliert werden. Auf Birke.

Der Pilz wurde 1 Stunde im Wasser gehalten, ohne sich zu verändern. Diese Tatsache, das einsame Wachstum und das Fehlen der für Kuehneromyces mutabilis charakteristischen zahlreichen Randcystiden trennen den Pilz von letzterem. Trotzdem bleibt die Bestimmung nicht völlig überzeugend.

P. lenta Pers. - 1. 10. - Cyst. $68 \times 14$, spindligbauchig.

P. lubrica Pers. - 20. 8. - Mitte des H. dunkler. Cyst. $30-40 \times 10-13$.

P. carbonaria Fr. - 1.9.

P. sp. - 28. 8. - H. bis 3.5 breit, gelbrötlich, Mitte rötlicher, sehr schmierig, dünnfleischig, zuerst mit eingebogenem Rand, später flach und flatterig. F. bis $3 \times 3$, faserig, olivgelbbraun, oben beinahe gelb, unten sehr verbreitet. L. olivgelb, mit Zahn angewachsen. Staub schmutzig. Sp. sehr hell, rundlich, 5.2-5.8 $\times 4.4-4.9$. Fl. nicht bitter. Auf Birke oder Eller. Reiner Laubwald. Erinnert äusserlich etwas an Deconica rhombispora und $D$. crobula, kann aber mit keinem dieser Pilze identifiziert werden. Es handelt sich hier wohl um eine nördliche Art der Gruppe Flammulae-lubricatae, die in der modernen (franz.) Lit. wenig erschöpfend behandelt wird. Steht offenbar $P$. carbonaria Fr. nahe.

P. spumosa Fr. - 6.9.

P. gummosa Lasch - 21.9.

P. astragalina Fr. - 18.9,

P. alnicola Fr. -21.9 .

P. myosotis Fr. f. typica - 13. 9. - H. bis 3 breit, olivbraun, sattelartig niedergedrüickt, kahl, nackt, etwas schmierig. F. bis $8 \times 4$, bräunlich, Spitze bereift. L. breit, mit Zahn angewachsen. Schneide weisslich, gesägt (Cyst.). Sp. $15 \times 9$ etc., braun. Cyst. cylindrisch oder flaschenförmig, circa 8 breit. Sumpf.

Kuehneromyces mutabilis Schff. - 17.6.

Naematoloma capnoides Fr. - 24.9. - P.

N. sublateritium Fr. - 16.9.

N. fasciculare Huds. - 18. 6.

N. elongatum Pers. - 26. 9. - H. bis 3 breit, honigbraun, weit gerieft, trocken beinahe weisslich (bräunlich in der Mitte), ungerieft. F. bis $10 \times 2$, fuchsig, oben blass, häufig etwas verbogen. L. schmutzig bräunlich-violett. Rand heller. Sp. $9-11 \times 6-7$, schmutzig braun, kaum violett. Cyst. meist spindelig, 13-14 breit. Es kommen aber auch sackförmige vor $(35-42 \times 16-20)$. Im Sumpf, auf Moosen.

N. udum Pers. - 3. 9. - H. bis 3.5 breit, gelbbraun, sattelartig, mit Schleierresten am Rande. F. $8 \times 2-3$, dunkelbraun, Basis weiss. L. ausgebuchtet, breit, gelbbraun. Sp. 13-18 $\times 8-9$, sehr dickwandig. Laubwald. Wohl identisch mit Psil. uda Pers. Eine Var. dieses Pilzes s. Karstenia III S. 40 und unten.

N. udum Pers. f. sphagnicola - 29. 9. - F. bis $15 \times 2$ im Moose. 
N. ericaeum Pers. - 29. 9. - H. 2 breit, rötlichgelb, glockig, ungerieft. Schwach hygrophan. Nass schwach durchscheinend gerieft. F. $4 \times 2$, oben hell, unten braunrot. L. werden oliv. Sp. 8.5$11 \times 6-7$, dickwandig. Im Laubwalde, nicht direkt auf Moos.

Stropharia aeruginosa Curt. - 29.9.

S. semiglobata Batsch - 18. 6.

S. stercoraria Fr. -5.8 .

Psilocybe merdaria Fr. - 28.6.

P. coprophila Bull. - 28. 6 .

P. atrobrunnea Lasch -4 . 9. - H. 1 breit, rotbraun, eher hochgewölbt als gebuckelt, kahl. F. $5 \times 1$, rotbraun. L. olivbraun, dicklich, angewachsen. Sp. $9-11 \times 5-6$ purp. Pleurocyst. nicht bemerkt. Bitterlich. Moor, im Moose.

Deconica (Naucoria, Tubaria) crobula Fr. - 8. 7. H. 1 breit, mit schleimiger, abziehbarer Haut, stumpf gebuckelt, mit dauerhaften Schleierresten am Rande, schwach gerieft, trocken ungerieft. F. etwa $4 \times 1$, faserstreifig, oben hell braun mit Schleierresten, unten relativ dunkel und kahl. L. angewachsen bis schwach herablaufend, dicht, Farbe des H. Sp. etwa $6 \times 4.25$, eiförmig, in Massen schmutzig violettbraun. Auf einem Grasshalm. Die Bestimmung dieser, mit $D$. inquilina nahe verwandten Art stösst leicht auf Schwierigkeiten, da die Sp. Farbe zwischen braun und violett liegt und verschieden gedeutet wird.

D. inquilina Fr. forma - 26.9. - H. bis 1 breit, rehfarben, kaum ausbleichend. Wenn nass Rand stark gerieft. Velumspuren am Rande. Huthaut nicht schleimig und abziehbar. F. bis $3 \times 1$, dicht besetzt mit wcissen Fasern, Basis sehr dunkel. L. angewachsen in der Art der Tubariae. Rand weiss (Cyst.). Sp. 5.5-7 $\times 4-5$ mit deutlichem Keimporus. Auf Gräsern. Wegrand.

D. atrorufa Schff. - 4.9.

D. rhombispora Britz. (tenax Fr. ss. Rick.) - 8. 8.

D. bullacea Bull. - 28. 8 .

Panaeolus retirugis Fr. - 21.9.

P. campanulatus L. ss. Langei, Bres. (sphinctrinus Fr. ss. K. et Rom.) - 6.8.

P. acuminatus $\mathrm{Fr}$. 26.8 .

P. sp. - 8. 9. - Im Gegensatz zu P. acuminatus. dem der Pilz nahe steht, ist er nicht hygrophan und hat deutliche Velumreste am Rande des H. Farbe des H. gelbbraun, braun befasert. Sp. citr.förmig, sehr breit, $12-15 \times 9-11$, mit deutlichem Keimporus. Feld.

P. subbalteatus $\mathrm{B}$. et $\mathrm{Br}$. - 8.9.

P. sp. - 21.9.-H. bis 4 breit, konvex, schwach und flach gebuckelt, tonfarben, Mitte etwas dunkler, event. mit schwachem rötlichem Ton. Schwach gerunzelt (viel schwächer als bei $P$. retirugis). Keine Spur hygrophan, d. h. ohne durchwässerte Randzone. (Von den Exs. haben die sub A 12 Stunden im Wasser gelegen ohne irgend eine Veränderung zu zeigen. Diejenigen. sub B wurden bei Regenwetter gesammelt, einer Wasserprobe aber nicht unterworfen. Beim Trocknen zeigten sie keinerlei Veränderung). Keine Velumreste am Rande. F. bis $8 \times 3$, unten verdickt und weissfilzig, dunkler als der $H$., vor allem rötlicher, oben weiss gepudert. L. sehr breit, bauchig und ausgebuchtet. Sp. $11-13.5 \times$
8.6-9.2, typisch $12 \times 9$. Cyst. 5-8 breit. Abgemähtes Kleefeld.

P. fimicola $\mathrm{Fr} .-10.8$.

Anm. Die Gattung Panaeolus ist ganz schlecht untersucht. So verbergen sich hinter $P$. campanulatus ss. lato mehrere Arten, meist mit breiteren Sp. als in der Lit. angegeben.

Panaeolina foenisecii Pers. - 13.9.

Anellaria separata L. - 21.6.

A. separata L. (A. semiglobata Sow.) var. minor Lange - 19. 8. - H. unter 1 breit.

Psathyrella gracilis Fr. - 1. 10. - Sp. 11-12×6-7.

P. infida Quél. - 24.8. - Ein Ex. Ähnlich $P$. prona. Bucklig und bis zum Buckel tief gefurcht. L. sehr breit und wenig dicht, dunkelbraun. Auf einem Waldwege.

P. atomata Fr. - 10. 9.

P. subatomata Lange - 24.8. - H. bis 1.5 breit, tonfarben, trocken weisslich, ungerieft. F. $5 \times 1.5$, kaum durchscheinend, weisslich, gepudert. L. braun mit Purpurton, mit Zahn angewachsen. Sp. $14 \times 7.5$ etc. elliptisch, dickwandig, etwas durchsichtig, en masse beinahe schwarz. Im Grase.

$P$. gracilis Fr. var. corrugis Pers. - 1. 10. - Grösser als $P$. gracilis. H. runzelig. $L$. ohne rote Schneide und schmäler als bei der Hauptform.

P. gracilis Fr. f. -23.8 . - H. bis 2 breit, graubraun, mit warzenartigem gelbbraunem Buckel, bleibend konisch-glockig, durchwässert zur Hälfte gerieft. Trocken weisslich, ungerieft. Nicht runzelig. Ohne Schleierreste. F. bis $8 \times 1$, gelbbräunlich, trocken weisslich, kahl, wurzelnd, unten weissfilzig. L. aufsteigend angewachsen, schmutzig violettlich. Schneide teilweise weisslich, nicht rot. Sp. nicht sehr dunkel purpurn, $11-12.5 \times$ 6.7-7.3. Randcystiden spitz, aber auch mit Köpfchen, unten etwa 9 breit. Länge nur einmal gemessen $=43$. Auf Holzstückchen, Blättern etc. Diese Form steht zwischen der Hauptform und der Var. corrugis.

P. velutina Pers. Sing. - 18. 9. - H. bis 3 breit, rehbraun, filzig-haarig. $F$. bis $8 \times 5$, hellbraun befasert. L. werden purpurschwarz mit weisser Schneide. Sp. $8-10 \times 5-5.5$ Auf dem Erdboden an einem Wegrande büschelig.

P. coprobia Lange - 29.8. - Nur junge Ex. H. bis 1 breit, kaum hygrophan, nicht gerieft, gelbbraun, mit schneeartigen Flocken besetzt, besonders am Rande, halbkugelig. F. bis $3 \times 1$, faserstreifig, flockig, oben hell, unten bräunlich. L. zuerst gelblich, dann violett, breit angewachsen, beinahe dreieckig. Die Sp., die den untersuchten Pilzen "abgezwungen» werden mussten, waren hellviolett (unreif). Sie erreichten eine Grösse von etwa 9-11×5.5. Gemessen wurde auch eine Cyst. $=34 \times 14$. Freie Stelle in einem sumpfigen Birkenwalde, der als Viehweide benutzt wurde, vermutlich auf verottetem Mist.

P. marcescibilis (Britz.) Romagn. - 30.8. - Nur ein Ex., das sich beim Trocknen leider stark verändert hat. H. 1.5 breit, graubräunlich, Mitte etwas dunkler, trocken weisslich (sehr schwach hygrophan), flachgewölbt. F. $4 \times 1$, oben sehr hell, nach unten zu mit schwachem violettlichem Ton, steif, gepudert. L. schwärzlich. Sp. $10-13 \times 6-8$, sehr dunkel. Grabenrand. Die Aufspaltung dieser Art in fragilissima Lange 
und lactea Lange (siehe Lange und Moser) ist nicht überzeugend.

P. spintrigera Fr. ss. Kühn. et Romagn. - 29.6. H. bis 6 breit, jung kastanienbraun, alt crème, eventuell mit violettlichem Schimmer, feinstens punktiert, Rand ausgesprochen gerieft und meist nicht behangen. $\mathrm{F}$. bis $6 \times 6$, verbogen, hohl, aber relativ fest, faserstreifig, besonders oben, strohfarben, unten und oben heller, Basis verdickt. Ring nur im Jugendstadium. L. ziemlich breit (bis $8 \mathrm{~mm}$.), bräunlich, dann dauernd violettlich. Sp. etwa eiförmig, oval, $6.5-7.5 \times$ 4.5-5.25, purpurn. Im Walde, unter verfaulten Holzstücken. Identisch mit Langes Stropharia spintrigera.

P. Candolleana Fr. ss. Langei - 23. 6.

P. hydrophila Bull. - 22.9. - H. einige $\mathrm{cm}$. breit (bei mir bis 3), dattel-bis rotbraun (Farbe gut getroffen bei Lange), halbkugelig, durchscheinend gerieft. F. blass $4 \times 8 \mathrm{kahl}$. L. blass bis schokoladenfarben. Sp. 6-7×3.5-4. Büschelig oder gesellig im Mischwalde.

P. egenula B. et Br. - 25. 7. - Nur ein Ex. H. ausgebreitet 3 breit, schmutzig honigfarben, trocken weisslich, mit violettlichem Schimmer und gelblicher Mitte. Rand, wenn trocken, runzelig. F. $6 \times 2-3$, gerade, weisslich, oben weissmehlig und gerieft. L. dicht, grauviolett, mit Zahn angewachsen. Sp. c. $7.5 \times$ knappe 5. Cyst. auf der Schneide zahlreich, von sehr versch. Grösse. Im Walde, einzeln. Vermutlich eine Var. von $P$. Candolleana.

P. gyroflexa Fr. ss. Moseri - 10.7. - Nur ein Ex. H. 2.5 breit, glockig, kahl, bis zur Hälfte gerieft, graubraun. F. 1 breit, kahl, weiss, seidig, verbogen. L. schokoladenfalb, ausgebuchtet, breit. Sp. 7.5-8.5 ×5.5-6. Cyst. nicht bemerkt. An einem Waldwege, einzeln.

Es muss dahingestellt bleiben, ob der Pilz in Karstenia III, S. 60 der gleichen Art angehört. $P$. gyroflexa wird sehr versch. interpretiert. Das Exs. ist leider nicht viel wert. Die meisten $P$. lassen sich nur sehr schwer konservieren.

P. subnuda Karst. - 14.8.

P. spadiceogrisea Schff. -25.9 .

P. obtusata Fr. -27.8 .

P. subnuda Karst. + P. obtusata Fr. - 6.9. Meine Exs. stammen alle von einer Gruppe und sicher aus demselben Mycel im Mischwalde. Eine ganze Reihe von Pilzen dieser Gruppe wurden von mir mikroskopisch untersucht und es entsteht die Frage, ob die Trennung obiger zwei Arten sinnvoll ist. Nur einige der jungen Pilze der Gruppe hatten einen faserigen Hutrand (= subnuda ss. Langei), die anderen nicht (= obtusata ss. Langei). Einige Ex. hatten keine Balloncyst. (= subnuda ss. Langei), andere wohl (= obtusata ss. Langei). Die Sp.farbe war überall dunkel (= subnuda ss. Langei). Die Sp.grösse war überall, wo gemessen, knapp $8 \times 5$ (= obtusata ss. Langei, aber subnuda ss. Moseri.)

Coprinus atramentarius Bull, - 24. 8.

C. fuscescens Schff. - 8.9.

C. radiatus Bolt. - 11.8. - H. bis $7 \mathrm{~mm}$ breit, gewöhnlich viel kleiner, gelblich, strahliggefaltet. Nur wenige L. Sp. $12 \times 7$ etc., schwarz. Auf Mist.

C. domesticus Pers. - 29. 7.
C. Friesii Quél. f. mit ovalen Sp. - 20, 6. - H. bis 1.5 hoch (unausgebreitet gemessen), graulich mit gelblicher Scheibe, stark gerieft, mit weisslichem Filz lange bedeckt. F. bis $6 \times 2$, weisslichgelblich, unten verdickt und schwach behaart. L. werden violettlich. Sp. $10-11 \times 6.5-7.5$, braun (ziemlich hell). Auf faulenden Getreidekörnern der vorigesjährigen Ernte, vor einem Speicher.

C. tomentosus Bull. - 1.10. - H. bis 2 hoch, walzig, grau mit fuchsigem Scheitel. Bis zum Scheitel gefaltet. F. $3 \times 3$, gerieft. L. dunkelgrau mit viol. Schimmer, langsam zerfliessend. Sp. braun, 8.5$10 \times 6-7$. Auf Holz.

C. micaceus Bull. - 19. 6 .

C. niveus Pers. - 1.9.

C. radicans Romagn. - 6. 7. - Von C. narcoticus schwer zu trennen. U'bler Geruch wenn zerrieben. Sp. schwarzbraun mit deutlichem Perispor, $11-13 \times 6-7$.

C. stercorarius Bull. ss. restr. - 6.7. - Schwarzes Sklerotium. Sp. schwarz, ohne Perispor, 7.5$9.5 \times 5-5.5$.

C. mycthemerus Vail. ss. Moseri - 11.8. - H. 1 breit, grau, faltig, mit gelbem Scheitel. Grauweisse Velumreste. F. weiss, mehlig, $3 \times 1$, nicht wurzelnd. Sp. $11-12 \times 7-9$, grauschwarz, ohne Perispor. Auf Mist.

C. curtus Kalchbr. - 20.7. - Junge H. zuerst gelbrötlich-braun, glimmerig, ausblassend, früh gerieft. Ausgewachsen bis höchstens $8 \mathrm{~mm}$ hoch, grau, zur Mitte zu bräunlicher, mit gelblicher nabelartiger Mitte, stärkstens gefurcht. F. bis $2 \times 0.5$, weiss, kleiig. Sp. $9.5-12 \times 5.5-7.5$, braunschwarz, ziemlich undurchsichtig, Form s. Abb. 518 bei K. et Rom. Auf Dünger.

C. Boudieri Quél. - 9.8- - H. bis 2 breit, zuerst rotbraun resp. gelbbraun, dann grau, nackt und kahl. Zuerst eiförmig, dann ausbreitend, sehr kurzlebig. F. bis $4 \times 2$, weisslich bis gelb. Sp. fünfeckig, $8.5-10 \times 7.5-8$ beinahe schwarz. Auf alter Brandstelle.

C. plicatilis Gurt. - 14.8.

C. phacosporus Karst. - 18.9. - H. bis 1.5 hoch, cylindrisch-glockig, dann ausgebreitet und überall gerieft. Velum besonders deutlich in der Mitte des H. in der Form von braunen, mit dem blossen Auge sichtbaren Flocken. Der Rand des H. wird allmählich violett. F. $4 \times 4$, weiss. L. werden dunkelbraun. Sp. dunkelbraun, $8-9 \times$ 6-6.5. Auf verfaulter Eller.

Russula delica Fr. - 31. 7.

R. nigricans Bull. - 13.9.

R. foetens Fr. - 7.8.

R. consobrina Fr. - 9.9.

$R$. vesca Fr. - 11.8.

R. claroflava Grove - 3.8.

R. decolorans Fr. - 18. 9

$R$. vinosa Lindbl. 18.9.

R. graveolens Romell ss. Langei - 1. 9.

$R$. xerampelina Schff. var. graveolens $\mathrm{f}$. subrubens Lange - 12.8

R. venosa Vel. ss. Melz. (nitida Fr. ex Pers. nec Pears.) - 28. 7.

R. sphagnophila Kauffm. - 11.8. - Nur ein schlechtes Ex. H. 5 breit, violett, Mitte olivbräunlich. Rand stark gerieft. $\mathrm{F}$ weiss, gebrechlich, $4 \times 10$. L. gelblich-weiss. Sp. $11 \times 8.5$, grobwarzig, 
Warzen isoliert. Farbe G-D. Sumpfwald, unter Birke. Zum Unterschiede von $R$. puellaris: sehr schwach gilbend, viel grössere Sp. Zum Unterschiede von $R$, venosa Vel.: viel hellere Sp.

$R$. lutea Huds. ss. Langei -2.8.

$R$. chamaeleontina Fr. ss. Langei (nauseosa (Pers.) Fr.) - 6.8.

R. aeruginea Lindbl. - 4. 7.

R. paludosa Britz, - 7.8.

R. Velenowskyi M. et Z. - 7.8.

R. Turci Bres. - 26.9. - Nur ein Ex. H. 6 breit, dunkelviolett, Mitte beinahe schwarz, matt. Haut dur Hälfte abziehbar. F. $5 \times 12.5-15$, weiss, ziemlich hart. L. sehr dicht, gleichlang, am Grunde nicht verbunden, beinahe frei, gelblich. Fl. weiss, durch $\mathrm{FeSO}_{4}$ rötlich. Mild. Sp. 8 $9 \times 7-8$, etwa F. Orn. 7 (stark netzig). Cyst. auf der L. Schneide c. 8 breit, durch SV nicht blauend, wie bei $R$. cessans Pears., der der Pilz sonst offenbar nahe steht. Cyst. auf der Huthaut nicht bemerkt. Geruch wegen Erkältung des Untersuchers nicht feststellbar.

R. integra Fr. ss. Pears. - 17.9.

R. Romellii Maire - 5.8. - Ergänzung zur Beschreibung in Karstenia III Seite 41: H. ausgesprochen violettlich, dann ausbleichend bis gelb. Das Fl. wird im Gegensatz zu alutacea und olivacea durch Phenol nicht eosinrot. Laubwald.

R. emetica Schff, var. typica-26. 9. - Grosser Pilz mit rotem $\mathrm{Fl}$, unter der Huthaut.

R. emetica Schff. var. crenulata Burl, - 1.9. - Nur ein schlechtes Ex. Gesägte L. Ausbleichend. Unter Sphagnum.

$R$. emetica Schff. var. silvestris Sing. f. phyllophila Romagn. - 4.8.

$R$. emetica Schff. var. siluestris Sing. f. pityophila Romagn. - 20.8. - Sp. bis $11 \times 9$.

R. Mairei Sing. ss. lato (Kühn. et Romagn.) 1.9. - H. einige $\mathrm{cm}$. breit, kirschrot. Haut ziemlich gut abziehbar. F. kurz, weiss. L. dicht. Fl. unter der Huthaut rötlich. Sp. höchstens $8.5 \times 7$, meist etwas kleiner. Warzen meist verbunden. Laubwald.

R. fragilis Pers. - 12.8.

R. riolacea Quél. - 19. 9.

R. atropurpurea Krbh. - 18. 8.

R. versicolor J. Schaeffer - 14. 8.

$R$. sanguinea Bull. var, rosacea Lange - 8. 8 .

R. sardonia Fr. - 18. 9.

Lactarius pubescens Fr. ss. Rick. Konr. et M. - 7.9.

L. torminosus Schff. - 14.9. - P.

L. repraesentaneus Britz. - 5.9.

L. uvidus Fr. var. subzonarius Karst. - 1. 10.

L. deliciosus L. - 5.9.

L. necator Pers. - 7.8.

L. vietus Fr. -7.8 .

L. trivialis Fr. - 18.8 .

L. fuliginosus Fr. f. albipes (azonites Bull.) - 3.9.

L. Hibbardiae (Burl.) Sacc. (glyciosmus Knauth et Neuhoff; confusus Lundell; fuscus Rolland.) 3. 9. - Zum Unterschiede von L. glyciosmus Fr: H. dunkelbraun bis dunkelgrau, grösser. L. werden dunkelocker. Laubwald mit vereinzelten Kiefern.

L. glyciosmus Fr. - 12.9.

L. flexuosus Fr. - 10.9.

L. lilacinus Lasch - 19.8.

L. mitissimus Fr. -5.8 .
L. cremor Fr. ss. Fr. Karst. non Langei - 8. 8

L. obscuratus Lasch (cyathula Rick.) - 8. 8. - Ein winziger, bis 2 (selten 3 ) $\mathrm{cm}$. breiter, höchst gebrechlicher Massenpilz unter Ellern, mit auffallend stark durchscheinend gerieftem Rand.

L. helvus Fr. - 16.8. - H. oder Fl. $+\mathrm{FeSO}_{4}$ gibt keine lila Farbreaktion, wie Pearson behauptet. Auch die Angaben Pearsons über die Sp. sind falsch. Nicht 9-10 $\times 5.5-6.6$, sondern $7.2-8.8 \times 5.4-6.4$ (grobe, vielfach grob verbundene Warzen).

L. rufus Scop. - 14. 7.

L. subdulcis Pers. ss. restr. Langei - 12. 8. - Viel grösser als $L$. obscuratus und ungerieft.

Cantharellus cibarius Fr. - 9.9.

Nidularia confluens Fr. - 2.9.

Lycoperdon umbrinum Pers. - 24. 9. - P.

L. gemmatum Batsch - 19.6. - Alte Ex von 1954

L. piriforme Schff. - 17.6. - Alte Ex. von 1954.

Bovista plumbea Pers. - 22. 9.

B. nigrescens Pers. - 15. 9.

Dacryomyces lutescens Bref. ss. Neuhoff. - 5. 7.-H. orangegelb. Konvex, nicht niedergedrückt, bei älteren Ex. etwas grubig, bis $5 \mathrm{~mm}$ breit, gelatinös, kissenartig, zäh. F. deutlich, bis $2 \times 1.5 \mathrm{~mm}$, weissgelblich, filzig, im Alter dunkelnd; bisweilen fehlend. Hyphen 3 breit. Sp. $11-12 \times 4.5-5$ wurstförmig, verbogen. Auf Laubholzast.

Clavaria cristata Holmsk. - 12. 8 .

C. lappa Karst. - 12.8.

C. cinerea Bull. f. sublilascens - 29.8. - Einige kleine Ex. Frk. $2 \times 2$. Strunk kurz, $7 \mathrm{~mm}$ breit. Reich verzweigt, gebrechlich. Zweige nach oben verdickt. Endästchen stumpf. Überall grau mit Violetton. Sp. graulich, $8-8.5 \times 5.5-6$. Kaum merklich bitter. Grabenrand im Laubwalde.

Peniophora sp. - 7.9. - Weissgelb. Fruchtschicht weiss mit gelblichen Erhöhungen, feinstens sammetig (mit Lupe gerade noch $\mathrm{zu}$ bemerken). Rand feinhaarig. Sp. $8-8.5 \times 3.5-4$. Auf einem Ellerast. Vermutlich $P$. incarnata Pers.

Cyphella sp. - 27. 8. - Napfform, bis $6 \mathrm{~mm}$ breit. Innen weisslich-gelb. Aussen filzig, bräunlich. Sp. konnten nicht isoliert werden. Basidie plus $4 \mathrm{Sp}$. haben von oben gesehen etwa die Form cines Kreuzes, 19-21 im Quadrat. In einem trockenen Graben.

Stereum hirsutum Willd. - 19. 6.

S. purpureum Pers. - 4.8.

S. rugosum Pers. - 15. 6.

Pleurodon auriscalpium L. - 12. 8.

Dryodon diversidens Fr. - 16. 9.

Calodon zonatum Batsch - 26. 9.

Phylacteria terrestris Ehrh. - 19.6.

Melanopus varius Fr. - 19.8.

M. nummularius Bull. - 25.6.

Leucoporus brumalis Pers. - 15. 6.

Leptoporus lacteus Fr. - 23.9. - H. 3-5 breit, dreieckig, weiss. Scharfer Rand. R. weiss. Sp. 
cyl. verbogen, $4 \times \max .1 .5$ (gewöhnlich um 1.25). Auf Ellerästen.

L. mollis (Pers.) Karst. - 21. 8.

L. albellus Peck - 19.8. - Dreieckig, $4 \times 3$, Mitte dick. Gelblichweiss, Mitte graulich, feinhaarig, auch am ziemlich stumpfen Rande. Trama weich, zäh. Poren rund, $0.15-0.25-0.45$ im Diam. R. c. $3 \mathrm{~mm}$ lang. Sp. $4.2-5.2 \times 2.4-$ 2.6, gebogen. Süsser aromalischer Geruch. Geschmack nicht bitter. Auf Birke.

L. albidus Trog -2.10 .

L. amorplius Fr. - 14. 7.

L. adustus Willd. - 17. 6.

Phacolus Schweinitzii Fr. - 9. 8.

Coriolus pubescens Schum. - 20. 7. - Dicker, haariger und farbiger als C. velutinus Pers.

C. velutinus Pers. - 9.7.

C. hirsutus Wulf. - 10.9.

C. hirsutus Wulf var. fibula Fr. - 10.9. - H. bis 1 im Diam., weisslich-grauweisslich, halbiert, schwach behaart, Rand nicht sonderlich scharf. R. sehr verschieden, bald regelmässig rund, bald zerrissen, bald beinahe irpexoid. Sp. 6--8 $\times 2.5-3$. Auf Ellerästen.

C. zonatus Fr. - 4.9. - H. bis $8 \times 7$, gezont, gelbbraun, dick, sammetig. Trama weiss. R. weiss, kurz, eng (0.15-0.20 $\mathrm{mm}$ im Diam.) Kein F. Sp. 5-6 $\times 2.0-2.75$, hell, nicht rein weiss. Stark riechend. Dachziegelig auf Birke. Auch resupinat.

C. versicolor L. - 15. 6 .

C. unicolor Bull. -17.6 .

C. abietinus Dicks. - 15. 6 .

C. Neesii Fr. var. alnea Fr. - 9. 8. - H. sehr klein, schmutziggrau, schwach zottig, muschelförmig, seitlich oder resupinat, $2 \mathrm{~mm}$ dick, Rand scharf. P. weiss, rundlich. Fl. weiss. Sp. $4-4.5 \times 2.5-$ 2.75. Auf Ellerast. C. Neesii wird in der modernen Lit. ignoriert. Vielleicht nur eine Form von Leptoporus albellus?.

Irpex violaceus Pers. (fuscoviolaceus Fr.) - 24.6. $\mathrm{H}$. einige $\mathrm{cm}$. breit, weissgrau, seidig, deutlich gezont, häutigdünn, halbkreis- bis nierenförmig, ohne F., nicht resupinat. Trama weisslich. Zähne braunviolett, einige $\mathrm{mm}$ lang, am Rande lamellig. Auf toter Kieferborke, dachziegelig. Coriolus abietinus sehr ähnlich.

Lenzites betulina Fr. - 15. 6.

L. sepiaria Wulf. - 16. 6 .

Tramctes cinnabarina Jacq. - 19. 6.

T. rubescens Alb. et Schw. - 9.8. - Sp. 6-8X $2-2.5$.

T. mollis Sommf. - 19. 6.

Ungulina fomentaria L. - 15.6.

U. marginata Fr. - 16. 6 .

U. betulina Bull. - 16. 6 .

Ganoderma applanatum Pers. - 15. 6.

Phellinus igniarius L. - 19.6.

Xanthochrous cinnamomeus Jacq. - 9. 7.

$X$. radiatus Sow. -14.8 .

Poria sp. - 13. 8. - Weiss, gilbend, resupinat und zusammenfliessend. Keine Sp. Auf Birke.

\section{ASCOMYCETES}

Gyromitra esculenta Pers. - 16. 6.

Cudonia confusa Pers. - 24. 9. - P.

Vibrissea truncorum Schw. - 15.6.
Mitrula cucullata Batsch - 21.6. - 2-4 mm lang und $1-2$ breit, orangegelb.

Geopyxis pustulata Hedw. (Fuckel) ss. Rehm, nec Rick. - 30.9. - Schüsselförmig, 6×4. Fruchtlager kastanienbraun, glatt. Aussenseite beinahe weiss, körnig. Sp. 13-15 $\times 8$, mit einem grossem Tropfen und körnigem Inhalt desselben. Laubwald. Am Rande eines alten Grabens.

Geopyxis cupularis L. - 5. 7. - Bis höchstens 2 breit, napfförmig, aussen und innen grauweisslichblassgelblich, aussen körnig. Rand gekerbtgezackt, einreissend. F. nur angedeutet, grubig. Fl. dünn, nicht zerbrechlich. Sp. elliptisch, ohne Öltropfen oder eintropfig, $16-20 \times 8.5-10.5$. Schläuche nicht blauend. Park. (Linden, Kiefern etc. Boden nicht gedüngt).

Plicaria badia Pers. - 7.8.

P. vesiculosa Bull. - 20.6.

Lachnea scutellata L. - 28. 8.

L. stercorea Pers. var. gemella Karst. - 10. 8. - Nur ein Ex. $2 \mathrm{~mm}$ breit, schüsselförmig, cinnober, oben mit weissen Haaren bedeckt. Haare etwa $200-250 \mathrm{mmm}$ lang und viclleicht 8 breit. F. winzig, gleichfarbig. Sp. $12-15 \times 8$. Auf einem Haufen, bestehend aus verfaulten Getreidekörnern und Dünger, vielleicht auf einem kleinen Holzstück? Bestimmt von Prof. Kujala.

Coryne sarcoides (Jacq.) Tu. - 29. 9. - H. c. 1 breit, schüsselförmig, mit nach innen gebogenem Rand. Fruchtlager purpur-fleischrot, kahl. Aussenseite nur violettlich, weissstaubig. Asci mit 8 Sporen. Sp. $8 \times 4$ etc. Dicht rasig auf Holz. Cordyceps sp. - 18.9. - Bis $2 \mathrm{~cm}$ hoch, in wenige Âste geteilt, orange. Basis weissfilzig. Äste bedeckt mit roten Wärzchen. Auf einem Blatte. Keine Lit.!

Cordyceps militaris L. - 23.9. - Keulenförmig, ungeteilt, $3 \times 3$, orange, mit roten Warzen bedeckt. Im Moos. Substrat nicht feststellbar.

Wenn ich nun zum Abschluss obige Liste im Zusammenhang mit meinen Notizen über die Häufigkeit des Auftretens ihrer Arten nochmals durchsehe und sie mit der Thesleffschen Zusammenstellung für Südostfinnland und einer Liste vergleiche, die ich ad hoc entwarf und die die Massenpilze der von mir bisher besuchten Gebiete enthält, die meiner Ansicht nach auch im Gebiete Kasuri gedeihen müssten, so komme ich zum Schlusse, dass obige Liste trotz den etwa 500 Arten und Var. doch nur ein verzertes, weil lückenhaftes Bild der Pilzflora des östlichen Teiles Mittelfinnlands gibt. Die Lücken sind, wie schon oben erwähnt, in der Hauptsache auf 2 Faktoren zurückzuführen. Der erste Faktor ist die eigentümliche Natur dieses landschaftlich unvergleichlich schönen. Gebietes, das von Wasser, Kiefer und Birke beherrscht wird. Oben dominiert die Kiefer, um allmählich der Birke zu weichen, die ganz unten im sumpfigen Gelände zwischen den Moränen 
und am Ufer der Seen allein oder im Erlengestrüpp das Landschaftsbild bestimmen. Die relative Seltenheit anderer Laubhölzer ist nicht gerade eine seltene Erscheinung in Finnland. Dagegen fällt das Fehlen der Fichte, die nur in Hecken und ganz vereinzelt im Walde anzutreffen ist, sofort auf. Entsprechend fehlen hier die zahlreichen Pilzarten, die an die Fichte gebunden sind oder Fichtenböden einseitig vorziehen. Daher fehlen, um nur einige Bespiele zu geben, zahlreiche waldbewohnende Hygrophoraceae, Clitocybe pithyophila, Tricholoma inamoenum, Micromphale perforans, die Agarici der arvensisGruppe, viele Cortinarii ss. lato, Clavariae usw. Die wenigen »Fichtenpilze», die ich fand, stammen ohne Ausnahme aus den staatlichen Anpflanzungen in Punkaharju. Zweitens, erweist es sich, dass der ungünstige
Herbst 54, der nasse, schneereiche Winter 54-55 und das kalte Frühjahr 55 die Mycele sehr ungleich beeinflusst haben. Es gibt Mycele, die diese schlechte Zeit sehr gut überstanden haben, - ich nenne nur die Mycele der auf Stämmen wachsenden Arten. Andere sind in ihrer Entwicklung so gehemmt und geschädigt worden, dass sie 55 keine Fruchtkörper hervorzutreiben vermochten. Ich nenne hier nur die im Freien wachsenden Hygrophoraceae, Tricholoma equestre, viele $H y d-$ naceae (z. B. repandum), Polyporus ovinus und vor allen Dingen Cantharellus cibarius. In normalen Jahren sind die hiesigen hohen Sandmoränen ab Anfang August buchstäblich gelb von diesem Pilze. Ich fand 55 nur einige wenige Exemplare. Dagegen wucherte die äusserlich ähnliche Art Hygrophoropsis aurantiaca.

\section{Mustila im Kirchspiel Elimäki 23. 10. - 21. 11.}

Die Zeit zwischen dem 23. 10. und 21. 11. verbrachte ich in Mustila, im Kirchspiel Elimäki. Fröste und starke Niederschläge (meist Schnee) hatten zur Folge, dass eine sichere Bestimmung der meist völlig durchwässerten und entfärbten weicheren Pilze von Tag zu Tag immer schwieriger und schliesslich völlig unmöglich wurde, so dass ich mich im November eigentlich nur den meist mehr oder weniger winter-, besser spätherbstharten aphyllophoralen Basidpilzen und Ascomyceten widmen konnte. Immerhin konnte ich in diesem reichen Gebiete zahlreiche Arten feststellen, die ich früher in Mustila nicht fand. (Siehe Karstenia III Kap. 2 und Nachtrag). Bei der Bestimmung mehrerer aphyllophoraler Basidpilze und Ascomyceten fand ich, wie schon früher, Hilfe bei Prof. V. Kujala.

\section{BASIDIOMYCETES.}

Clitocybe hydrogramma Bull. - 12. 11.

C. ditopus Fr. - 24. 10.

C. Flangei Sing. - 26. 10.

Collybia tuberosa Bull. - 23. 10.

Cantharellula obbata Fr. - 12. 11.

Catathelasma imperiale Fr. - 28. 10. - Ich erwähne diesen seltenen Pilz besonders, obgleich ich ihn schon früher in Mustila sah. Er zeigte ich genau an der gleichen Stelle wie in früheren Jahren. Siehe Karstenia III. Kap. 2.

Pleurotus salignus Pers. - 9.11. - Sp. 8-11 × 3-4.

Panellus violaceofulvus Batsch - 18.11. - H. bis 1 breit, violett, ausbleichend, gerieft. Befestigt durch seitlich ausgezogenen, filzigen Rand. L. fleischfarben, scharf abgegrenzt. Sp. $6-8 \times 2-3$. Auf Nadelholzzaun. Die Exsikkate bleichen leider stark aus.

Marasmius epiphyllus Pers. - 26. 10.

Mycena alcalina Fr. var. chlorinella Lange. - 13. 11. $M$. vitilis (Fr.) Quél. (filopes Bull. ss. Rick. Kühn.) $-23.10$.

Rhodophyllus griseorubellus Lasch ss. Karst. - 10. 11. Volvariella speciosa Fr. - 24. 10.

Amanita strangulata Fr. - 23. 10.

Crepidotus scalaris Fr. (applanatus Pers. ss. Karst.) 26. 10. - Bis einige $\mathrm{cm}$. breit, meist klein, kanelbraun, trocken lederblass, nierenförmig, kahl, dachziegelig aufsitzend. Basis filzig. L. schliesslich kanelbraun, gedrängt. Sp. sehr hell (beinahe hyalin), 5-6.5 im Diam., fein warzig. Auf Laubholzast.

Tubaria pallidispora Lange, ss. K. et Rom. - 10. 11.

Inocybe descissa Fr. var. auricoma Batsch .... 28. 10.

I. tigrina Heim - 28.10. - H. 1.5-2 breit, glockig-konvex bis spitz, auf hellem Grund dunkel braunschuppig. F. 3-4 4 , hell, bräunend. L. ausgebuchtet, ockerlich braun, mit heller Schneide. Sp. c. $9-11 \times 6$. Cyst. 50$60 \times 15$. Nadelwald.

I. posterula Britz. - 26. 10 .

Galerina mniophila Lasch - 15.11. - H. bis 1.5 breit, glockig, bis $2 / 3$ stark gerieft, honiggelb. $\mathrm{F}$. bis $6 \times 1.5$, oben gepudert, sonst kahl und ohne Velumreste. L. aufsteigend, breit angewachsen. Sp. rauh, $9-12 \times 6$. Unter Moosen Geruch und Geschmack fehlend.

I. pumila Fr. - 23. 10.

Dermocybe cinnamomea L. var. conformis, f. croceifolia Peck - 29. 10.

Hydrocybe saturnina Fr. var. Bresadolae Moser - 30. 10. - Sp. $8.5 \times 5$. 
H. erythrina Fr. ss. Favre - 30. 10.

H. bulbosa Sow. - 24. 10.

H. paleacea Fr. - 12. 11 .

$H$. rigida Scop. ss. OvS. - 11. 11.

H. subbalaustina Hry (balaustina Lange) - 26. 10 .

H. acuta Fr. ss. Favre. - 23. 10.

Myxacium salor Fr. - 24.10. - H. bis 5 breit, blauviolett, vom Scheitel aus ocker werdend. F. bis $10 \times 10-15$, weisslich, hohl, feucht klebrig. L. werden ocker-kanel. Sp. $7-8 \times 6-7$. Fl. weiss, mild. Fichtenwald.

Russula atropurpurea Krmbh. - 28. 10. - Bisweilen beinahe mild.

Calvatia saccata Vahl - 27. 10.

Tremella mesenterica Retz. - 20. 11. - Fruchtkörper lebhaft goldgelb, gekröseartig gefaltet, ziemlich zäh. Konidienfrüchte rund, um 3 im Diam. Sp. $8-12 \times 6-10$. Auf Laubholzästen.

Exidia cartilaginea L11. et Neuh. -19. 11. - Frk. harzbräunlich, sehr hell, trocken olivbräunlich, gallertartig weich, Oberfläche gehirnartig mit flachen Falten, kahl, am Rande und zwischen den Falten weisshaarig. Sp. $10-14 \times 4.5-5.5$, meist schwach gekrümmt, bohnenförmig, granuliert. Auf Prunus, dem Substrate aufliegend.

Calocera palmata Schum. - 28. 10.

Clavaria rugosa Bull. - 28. 10.

Corticium laeve Pers. - 19. 11. - Sehr weich. Leicht abtrennbar vom Substrat (Laubbrennholz). Hyphen des Tramas unter gewöhnlicher Lupe sichtbar, c. 5 breit. Fruchthaut zuerst weisslich, bald isabell-ocker. Sp. weiss, $7-11 \times 4.5-7$, ei- bis birnenförmig.

Peniophora velutina DC. - 19.11. - Ausgebreitet, rosenrosa mit ziemlich stumpfem Rand. Rand weisshaarig. Cyst. vorhanden (c. 6-8 breit, Länge z.B. 90). Sp. nur wenige $5 \times 3$ (?). Auf toter Salix caprea.

P. mutata Peck. - 16.11. - Ausgebreitet. Subiculum weiss, mit wolligem Rand. Fruchtschicht auf weissen, zahnartigen Auswüchsen, wic bei Radulum. Sp. 9-15×3-4. Im Gegensatz zu Radulum orbiculare mit Cyst. versch. Form und Grösse. Sonst von diesem Pilze kaum zu unterscheiden. Laubholz.

Phlebia radiata Fr. (aurantiaca (Sow.) Karst. var. radiata) - 9.11. - Ausgebreitet, glatt, orangerot. Rand gefranst-gezähnt. Falten der Fruchtschicht radial ausstrahlend. Sp. c. 5-5.5 $\times 2$. Auf totem Ast von Prunus serotina.

Radulum orbiculare Fr. - 9. 11. - Zuerst rund, dann zusammenfliessend, wachsartig-fleischig. Rand weisslich behaart. Zähne 2-6 mm lang, grob, stumpf, weiss, stark gilbend bis bräunend. Sp. $9 \times 3-5$. Auf totem Ast von Prunus serotina. Von $R$. membranaceum nur schwer zu trennen.
Leucoporus arcularius Batsch f. scabellus - 16.11. H. 7-20 mm breit, braun, filzig. F. $1.2 \times 3$ etc., braun, weisslich gepudert. Fruchtschicht am F. herablaufend. R. weiss. P. weit, rhombisch, zum F. zu verlängert. Sp. $5-6 \times 2-3$. Auf Salix caprea.

Leptoporus caesius Schrad. - 30. 10. - H. 2-5 breit, weiss, stellenweise blaugefärbt, radial gefurcht, mit scharfem Rand. R. kurz. P. rund, oval, schliesslich zerrissen. Trama weiss, dicklich, weich-zäh. Sp. $4-5 \times 1-2$. Nadelholzstümpfe und -Wurzeln.

L. amorphus Fr. - 13. 11 .

L. amorphus Fr. var. vitrea Quel. - 30.10. Weisse Abart, mit breitem, sterilem Rand.

L. adustus Willd. -- 11. 11.

Coriolus hirsutus Schrad. - 14. 11.

C. unicolor Bull. - 15. 11 .

C. connatus Weinm. - 12.11. - Mehrjährig. Sp. $4 \times 3.5$. Auf Ahorn in grossen Rasen.

C. populinus Schum. ss. Rick et Karst. - 16.11. H. meist sehr klein ( $2 \times 1$ etc.) weisslich, schwach weissfilzig, häufig mit Moos überzogen. Rand stumpf und steril. Ohne F. Dachziegelig wachsend. R. bis $4 \mathrm{~mm}$ lang. P. sehr regelmässig, rund, 0.14 breit, resp. $6-7$ per $1 \mathrm{~mm}$. Sp. $4 \times 3$. Auf Ahorn. Bisweilen mehrschichtig, was weder von Ricken, noch von Karsten erwähnt wird. Wohl nur eine kleine Form von C. connatus Weinm.

Phellinus Friesianus Bres. (punctatus Fr.; igniarius L. var. resupinatus Bres.) - 8.11. - Fruchtkörper beinahe nur aus mehrschichtigen $\mathrm{R}$. bestehend. Völlig resupinat und weit ausgebreitet. R. kaffeebraun, dunkel bestaubt. P. 5-6 per $1 \mathrm{~mm}$. oder 0.14-0.17 im Diam. Cyst. nur wenige, 35$50 \times 4-6$. Sp. circa $7 \times 6$. Auf absterbender Salix caprea.

Xanthochrous nodulosus Fr. - 20.11. - Aus halbkugeligen, aufsitzenden Polstern, die oft den Stamm von oben bis unten überziehen, entwickeln sich knotenförmige oder kosolenförmige Hüte. Diese sind rostbraun, mit gelblicherem Rand. Bisweilen gezont, strahlig-runzelig, 1-2, aber auch bis $4 \times 3$. R. bis 1 lang, zuletzt zerrissen. P. häufig schräg gezogen. Substanz rostfarben, hart. Sp. etwa $5 \times 4$. Auf Hasel. Von $X$. radiatus bisweilen kaum zu trennen.

\section{ASCOMYCETES.}

Helotium scutula Pers. - 16.11. - Pezizaartig. 0.7 $\mathrm{mm}$. breit, gelbbraun, mit F. Sp. $20 \times 3$ etc. Auf Rosenast.

Dasyscypha calyciformis Willd. - 12.10. - Pezizaartig, gelb, mit dunklerem F., $1 \mathrm{~mm}$. breit. Sp. $6 \times 3$ etc, hyalin. Asci c. $60 \times 5$. Auf Nadelholz.

Cordyceps militaris L. - 11. 11. Auf Puppe.

Nectria cinnabarina Tod. - 25. 10.

Hypocrea citrina Pers. - 25. 10. 


\section{Zweite Fortsetzung: Das Jahr 1956}

$\mathrm{Zu}$ den früher erwähnten Werken traten in der Saison 1956 nur:

P. A. K a r ste n: Pyrenomycetes. 1873.

M. Mos e r: Blätter- und Bauchpilze.

Zweite, wesentlich vergrösserte Auflage 1955.

W. Neuh off: Die Milchlinge. 1956.
R. S in g e r: The Agaricales in Modern Taxonomy. 1949.

Bei Bestimmung der Ascomyceten und vieler aphyllophoraler Basidpilze wurde mir, wie schon früher, die wertvolle Hilfe von Prof. Dr. V. Kujala zuteil.

\section{Mustila im Kirchspiel Elimäki 29. 5. - 7. 6. und 13 - 19. 11.}

Die früheren Funde sind zu ergänzen mit:

Pseudohiatula tenacella Pers. ex Fr. ss. Schroet. Favre - 29.5.

Rhodophyllus aprilis Britz. Romagn. f. typica - 2. 6 . $R$. vernus Lund. Romagn. - 29. 5. - H. 2-4 breit, halbkugelig-glockig, dann ausgebreitet, gebukkelr, faserstreifig, graubraun, trocken ausbleichend, aber nicht cder kaum hygrophan. F. bis $3 \times 6$, ausgesprochen faserstreifig, Farbe des H., hohl. L. ausgebuchter angewachsen, grau mit schmutzigrötlichem Schimmer. Sp. $9 \times 7$. Nadelwald, Wegrand. Steht $R$. aprilis sehr nahe. Geaster Bryantii Berk. - 2. 6. - Exemplare von 1955, mit kragenartiger Wulst um den F. Mag. N. Malmström glaubt, dass es sich hier um $G$. pectinatus Pers. handelt. Die Wulst sei beim Eintrocknen entstanden. Da keiner von uns die von mir 1956 gesammelten und dem Botanischen Institut in Hels. übergebenen Ex. im frischen Zustande gesehen hat, ist eine einwandfreie Entscheidung kaum möglich. Mein Eindruck ist eher der, dass diese zwei Pilze einander so nahe stehen, dass man sich versucht fühlt, sie als blosse Var, einer Art anzusehen.
Peniophora incarnata Pers. - 13.11. - Sp. $10 \times 4$ Hyphen 2.5-4.5.

Grandinia raduloides Karst. - 31. 5. - Dünn, ausgebreitet, flockig, weiss. Warzen ziemlich spitz, bis $1.5 \mathrm{~mm}$. lang. Sp. 7-8 $\times 3-3.5$. Keine Cyst. Auf Borke von Picea omorica.

Phaeolus rutilans Pers. - 13. 11.

Trametes serialis Fr. - 30. 5 .

Phellinus tremulae Bond. et Boriss. (P. igniarius L. $\mathrm{f}$. tremulae Bond.) - 13.11. - Viel kleiner als $P$. igniarius L., mit Tendenz sich auszubreiten, besonders bei Wachstum auf horizontalen Ästen. Kleinsporig. (Messung von Prof. Kujala $5.5 \times$ 3.7 , bei mir c. $5 \times 4)$. Nur auf Espe.

Xanthochrous radiatus Sow. - 29. 5.

X. obliquus Pers. (Poria o.) - 13.11. - Entwickelt sich zwischen Holz und Borke alter Birken, sprengt dann die Borke und tritt in der Form amorpher, schliesslich schwarzer, steriler Auswüchse ans Tageslicht.

Poria xantha Lind. - 4.6. - Ausgebreitet, $1 \mathrm{~mm}$. dick. Subiculum kaum vorhanden. Sp. nicht gemessen. Auf Nadelholz.

\section{Kasuri im Kirchspiel Parikkala 19-24. 6.}

Die früheren Funde (1955) sind zu ergänzen mit:

Hygrocybe miniata Fr. - 23. 6.

Collybia crythropus Pers. ex Fr. ss. Bres. - 19.6. Schwach hygrophan. H. rötlichgelb, bis 3 breit, Hyphen der Huthaut unregelmässig verästelt, bis 13 breit. F. bis $6 \times 2$, Farbe des H. oben heller, völlig kahl. L. mittel gedrängt, weisslich. Sp. $6.5-7.5 \times 3.75-4$, mit etwas zugespitzter Basis. Cyst. in der Form langer, cyl. Haare. Meist büschelig, im Mischwalde. Sieht etwa wie $C$. confluens aus, hat aber einen ganz kahlen F.

Pseudohiatula tenacella (Pers.) Fr. ss. Schroeter. Favre - 19. 6.

Mycena praecox Vel. - 21.6. - H. bis 2.5 breit, kegelig-stumpf, gestreift, braun. F. bis $6 \times 2$, röhrig, blass, ganz kahl. L. weisslich. Sp. 9$10 \times 5-6$ etc. Cyst. glatt, lang, z. T. mit kegeliger Spitze. Kein alkalischer Geruch. Auf Strünken.

M. sp. - 22. 6. - H. ausgebreitet bis $8 \mathrm{~mm}$. breit, graubraun, gestreift. F. bis $4 \times 0.5$, rosa, oben heller, faserstreifig. L. Farbe des $\mathrm{H}$, rotbraun gerandet. Sp. $8.2-10 \times 5.5-7$. Cyst. glatt, z. T. mit Köpfchen. Nasser Wald. Im Moose.

Naucoria reducta Fr. - 24.6. - H. bis 2.5 breit, gebuckelt, zur Hälfte gerieft, olivbräunlich, trocken lederfarben (in der Art von $K$. mutabilis ausbleichend). Huthaut hyphisch. F. bis $6 \times 2$, braun, unten dunkler, röhrig, kahl, oben bereift. L. oliv, angewachsen bis etwas herablaufend. Sp. schmutzig, 6-7 $\times 4-4.5$. Cyst. haarförmig, z. B. $32 \times 4-6$. An einem Waldweg, rasig. Stimmt mit dem Pilz bei Karsten, Lange, Ricken und Moser gut überein, nur sind die $\mathrm{Sp}$. etwas kürzer. Kühn. et Romagn. Pilz ist kaum identisch. Conocybe tenera Schff. var. semiglobata Kühn. - 19. 6. Russula Mairei Sing. var. typica - 22. 6.

Exidia glandulosa Bull. - 22. 6.

Exidia repanda Fr. - 22. 6. - Fruchtkörper 3-5, zimt-bis rotbraun, fast glatt, Papillen selten, Rand gekerbt-kraus. Sp. wurstförmig, 12-14x 5-5.5. An toter Birke.

Xanthochrous perennis L. - 24. 6 .

Nectria cinnabarina Tod. -21.6. 


\section{Rasila im Kirchspiel Lapinlahti 25. 6. - 3. 10.}

Dieses Gebiet hat den Ruf zu den besten Pilzgegenden des Landes zu gehören. Nirgends fand ich so viele Arten wie hier, obgleich die Saison nach Ansicht der örtlichen Bevölkerung keine günstige war.

\section{BASIDIOMTCETES.}

Suillus luteus L. -8.8 .

S. flavidus Fr. -10.8 .

S. bovinus L. - 9. 8.

S. variegatus Sow. - 20.8.

S. piperatus Bull. - 4. 8 .

Leccinum aurantiacum Bull. - 7. 9. - Nadelwaldform.

L. testaceo-scabrum Secr. - 25. 8.

L. scabrum var. niveum Fr. (holopus Rostk.) - 25. 8.

L. duriusculum Kalchbr. - 11.8. - Abweichungen von L. leucophaeum Gilb.: H.meist dunkler. Haut den Rand überragend. F. mit schwärzlichen Schuppen, wird unten blaugrün. Fl. im F. zuerst rötend, dann schmutzig grün. Sp. elliptisch, $12-14 \times 5.5-6.5$. Der ganze Pilz stets kräftiger.

L. leucophaeum Gilb. - 30.6.

L. Carpini R. Schulz. - 12.8. - Abweichungen von L. leucophaeum: H. rissig-felderig. Rand erreicht kaum die Röhrenschicht. Huthaut zellig (übrigens nicht immer ausgesprochen). F. wird schmutzig, durch $\mathrm{FeSO}_{4}$ blaugrün und durch Formol rosa. Sp. bis 7.3 breit.

Boletus edulis Bull. - 20. 8.

Xerocomus badius Fr. - 23.8.

X. chrysenteron Bull. - 5.9.

$X$. subtomentosus L. -2.8 .

Paxillus involutus Batsch - 11. 7.

P. filamentosus Fr. - 27. 6.

Gomphidius glutinosus Schff. - 11.7.

G. subroseus Kauffm. - 31. 7. - H. an der breitesten Stelle 6.5 breit, ausgesprochen rosa bis rot, mit schwarzen Flecken, klebrig. F. hart, durchschnittlich 15 breit, schmutzig-weisslich, schwarzfleckig, Basis im Gegensatz zu G. glutinosus nicht gefärbt. L. stark herablaufend, schmutzigfarblos. Der ganze Pilz, der deutlich die Tendenz hat zu schwärzen, ist von Hutspitze bis Fussbasis $11 \mathrm{~cm}$. hoch. Sp. 17-20×5.5-7, etwas breiter als bei G. glutinosus. Gemischter Wald (Fichte, Birke), sehr nass. Ich"sah diesen Pilz bisher nirgends in Finnland oder anderswo in Europa. Offenbar eine amerikanische Art, die sich hierher verirrt hat.

G. viscidus L. - 16. 8.

Hygrophorus picrat Kühn. - 31.8.

H. hj; oth jus I:. - - 6.9.

$H$. olivaceo-allit Fr. (mesotephrus Berk. et Br. ss. Langei) -.. 9. 9.

H. olivaceo-albus Fr. in einer Übergangsform zu $H$. limacints Scop. (Schuppen am F. kaum sichtbar). - $\angle 8.8$.

H. fuscoalbus Lasch - 28. 8. - H. bis 7 breit, Farbe von $H$. olivaceo-albus, Mitte dunkel gebuckelt. F. bis $13 \times 10$, weiss. L. weiss. Sp. $11-13 \times 6-7$.
Offenbar nicht identisch mit der in Karstenia III, S. 62 beschriebenen Art.

H. erubescens Fr. - 8.9.

H. agathosmus Fr. - 18. 8.

Camarophyllus pratensis Pers. - 1.9.

Hygrocybe nitrata Pers. - 11.9.

H. conica Scop. - 1.9.

H. citrina Rea var. glutinipes Lge - 1.9. - Siehe Karstenia III S. 33. Verwandtschaft mit $H$. Reai Mre var. insipida Lge (s. Karstenia III S. 48) ungeklärt. Vielleicht identisch?

H. Reai Mre. var. insipida Lge - 3.9. - Sp. $7.75 \times 3.5$.

H. miniata Scop. -28.6.

Asterophora lycoperdoides Bull. - 19.9.

Lyophyllum carbonarium Vel. (ambustum Schroet.; sphaerospermum Kühn. et Rom.) - 24. 8. -. H. 1 breit, schwarzbraun, trocken graubraun, nass gerieft, halbkugelig bis glockig. F. $3 \times 1$, kahl, graubraun, oben weissmehlig. L. weisslichgrau, schwach herablaufend. Sp. $5.5 \times 5$ etc. Mehlgeruch und Mehlgeschmack.

L. palustre (Peck) Sing. - 28.6.

L. plexipes Fr. ss. lato Kühn. - 29. 8. - H. 3.3 breit, graubraun, ungerieft, schwach nieriergedrückt. F. $6.5 \times 3$, Farbe des H. nur blasser. L. weisslich, bauchig, nach Art der Collybia angewachsen, sehr dicht. Sp. warzig, etwa $6.5-7 \times 5.5$. Man unterscheidet heute: f. typicum = erosum Fr. ss. Lge = tesquorum Fr. ss. Romagn., geriefelt, mit langem $\mathrm{F}$. und $\mathrm{f}$. atrum Kühn. et Romagn. (tylicolor Fr. ss. Lge), ungerieft, mit kurzem F. Das Exs. gehört offentar einer dritten Form an. Konfuse Sammelart.

L. conglobatum Vitt. - 3.9.

L. decastes Fr. var. ovisporum - 7.9.

Calocybe onychina Fr. - 5.9. - H. bis 4 breit, mit zelliger Haut, kastanienpurpurbraun (bei einigen Ex. mit gelblichem Ton dem Rande zu), kahl. F. bis $4 \times 7$, blass, faserig. L. goldgelb, horizontal, ziemlich frei. Sp. $4 \times 2$ etc. Fl. gelblich-weisslich, säuerlich und bitterlich. Nadelwald.

Hygrophoropsis aurantiaca Wulf. - 4. 8.

Clitocybe odora Bull. - 19.8.

C. odora Bull. var. alba Lge - 19.8.

C. sp. - 1.9. - Nur ein Ex. H. 2 breit, unveränderlich weiss, ungerieft, glockig, schwach gebuckelt. Rand scharf. F. $2.5 \times 1.5$, kahl, weiss. L. weiss, weit herablaufend. Sp. $4.5 \times 2.5$ etc. Intensiver Anisgeruch. Viehweide.

C. clavipes Pers. -20.8 .

C. squamulosa Pers. - 2. 7.

C. infundibuliformis Schff. -1.8 .

C. subalutacea Batsch - 11.8. - Nur ein Ex. In allen Teilen ledergelb, nicht hygrophan. H. 2.25 breit, kahl, niedergedrückt. F. $3.5 \times 3$, kahl. L. etwas blasser. Sp. 3-4 $42.5-3$. Anisgeruch.

C. rufoalutacea Métr. - 17. 7. - Nur junge Ex. H. bis 1.5 breit, gelbbraun, mit rötlichem Ton, filzig, Mitte niedergedrückt, Rand ganz. F. bis $5 \times 6-10$ (unten), Farbe des H. L. breit angewachsen, dick, einige gegabelt, weisslich. Sp. 4.5-6 $\times 3-4$. Nadelwald, an einem Weg. Steht C. subalutacea Batsch (sericella Kühn. et Romagn.) 
sehr nahe. Nur die Farbe ist abweichend. Auch C. sinopicoicies Peck ist nahe verwandt.

C. inversa Scop. (flaccida Sow.) - 18. 8

C. cerussata Fr. (phyllophila Fr.) - 2.9.

C. dealbata Sow. f. - 21.8. - H. 4 breit, Rand eingebogen (wie bei Paxillus). F. sehr robust, $3.5 \times 12-17$ (unten). Sp. $4 \times 2.5$ etc., völlig. weiss. Nicht $=C$. cerussata -phyllophila mit ähnlichem Geruch und Geschmack von Mehl, aber rötlichen Sp. Die Zahl der nicht hygrophanen, weissen Clitocybe-Arten mit so kleinen Sp. ist sehr gering. Von diesen kommt nur die mir wohlbekannte $G$. dealbata in Frage, es sei denn man nimmt eine neue Art an.

C. rivulosa Pers. - 13. 8 .

C. catina Fr. ss. Moseri - 22.8. - H. 5 breit, trichterig (die kleineren Ex. flach), flatterig, dünnfleischig, weiss, nass eher gelblich-rötlich. F. $6 \times 8$. Sp. $4 \times 2.5$. Von C. cerussata Fr. ss. Qu. und phyllophila Fr. ss. Kühn. et Romagn. kaum zu trennen.

C. candicans Pers. - 17, 8 .

C. olorina (Fr.) Gill. - 19. 8.

C. fragrans Sow. - 14.9.

C. suaveolens Schum. - 22.8.

C. hydrogramma Bull. - 6. 9. - Geruch von Ciystoderma carcharias.

C. fuligineipes Métr. (fritilliformis Rick. nec Lasch) - 18. 9. - H. bis 5.5 breit, olivbraun, trocken grau bis schmutzig lederfarben, genabelt bis trichterförmig, mit gerieftem Rand. F. bis $4 \times 6$, wenn breitgedrückt und kanalisiert bis beinahe 10 breit, schwach gerieft, schmutzigoliv (dunkel). L. gelblichgrau. Sp. $7-8 \times 3.5-4$. Riecht wie Cystoderma carcharias.

C. ditopa Fr. - 6.9. - Sp 2-4×2-3. Geschmack unangenehm (Mehl), aber nicht bitter.

C. Langei Sing. - 26.9

C. vibecina Fr. - 6.9.

C. angustissima Lasch - 17.9.

C. diatreta Fr. nec. Langei - 31. 8. - H. 2.5-4 breit, fleisch-honigbraun bis fleischrötlich. Trokken isabellrötlich, ungerieft, mit Ausnahme von ganz alten Ex. F. blass mit rotbräunlichem Ton. L. herablaufend, bisweilen auch fast abgerundet und mit Zahn angewachsen, crèmefarben. Sp. 4-4.5 × 2.5-3. Aromatischer Geruch. In Massen auf Nadeln. Erscheint vor C. brumalis.

C. pinetorum Vel. - 10.8

C. dicolor Pers. - 31.8.

C. metachroa Fr. -22.8

C. brumalis Fr. -28.9.

Laccaria amethystina Bolt. - 7.7.

L. proxima Boud. - 30. 6.

L. laccata Scop. var. rosella - 29. 6.

L. echinospora (Speg.) Sing. (tortilis Fr. Pat.) - 19. 7. - Úberall fleischrot. H. bis 1 breit. F. bis $1-2 \times 1$. Sp. 13 im Diam. Nasses Gebiet. Der Pilz, den ich in Lemböte auf Åland am 7.8.50 fand (Karstenia III S. 20) war wahrscheinlich $L$. pumila Fayod (nana Mass.)

L. pumila Fayod (nana Mass. ss. Moseri) - 16. 7. Tricholomopsis rutilans Schff. - 30.6.

T. decora Fr. - 5.9.

T. ornata Fr. ss. Kühn. - 15. 7. - H. bis 3.5 breit, gelb, mit braunen Schuppen. Gesamteindruck oliv. F. bis $4.5 \times 8$, gelb, in der oberen Hälfte braunschuppig, an der Spitze schwach weiss- mehlig, unten weissfilzig. L. auffallend goldgelb, horizontal angewachsen, ziemlich dicht, normal breit. Sp. $7 \times 5.5$, glatt, F. gelblich weiss, nur im F. gelb. Geruch von Lepista nuda. Auf Fichtenstumpf. Ein Blick in die Lit. zeigt, dass es sehr schwer ist zwischen $T$. decora und ornata eine zuverlässige Grenze zu ziehen.

Collybia cirrhata Schum. - 9.8.

C. tuberosa Bull. - 5.8.

C. putilla Fr. - 17.9.

C. confluens Pers. - 14.8.

C. ocellata Fr. - 4.7. - Langstielige Sumpform.

C. extuberans Fr. - 4.7. - H. bis 3 breit, halbkugelig, dann etwas ausgebreitet, schwach klebrig, kastanienbraun, schwach hygrophan. F. bis $8 \times 6$, meist $6 \times 3$, glatt, erst im Alter faserstreifig, anfangs strohbräunlich, später dunkler, unten verdickt wurzelnd und weissfilzig. L. gedrängt, weiss. Fl. weiss, geruchlos. Sp. $5-7 \times$ etwa 3. Auf dem Erdboden, bei Stämmen, häufig, aber keineswegs immer schwach büschelig.

C. acervata Fr. - 1.7.

C. dryophila Bull. - 27.6.

C. dryophila Bull. Riesenform. Ervähnt bei Michael Aufl. 24-27. sub N:o 41 als var. xanthochroa R. Sch. - 8. 8. - Vermutlich eine selbständige Art. H. bis 10 breit, gelbbraun, hygrophan, glatt. F. bis $13 \times 10$, etwas rötlicher als der $\mathrm{H}$., kahl, stärkstens gerieft, meist plattgedrückt, verdreht. L. gelblich, wie bei der Hauptform, aber 150 Stück. Sp. 5.5-6.5 $\times 2.5-3$. Cyst. kurz, haarförmig, das sichtbare Ende $2-4$ breit. Dicht zusammengepresst wachsend, nicht striegelig verbunden. Auf dem Erdboden oder (meistens?) direkt auf Abfällen von der Entrindung von Papierholz. In Riesenmassen.

C. dryophila Bull. var. funicularis - 7.8.

C. dryophila Bull. var. oedipus Quél. - 18.7. Rand dicht gerieft. F. bis $10 \times 3$, mit knolligzwiebeliger Wurzel. Sp. 5-6.5 × 2.75-3.75. Auf Sphagnum, im Sumpfe.

C. exsculpta Fr. (Var. von C. dryophila?) - 15.8. Schokoladenbraun.

C. aquosa Bull. (Var. von C. dryophila?) - 29.7.

C. asema Fr. - 20.8. - Var. oder Form von $C$. butyracea Bull.

C. butyracea Bull. - 19.8.

C. strumosa Fr. Rick. - 24. 8. - H. 2.5-3.5 breit, milchweiss, mit kaum wahrnehmbarem gelblichem Ton in der Mitte, Rand gerieft. F. weiss, $2-3 \times 4-5$, hohl, in der Längsrichtung aufspaltend, unten verdickt. L. weiss, stark ausgebuchtet (wie butyracea). Sp. $7 \times 3$, apfelkernförmig. Nasser Nadelwald.

C. distorta Fr. - 13.8

C. prolixa Fl. Dan. ss. Moseri - 14. 8.

Omphalina umbellifera L. -26.6 .

O. umbellifera L. f. albida -2.7 .

O. scyphiformis Fr. ss. Langei - 10. 8.

O. oniscus Fr. - 19.7.

O. philonotis Lasch ss. Kühn. Moseri, nec Karst. - 27.7. - H. 2.5 breit, beige, feinfaserig, feinschuppig, trichterförmig. F. $3.5 \times 3.5$ (oben), etwas dunkler, grau bereift. Sp. 6-8 $4-5.5$. Sphagnumsumpf.

Armillaria mellea Vahl - 8.8.

Tricholoma flavobrunneum Fr. - 14.9.

T. pessundatum Fr. -10.9 . 
T. inodermum Fr. var. amarum Moser - 17.9. Nur junge Ex. H. bis 5 breit, rötlichbraun, durch strahlich verlaufende, grobe Fasern bunt, etwa wie Inocybe Bongardi. F. bis $6 \times 9$, abwärts verdickt, schwach faserig, rötlich-bräunlich. L. weiss, rötend. Sp. 5.5-6.5 ×4-4.5. Fl. überall unbedeutend rötend. Schwacher Geruch von Cystoderma carcharias. Geschmack schwach bitter. Nadelwald.

T. portentosum Fr. - 3. 10.

T. equestre L. -21.9.

T. inamoenum Fr. ss. Rick. - 20. 8. - Sp. 8-9× 4-5.

T. inamoenum Fr. ss. Kühn. nec. Rick. - 11.9. Sp. $9-13 \times 5.5-8.5$.

T. lascivum Fr. - 19.9. - Wie T. album, nur mit Geruch von Cystoderma carcharias ( $T$. album hat mehlich-ranzigen Geruch). Sp. etwa die gleichen $(4.5-6 \times 3-4)$.

Cantharellula umbonata Gmel. - 25. 8.

C. cyathiformis Bull. - 30.8.

C. obbata Fr. ss. OvS. - 19.9. - H. bis 1.5 breit, oliv-schwarzbraun, trocken grau, gerieft, schwach genabelt. F. bis $6.5 \times 3$, kahl, hellgrau, oben weissmehlig. L. angewachsen bis schwach herablaufend, dicklich, kaum gegabelt. Sp. amyloid, glatt, $6-8 \times 5.5-7$ mit winzigem Stielchen. Farbe der Sp. nicht rein weiss, neigt zu graulichrötlich. Geruch neigt deutlich zu Cl. prunulus.

Melanoleuca verrucipes Fr. - 30. 7. - H. bis 6 breit, weiss, Mitte bräunlich, eingebogener Rand, kahl bis sammetig. F. bis $7 \times 8$, weiss, bedeckt mit braunen bis schwarzen Schüppchen. Basis sehr verdickt. L. weiss, dicht, schwach herablaufend. Sp. $8.5-10 \times 5-5.5$, rauh. Cyst. nur wenige, lanzettlich. Angenehmer Geruch. Kleine Wiese im Walde.

M. strictipes Karst. - 28. 6 .

M. evenosa Sacc. - 27.6.

M. melaleuca Pers. - 1.8.

M. amicta Fr. - 16. 8.

M. cognata Fr. - 19.8. - Nur ein riesiges Ex. H. 7.5 breit, milchkaffeefarben, eingebogener Rand. Keine Spur von Riefelung, schwach niedergedrückt und schwach breit gebuckelt, wenig hygrophan. F. $11 \times 10-23$ (Knolle), graulich und grob dunkel befasert, unten weissfilzig, wurzelnd. L. beinahe völlig weiss, etwa 50 lange, ausgebuchtet, mit Zahn angewachsen. Sp. die bei den Melanoleuca üblichen. Cyst. allmählich zugespitzt.

Lentinellus bisus Quél. - 27.8.

Pleurotus salignus Pers. - 27. 8.

Panellus mitis Pers. - 16.9.

Panus conchatus Fr. - 9.8.

Hohenbuehelia serotina Schulz. - 11.9.

Oudemansiella platyphylla Pers. - 26.6.

Mycenella margaritispora Lange - 25. 7. - H. 0.4 breit, graubraun, gerieft, schwach bereift. F. $3 \times 0.5$, graubräunlich, schwach bereift, nicht wurzelnd. L. weiss, dicht frei. Sp. warzig, 6 im Diam. Sphagnumsumpf.

M. salicina Vel. - 25. 7. - H. ausgebreitet 1 breit, graulich. F. $2 \times 0.5$, braungrau, bereift. L. grau. Sp. rundlich, glatt, aber bisweilen etwas kantig, 5-7 $\times 5-6$. Sumpf im Sphagnum-Moose, unter Weide etc.

Flammulina velutipes Curt. - 3. 10.
Pseudohiatula tenacella (Fr.) Métr. (Marasmius conigenus ssp. esculentus Wulf.) - 26. 9.

Marasmius perforans Hoffm. - 26. 6.

M. scorodonius Fr. -29.7.

$M$. oreades Bolt. -25.8 .

$M$. androsaceus L. - 23. 7 .

M. epiphyllus Fr. - 18. 9.

Xeromphalina campanella Batsch - 30.8.

$X$. sp. Singer. - 27.6. - Grenau wie $X$. campanella, vielleicht etwas grösser. Wächst aber auf toter Birkenrinde. Über diesen Pilz siehe Singer: The Agaricales, p. 368 und 369. Schönes Exs. im Forstwiss. Institut der Univ. Helsinki.

$X$. cauticinalis With. -23.9 .

Mycena capillaris Schum. - 28.9. - Ganz weiss. H. $1-2 \mathrm{~mm}$. breit. F. bis $3 \times 0.25$. L. nicht herablaufend, meist aufsteigend. Sp. $11-12 \times 4$. Auf Blättern.

M. aurantiomarginata Fr. (elegans Pers.) - 29. 9.

M. vitilis Fr. ss. Schroet. Rick. - 30. 9 .

M. galericulata Scop. - 30. 7 .

M. parabolica Fr. ss. Langei (f. maculata Smith.) 27. 7. - H. bis 2.5 breit, braungrau, gerieft. F. bis $7 \times 3$, graubraun. L. grau. Sp. c. $9 \times 6$. Cyst. stachelig (15 breit). Wächst büschelig, wurzelnd, auf Laubholz.

M. citrinomarginata Gill. -31.8 .

M. rubromarginata Fr. - 22. 8.

M. avenacea Fr. var. typica (plicosa Fr. ss. Rick.) 4. 8. - H. bis 2 breit, gerieft, olivfarben. F. bis $4 \times 1.5$, gelblich, unten olivlich. L. entfernt, hell, Schneide braun. Sp. c. $9 \times 5$. Cyst. spärlich, glatt, aber anders geformt als bei Lange abgebildet, sehr schlecht sichtbar.

M. pura Pers. var. typica-3.8.

M. pura Pers. var. lutea Secr. - 18. 8. - H. gelblich. F. violett.

M. pseudopura Cke nec Kühn. - 2.8. - H. nur 2.5 breit, sehr hell. F. $3 \times 2$, violettlich. L. horizontal, mit Zahn herablaufend, weisslich, mit violettlichem Ton. Sp. nicht amyloid, c. $7 \times 4$. Flächencyst. vorhanden. Wieder eine Zwischenform!

M. laevigata Lasch - 1.7. - Ergänzung zu Karstenia III S. 45: Rand bisweilen fuchsig werdend. F. steif, hohl. L. fast herablaufend. Cyst. bisweilen warzig. Rasig auf Strünken.

M. polygramma Bull. - 9. 8 .

M. leptocephala Fr. (alcalina Fr. var. chlorinella Lange) - 2.7.

M. filopes Bull. ss. Schroet. - 29. 6 .

$M$. niveipes Murr. (Jacobi Mre; pseudogalericulata Lange) -24.7.

M. praecox Vel. - 5. 7 .

M. aetites Fr. (ammoniaca Fr. ss. Langei) - 2. 8 .

$M$. alcalina Fr. -26.6 .

M. epipterygia Scop. - 3. 8.

M. cinerella Karst. (Omphalia grisea Rick.) - 28. 9. H. bis 1.3 breit, graubraun, gerieft-gestreift, halbkugelig, bisweilen mit schwachem Buckel. F. bis $7 \times 2$. L. schwach herablaufend, bisweilen queradrig verbunden. Sp. 7-9.5 ×4-5. Mehlgeruch und Mehlgeschmack. Nadelwald. Im Moose.

M. vulgaris Pers. - 2. 10 .

M. sanguinolenta Schw. - 1.8.

M. haematopoda Pers. - 9. 8.

M. flavoalba Fr. - 2. 7. 
M. olida Bres. (gypsea ss. Langei) - 30.6. - Ergänzung zu Karstenia III, S. 34: F. bald oben flaumig, bald - abgesehen von der behaarten Basis - kahl. Sichtbarer Teil der Cyst. z. B. $65 \times 13$. Auf Laubholz.

M. hiemalis (Osb.) Fr. - 19. 9. - H. bis 1.2 breit, glockig, Rand blass, Mitte und Riefen braun. $\mathrm{F}$. bis $3 \times 0.5$, weisslich, unten dunkler. L. weisslich. Sp. nicht amyloid, Grösse sehr wechselnd, meist 6-8 8 4-5.5. Auf moosiger Holzrinde,

M. alba Bres. - 2.9. - H. 6-10 mm. breit, Rand weiss, Mitte nur weisslich. F. $2 \times 0.5$, weisslich. L. weisslich. Sp. kugelig, 5-8 im Diam. Auf Laubholz.

M. fibula Bull. - 27.7.

M. Swartzii Fr. - 27.7.

M. lactea Pers. ss. Langei - 1. 10. - H. bis 0.9 breit, weiss, gerieft. F. bis $2 \times 1$, weiss, bereift. L. weiss, angeheftet. Sp. 8-11 $113-4$, an einem Ende zugespitzt. Auf Nadeln.

M. delectabilis Peck - 6. 8. - H. 5-7 mm. breit, weiss, Mitte etwas gelblich, kahl, gerieft. F. etwa $2 \times 1$, kahl, weiss. L. gut ausgebildet. Sp. $5.5-6.5 \times 3-4$, nicht amyloid. Grosse Randcystiden mit Schnabel.

M. sp. - 30.6. - H. bis 1.5 breit, bis zum kahlem hohen Buckel stark gerieft, rehbraun, Buckel dunkler. Huthaut amyloid, hyphisch. F. bis $12 \times 1$, Farbe des $H$, oben weisslich, nur unter starker Lupe faserstreifig. L. weisslich. Sp. amyloid 9-11(-13) × 7.5-8. Cyst. reichlich, lang (sichtbarer Teil bis 55) und schmal (3-5). oben bisweilen sogar mehrfach gegabelt, Geruch angenehm, aber schwach. Auf Moos. Sumpf. Vermutlich eine nordische Art.

Baeospora myosura Fr. - 12.8.

Lepista nuda Bull. - 31.8.

L. panaeola Fr. - 15. 8. - H.) bis 5 breit braungrau, dunkler gefleckt, Rand eingebogen. F. bis $4 \times 13$, blasser. L. blass (Farbe des H.). Spp. rötlich. Sp. punktiert, $4-5 \times 3-3.75$. Geruch stark und lästig nach schlechtem Mehl. Offene Stelle, an einem Wege.

Clitopilus prunulus Scop. - 8.8.

Rhodophyllus speculus Fr. ss. Kühn. et Romagn. 14. 8.

R. clypeatus L. - 21.8.

R. majalis Fr. ss. Langei (R. aprilis Britz. f. majus) - 9. 8.

R. nidorosus Fr. - 23. 8.

R. rhodopolius Fr. -23.8.

R. ameides Bk. et $\mathrm{Br}$. - 30.8. - H. bis 5 breit, gewölbt, dann flach, ohne Buckel, braungrau, trocken weisslichgrau (seidig). F. bis $7 \times 5-10$ (unten), Farbe des trockenen H., sehr zäh, oben bereift, schwach riefelig. L. weisslich, werden hell rosa, schwach herablaufend. Sp. meist rundlich, aber auch längliche kommen vor, stets ziemlich klein: $7-9.5 \times 6-7$. Die Beschreibungen in der Lit. weichen stark von einander ab. Bei der Bestimmung entscheidet sofort der Geruch von Hebeloma sacchariolens!

R. sericeus Bull. - 11.8 .

R. Cordae Karst. - 5.8.

R. costatus Fr. f. - 17. 8. - H. bis 3 breit, schwarzbraun, hygrophan, zu kast.braun ausblassend, aber ziemlich dunkel bleibend, ungerieft. F. bis
$4.5 \times 6$, dunkel, auffallend grob gerieft, hohl, oben weissmehlig. L. nur teilweise queradrig, schmutzig rötlich. Sp. isodiam. 5-6-eckig, bis $8 \times 8$. Riecht unangenehm, nicht nach Mehl. Sumpf.

R. staurosporus Bres. - 5.8.

$R$. staurosporus Bres. var. Rickenii Romagn. - 30. 7.

R. limosus Fr. - 17.8.

$R$. hirtipes Schum. Lange. - 27.6.

R. hirtipes Schum. var. (OvS.) - 25. 7. - Identisch mit dem Funde vom 15.6.55. in Kasuri.

R. clandestinus Fr. ss. Langei - 7. 7.

R. junceus Fr. - 1.8.

R. infulus Fr. - 4. 7. - Mit einigen Randcyst. im Gregensatz zu der Beschreibung bei Kühn. et Romagn.

R. cetratus Fr. Quél. - 31.7.

R. (Nolanea) sp. - 25.7. - H. 1.7 breit, glockig, rehbraun (hell), radialfaserig. Nass bis zum Scheitel gerieft, trocken ungerieft. F. $7 \times 3$, kahl, strohfarben. L. rosa, angeheftet. Sp. meist isodiametrisch, höchstens $8 \times 7$. Sumpf. Auf oder im Sphagnummoose. Steht offenbar $R$. infulus sehr nahe.

R. placidus Fr. ss. Kühn. et Romagn. - 30. 7.

$R$. anatinus Lasch ss. Moseri, OvS. - 31.8. - H. 1.5 breit, braun, beinahe sparrig und radialschuppig. F. $5 \times 3$, blau, unten stark weissfilzig, faseriggestreift. L. blass, werden rosa. Sp. länglich, bis $11 \times 7$. Cyst. an der Schneide, im Gegensatz zu $R$. placidus und lampropus (s. Kühn. et Romagn.).

R. asprellus Fr. - 22. 8.

R. serrulatus Pers. - 2.8.

R. atrides Lasch-18. 8. - Dies ist die ecciliale Var. von $R$. serrulatus.

R. griseo-cyaneus Fr. - 17. 8 .

R. lampropus Fr. - 30. 7.

$R$. sarcitus Fr. (R. sarcitulus Kühn. et Romagn.?) 3. 7. - Über diese Art herrscht die grösste Unklarheit. Das Exs. hat L. ohne dunkleren Rand und weicht insofern vom Exs. von 1954 (Karstenia III S. 64) ab.

R. minutus Karst. - 25.7.

R. sericellus Bull. - 18. 8. - Nur ein Ex. H. 1 breit, gelb, überall mit braunen Schüppchen, niedergedrückt und schwach genabelt, Rand eingebogen. F. $3.5 \times 2$, oben etwas verdickt und breitgedrückt, gelb (rötend), oben weissmehlig, unten schwach weissfilzig. L. breit angewachsen, beinahe weiss (rötl. Schimmer) und bewimpert. Sp. 8-9.5 $\times 6-7.5,5-6$-eckig.

R. parkensis Fr. - 27.8. - Nur ein Ex. H. 1.2 breit, bis beinahe zur Mitte gerieft, grau, trocken beinahe schwarz. F. $4 \times 1.5$, Farbe des H. L. werden fleischrot. Sp. 5-6-kantig, 6.5-9.5× $6-8$.

Pluteus cervinus Schaeff. - 27. 6.

P. sp. - 4. 8. - Identisch mit dem Pilz aus Rasila 1955. Vermutlich eine Form von $P$. roseipes v. Hoehn.

P. cinereus Quél. ss. Langei - 5. 7. - Nur 1 Ex. H. ausgebreitet 2 breit, zuerst glockig, braungrau, stark gefurcht. Huthaut hyphisch, zum Teil netzig (in der Mitte). F. $5 \times 2$, grau, faserig, unten auffallend weiss bereift. Sp. $6-8 \times 5.5-7$. Randcyst. aufgeblasen. Auf Holz. 
P. sp. - 8. 9. - H. bis 3 breit, Haut hyphisch, klebrig, radial runzelig, nass mit gerieftem Rand, kast. braun. F. bis $4.5 \times 4$, oben bereift und daselbst mit grünlich-bläulichem Ton. Unterhalb braun, gerieft, grob braun befasert, hart. L. bräunlich mit rötlichem Ton, auffallend breit, bauchig, nicht völlig frei. Schneide gleichfarbig. Sp. 8-9 $\times 5-6$. Cyst. auf der Fläche nicht gefunden. Auf dem Rande meist haarförmig, sichtbarer Teil z. B. $38 \times 6$, das obere Ende nicht selten verdickt. Ausserdem einige mehr konische Cyst. z. B. mit sichtbarem Teil von 15 Höhe und 10 Breite. Intensiver Rettichgeruch. Im Walde, wohl auf Holzresten. Vermutlich eine Var. von P. plautus Weinm.

Amanita vaginata Bull. var. typica ("grisette») - 1.9.

A. vaginata Bull. var. alba Fr. - 5.8.

A. vaginata Bull. var. badia Schff. - 4. 8 .

A. crocea Quél. - 23. 8.

A. umbrinolutea Secr. - 20.8. - Abweichungen von $A$. vaginata: $H$. graubraun mit blassem Rand. F. graubraun, genattert. Sp. nur subglobal, $9.5-12.7 \times 7.5-9.5$.

A. muscaria L. - 31.7 .

A. muscaria L. f. aureola -20.8 .

A. regalis Fr. - 18.7 .

A. porphyrea A. et S. - 17.9.

A. rubescens Pers. - 25. 8.

Lepiota alba Bres. - 28. 8.

L. laevigata Lange = oreadiformis Vel. - 12.8.

L. clypeolaria Bull. var. typica - 14.8.

L. clypeolaria Bull. var. - 28. 8. - H. auf weisslichem Grunde braunschuppig, Mitte dunkler und glatt. F. bräunlich, braun beschuppt, $7 \times 7$ etc. Sp. spindelig, sehr lang und schmal, 4-1 $21 \times 4-5.5$, intensiv amyloid.

Agaricus campestris L. - 16. 8.

A. silvicolus Vitt. - 19. 9.

A. abruptibulbus Peck - 20.8.

A. rusiophyllus Lasch - 19.8. - Cyst. auf der Schneide. Daher nicht $=$ comtulus Fr.

Cystoderma amianthinum Scop. - 8. 8. - Gelbe und braune Formen.

C. carcharias Pers. - 12.8.

C. fallax Smith-Singer - 23. 8. - H. bis 4 breit, in der Mitte hoch gebuckelt, rostbraun, mit gleichfarbigen Körnchen dicht besetzt. F. bis $4.5 \times 8$, gleichfarbig, einschliesslich der Ringunterseite körnig-schuppig. Ring sehr dauerhaft. Ưber dem Ring heller. L. stark ausgebuchtet, mit Zahn angewachsen, weiss, mit rötlichem Schimmer. Fl. im F. rötlichgelb. Sp. 3.6-5x 3-3.8, amyloid. Geruch von $C$. carcharias. Nadelwald.

C. granulosum Batsch - 28. 8 .

C. cinnabarinum A. et S. -2.9 .

C. sp. -24.9 . - H. bis 5 breit, rostgelb, strahligrunzelig, bräunlich gekörnt. F. bis $4 \times 10$ (in der Mitte 8), bräunlich gekörnt bis zur Ringzone. Úber dieser etwas dunkler als H. L. nicht völlig frei. Sp. $4-5.5 \times 3$, nicht amyloid. Keine Randcystiden bemerkt. Flächencystiden vorhanden, aber nur wenn isoliert einigermassen wahrnehmbar, Grösse sehr schwankend, 40-75×12-19 (meist $40-65 \times 12-13$ ), cylindrisch/sackförmig. Auch kleinere Elemente waren zu sehen, wohl nicht ausgewachsene Cyst. Geruch von $C$. carcharias. Nebengeruch Mehl. Zusammenfassung: der Pilz gehört der Gattung $C$. an. Er hat die nichtamyl. Sp.von granulosum und cinnabarinum, die Farbe von amianthinum, den Geruch von carcharias und fallax und Drosella irrorata, endlich die typischen Flächencyst. von Drosella irrorata Quél.

Crepidotus Bresadolae Pilát (Dochmiopus pubescens Bres. Konr. et M. = pubescens Lge?) $-22.9 .-\mathrm{H}$. bis 1.8 breit, muschelförmig, ohne F. weissseidig, bisweilen mit schwachem bräunlichem Ton bei älteren Ex. L. tonbraun. Spp. gelblichrötlich. Sp. 9-11 lang. Breite etwa Hälfte davon. Ohne Cyst. Auf sehr verfaulter Birke.

Tubaria pallidispora Lange - 26. 6 .

T. minutalis Romagn. = minima Lange -5.8 .

T. pellucida Bull. ss. Quél. - 29. 7.

T. conspersa Fr. ex Pers. - 26. 6.

T. praestans Romagn. - 9.8. - H. bis 4 breit, gelbbraun (braunfilzig), nicht durchscheinend gerieft. F. $5 \times 4$, bräunlich, aber dicht besetzt mit weissen Flocken, gleichdick (nur Basis etwas verdickt). L. breit, bauchig, mit kleinem Zahn angewachsen. Spp. gelb. Sp. verschiedener Grösse, stets relativ kurz und dick, z. B. $7 \times 5$ etc. dickwandig, elliptisch (nicht mandelförmig). Viele Cyst. auf der Schneide.

I. ferruginea Maire - 29.7.

Rozites caperata Pers. - 23. 7.

Hebeloma strophosum Fr. - 30.7.

H. versipelle Fr. ss. Rick. - 28. 7. - H. bis 5 breit, sehr schmierig, falb, Mitte rotbraun, Velumreste am Rande. F. $6 \times 7$, oben weiss, längsfaserig, mit Velumresten, unten graubraun, zäh, schwach wurzelnd. L. schmutzigrosa, bis $10 \mathrm{~mm}$. breit, dün. Sp. $9-11 \times 5.5-6$, schwach warzig. Geruch sehr schwach.

H. mesophaeum Pers. - 18. 8.

H. fastibile Fr. - 18.9.

H. hiemale Bres. ss. Moseri - 12. 8.

H. testaceum Batsch - 9. 8.

H. firmum Fr. ss. Rick. - 11. 8.

H. claviceps Fr. - 14. 8.

H. pumilum Lange -26.9 .

H. sinapizans Fr. - 20. 8.

H. crustuliniforme Bull. - 14. 8 .

H. truncatum Schff. - 12. 8 .

H. nudipes Fr. - 14.8. - Nur ein Ex. H. 3 breit, glockig, leder- od. sahnefarben. F. $7 \times 7$, weisslich, oben mehlig, sonst kahl, unten verbogen. L. nicht tränend, sehr blass. Sp. subcitronförmig, $10-11 \times 5-6$. Cyst. keulig, oben 4-7 breit. Schwacher Rettichgeruch.

Inocybe scabra O. F. Müll. - 21: 8 .

I. cincinnata Fr. -28.7 .

I. pusio Karst. - 11. 8.

I. geophylla Sow. var. alba Schum. (candida Batsch) $-11.8$.

I. viscidula Heim - 23.7. - H. bis 1.5 breit, feucht, ockerbraun, gebuckelt. F. bis $3 \times 2$, Farbe des H., faserig, Spitze mehlig. L. bauchig, 30 Stück, Farbe des H., Rand heller. Sp. mandelförmig, $8.5-13 \times 5.5-7.5$. Cyst. von der grössten Mannigfaltigkeit, cylindrisch, spulenförmig, beinahe stets ohne Schopf, meist über 100 lang. Moor (Eller, Weide, Birke).

I. hirsuta Lasch - 3.7. - Mit grünlicher Basis.

I. dulcamara A. et S. ss. Karst. Rick. (»Herbstform») OvS. - 20. 8. - H. bis 3 breit, scharf gebuckelt, 
radialfaserig (Mitte glatt), bräunlich, mit ganz ausgesprochen olivgrünlichem Ton. F. bis $5 \times 4$, bräunlich, mit schwachem Olivton, hohl, glatt, nur ganz oben bereift, verbogen, ohne Knolle. L. ausgesprochen olivgrün, bauchig, beinahe frei. Sp. 8-11 $\times 5-7$, eiförmig. Keine Cyst. auf der L.-Fläche. Geruchlos.

I. fastigiata Schff. - 8.8.

I. sp. - 6.9. - H. bis 5 breit, nass kast. braun, trocken fuchsig und glänzend, radialfaserig und aufspaltend, bucklig. F. ohne Knolle, bis $5 \times 6$, Farbe des H., Basis und Spitze weisslich. Cyst. nur ganz oben. L. dunkel rostfarben, wie bei vielen Cortinarii, bis, 8 breit, bauchig angewachsen. Sp. klein, 5.5-6.6×3-4. Cyst. dünnwandig, ohne Schopf, keulig, 60-97×16-30, meist mit dem schmalen Ende, aber auch in der Längsrichtung aneinander gekettet. Kein ausgesprochener Geruch. Nächster Verwandter I. maculata Boud.

I. lacera Fr. - 27. 6

I. descissa Fr. ss. Bres. - 4.9. - H. bis 2 breit, hellbraun, radialfaserig, dann aufspaltend, Rand hell (üppige Schleierreste, sogar behangen). F. bis $5 \times 3$, durch dichte Schleierreste beinahe weisslich, oben (an der Spitze) mit Cyst. L. sehr hell, wie überhaupt der ganze Pilz einen hellen Eindruck macht. Sp. 8-10×6-7. Cyst. 66$81 \times 16-19$. Fl. im F. bräunlich mit einem schwachen rötl. Ton. Vielleicht identisch mit Kühners phaeodisca?. Lit. dürftig.

I. abjecta Karst. - 26. 6.

I. descissa Fr. var. brunneoatra Lange - 21. 7.

I. deglubens Fr. var. subbulbillosa Heim - 24. 7. $\mathrm{H}$. bis 2.5 breit, bucklig, nicht sehr hell braun, geglättet-feinfaserig. F. $3 \times 3$, weisslich-gelblich, kahl, Cyst. nur an der Spitze, unten weisse Knolle. L. bauchig, oliv, beinahe frei. Sp. $8-9.5 \times 5-5.5$. Cyst. $60-70 \times 13-20$. Paracyst. z.B. $32 \times 14$.

I. flocculosa Berk. - 8.7.

I. inconcinna Karst. - 26. 8. - H. bis 2.5 breit, gebuckelt, eingewachsen faserig, braun mit hellerem Rand. F. bis $4 \times 4$, unten schwach verdickt (6). Obere Hälfte bereift, strohfarben. L. strohfarben bis oliv, bauchig angewachsen, Rand weiss. Sp. $7.5-8.5 \times 5-5.5$, es kommen beinahe runde vor. Cyst. auf der Fläche dünnwandig und meist ohne Kristalle, $60-66 \times$ $13-16$.

I. posterula Britz. - 9.8. - Sp. 8-9.5 $\times 5-5.5$. Cyst $60-65 \times 14-19$.

I. lucifuga Fr. $-10.7-\mathrm{H}$. bis 4 breit, rehbraun bis braun, halbkugelig, dann ausgebreitet mit breitem Buckel, angedruckt faserig, in der Mitte bisweilen schuppig. F. bis $5 \times 5$, gleichdick oder nach unten etwas verdickt, heller als $\mathrm{H}$., event. mit rötlichen Ton, oben schwach weissmehlig, Mitte kahl, unten bisweilen weissfilzig. L. olivbraun, bauchig, frei, dicht. Sp. 7.5-12 $(-13) \times 4.5-6(-7.5)$, ei- resp. mandelförmig. Cyst. $32-73 \times 11-21$, spitz, mit oder ohne Schopf. Paracyst. spitz, $27 \times 17$ etc. Fl. weiss, im F. etwas rötend. Geruch unangenehm rüben- resp. schwach geophyllaartig. Nadelwald. von $I$. deglubens Fr. häufig schwer zu trennen. Kühn. et Rom. werfen die Arten zusammen.

I. auricoma Batsch (descissa Fr. var. auricoma) - 21. 7 .
1. brunnea Quél. - 18. 7. - H. bis 2.5 breit, konvex, schwach gebuckelt, braun, schuppig, Rand anfangs eingebogen. $F$. bis $3 \times 3$, grob faserig, bekommt Farbe des $H$., überall bereift durch Cyst., Basis weiss, etwas verdickt, die weisse Cortina lange sichtbar. L. braun, bauchig. Sp. 10-16 $\times 5.5-8.5$, (die Maasse nähern sich bisweilen denjenigen von 1 . lacera). Gyst. ohne Hals oder kurzhalsig, 50-70×16-23. Fl. im F. rötend, schwacher Spermageruch. Weg. Nadelwald.

I. subbrunnea Kühn. - 20.7. - H. 1 breit, braunschuppig, mit kleinem Buckel. F. $3.5 \times 2$, voll, junge Ex. überall gepudert, faserig, rötlichbraun, unten etwas verdickt, bisweilen ganz schwach knollig. Sp. $11-13 \times 6-7$. Cyst. $46-54 \times 13-16$, unter dem dicken Schopf fein bereift.

I. sp. - 22.8. - Nur ein Ex. H. 3 breit, auf gelbbraunem Grunde radial braunfaserig gestreift, so dass die Grundfarbe (mit Ausnahme unter dem Buckel) überall sichtbar wird, Buckel sehr hoch und ziemlich spitz. F. $9 \times 4$, verbogen, unten 7 breit (keine richtige Knolle), gelbbraun mit schwachem rötl. Schimmer, nur an der Basisweiss, kahl, nur an der Spitze bereift. L. breit, ausgebuchtet, mit Zahn angewachsen, Schneide weiss und bewimpert (Cyst.). Sp. 8-9 $(-10) \times$ $5-6(-7)$, glatt. Cyst. 57-67 × 16-24, dickwandig, meist kurzhalsig. Nur eine Cyst. $81 \times 14$. Kein Spermageruch, aber ecklig. Vielleicht = I. abietis Kühn.? Lit. über diese Art ungenügend.

I. fibrosa Sow. var. trivialis Lge $-15.8,-\mathrm{H}$. bis 4 breit, hellbraun, stumpf konisch, Mitte heller, radialfaserig. F. bis $7 \times 6$, ohne Knolle, weisslich, verbogen. L. sehr blass. Sp. unregelmässig kantig, ohne hervortretende Warzen, 8.5-11 $x$ 7-8.5. Cyst. 55-70×14-19. Spermageruch.

I. asterospora Quél. - 7.8.

I. grammata Quél. - 5.8. - H. 4.5 breit, breit gebuckelt, rehfarben-faserschuppig mit weissseidigem Rand. F. 4.5-7, überall bereift, strohfarben, oben mit ganz schwachem rötl. Ton, deutliche Knolle. L. beinahe frei. Sp. schwach kantig, sehr klein, 7-8 5-6. Cyst. $54-62 \times 16-19$, wie bei Lange. Diese Art wird von den Autoren ganz verschieden aufgefasst.

I. xanthomelas Kühn. - 23. 7 .

I. mixtilis Britz. (scabella ss. Heim) - 13. 7. H. 2-2.5 breit, glockig, schliesslich konvexgebuckelt, mit eingebogenem Rand, ocker, seidenfaserig. F. $3 \times 4-5$, weiss, voll, mit napfförmiger Knolle. L. weisslich, später mit rötl. Ton. Sp. $7-8 \times 5.5$, unregelmässig kantig. Cyst. kurz und relativ dick, $43-54 \times 16-19$. Spermageruch. Mischwald. Sehr nahe verwandt mit 7. praetervisa.

I. praetervisa Quél. Hauptform. - 25. 7.

I. praetervisa Quél. Form ohne Knolle. - 21.7. Sp. $8-9.5 \times 5.5-7$. Gyst. $50-62 \times 16-21$.

I. napipes Lange - 14.7 .

I. acuta Boud. (umboninota ss. Heim. Lge.) - 28. 7.

I. umbrina Bres. - 19. 7 .

I. Boltoni Heim - 13. 8. - Cyst. 57-63×19-23.

I. decipientoides Peck ss. Kühn. et Romagn. - 3. 7.

I. lanuginella Schroet. (cicatricata Ellis et Everhart) - 17.7. - Ergänzung der Beschreibung in Karstenia III S. 37: Sp. 8-9.5×6-7. Cyst. ohne Hals oder aufgeblasen mit kurzem Hals, 
$44-73 \times 13-24$. Nicht identisch mit $I$. decipientoides Peck $=$ globocystis Vel.

I. putilla Bres. - 21.7.

I. lanuginosa Bull. typ. Form (= longicystis Atk.?) -28.7 .

I. lanuginosa Bull. var. Casimiri Vel. - 20.7. Ohne Cyst. auf der Fläche. Zahlreiche, meist nicht schopfige Cyst. (cyl. oder aufgeblasene) auf der Schneide (41-51 $14-19)$.

I. sp. (Clypeus) - 3.8. - Nur ein Ex., aber vielleicht einer meiner besten Funde überhaupt. H. 3 breit, mit nach oben gebogenem Rand (offenbar ziemlich alter Pilz), grob radial faserig; wird rissig, leuchtend ocker. F. $4 \times 6$, faserstreifig, gleichdick, hellbraun (ockerlich), nicht bereift. Sp. vielkantig, mit oder ohne grobe Warzen, 8-11 $\times 6-8$. Keine dickwandigen Cyst. Nur auf der Schneide an einigen Stellen cystidienartige Haare (50-80 lang und 2.5 breit) mit eiförmigem Kopf $(8-9 \times 3-5)$.

Alnicola escharoides Fr. - 2. 8.

A. subconspersa Kühn. - 19.8.

A. luteofibrillosa Kühn. - 8. 8. - H. bis 1.5 breit, schmutzig strohfarben mit gelblichem Ton, schuppig-faserig resp. kleiig. F. gelblich, schwach faserig (Velumreste). L. gelblich. Sp. $9.5 \times 5.5$. Cyst. mit Schnabel, bisweilen mit winzigem Köpfchen. Unter Ellern.

A. pseudoamarescens Kühn. et Romagn. - 2.8. Wie A. escharoides Fr. Sp. $10 \times 6$ etc. Cyst. nur 2-4 breit, mit deutlichem Köpfchen von 4-6 Breite.

A. bohemica Vel. (scorpioides Fr. ss. Langei) - 12. 8. -

A. phaea Kühn. -23.7.

A. scolecina Fr. f. gracillima Lge - 27. 7. - Unterart von $A$. phaea Kühn. H. bis 1 breit, gerieft. F. $2 \times 1$. Sp. $11-12 \times 5.5-6$. Sumpf.

A. submelinoides Kühn. - 30.7. - Huthaut aus keuligen Körperchen.

A. macrospora f. tetraspora Lange - 29. 8. - H. bis 2. 5 breit, braun, hygrophan, stark ausblassend, gerieft. F. bis $5 \times 2$, rötlich. L. kanelfarben. Sp. $11-13 \times 5-6$. Cyst. keulig, der sichtbare Teil $36 \times 5.5$-8. Steht A. submelinoides Kühn. sehr nahe. Sp. abweichend.

A. scolecina Fr. ss. Romagn. (badia Kühn.) - 2.8 .

Phaeomarasmius limulatus Fr. (Gymnopilus limulatus Fr.) - 22.7. - Ergänzung zu der Beschreibung vom Jahre 1955: Das einzige Ex. das ich am 22.7. in Rasila fand, war erheblich kleiner, nämlich 1.5 breit. F. $1.5 \times 1.5$, deutliche Velumreste. Spp. beinahe goldgelb. Sp. $6.5-7.7 \times$ 4-5.2, glatt. Auf Birkenstamm (im Gegensatz zu den Angaben in der Lit.).

P. carpophiloides Kühn. - 20.7. - H. 0.8 breit, konvex, ocker mitrötlichem Ton, kaum hygrophan, Oberfläche kleiig-glimmerig. F. $1.5 \times 1$, etwa gleichfarben, unten weiss (filzig). L. angewachsen (im Gegensatz zu Tubaria). Sp. sehr breit, z.B. $7 \times 5$, elliptisch, ohne Keimporus. Auf unbestimmbaren Pflanzenresten.

Galerina stagnina Fr. - 15.8. - H. bis 2.5 breit, ausgewachsen niedergedrückt, hygrophan, dunkel rotbraun, wird ocker. F. bis $14 \times 4$, schokoladenfarben mit rötl. Ton. Sowohl H. als F. mit weissen Velumresten. L. fast dreieckig. Sp. $13 \times 8.5$ etc. glatt, dickwandig, mit abgerundetem oberen Ende und schlecht oder garnicht sicht- barem Keimporus. Auf Sphagnum.

G. sphagnorum Pers. ss. Atk. - 11.7. - H. 1-2 breit, braungelb, konisch-gebuckelt, gerieft. F. $5 \times 1.5$. L. mit ganzer Breite angewachsen. Sp. $10-12 \times 6-7.5$, ziemlich glatt. Cyst. unten verdickt, mit oder ohne Köpfchen. Mehlgeschmack kaum zu bemerken. Auf Sphagnum.

G. tibiicystis Atk. - 5.7.

G. paludosa Fr. - 27.6.

G. mycenoides Fr. - 19.7. - Ring oder deutliche Ringzone.

G. hypnorum Schrank - 27.7.

G. mniophila Lasch - 30.7.

G. triscopa Fr. - 23. 7.

G. uncialis Britz. -31.7

G. nana Petri - 6. 8 .

G. sideroides Fr. - 22.9. - H. bis 3 breit, honigfarben, fettig glänzend, bucklig, Rand gerieft. Haut ziemlich weit abziehbar. F. gewöhnlich $3 \times 3$, honigfarben, vom weissen Velum wie eine Telamonia bedeckt. L. mit Zahn angewachsen. Sp. $6.5-7.5 \times 4-4.5$, meist $6.75 \times 4$. Cyst. haarförmig, dünn. Geruch und Geschmack mehlartig. Auf verfaultem $\mathrm{Holz}$, auch zwischen Holzstücken. Rasig, im Nadelwald.

G. marginata Batsch -27.6 .

G. unicolor Fl. Dan. - 6.7.

G. ambigua Karst. - 2. 7.

G. confragasa Fr. -26.8 .

G. sp. - 1. 8. - H. 7 breit, nicht hygrophan, breit gebuckelt, schokoladenbraun, glatt und kahl. (Ein zweites Ex. (Exs.), das viel kleiner war, hatte auf dem $\mathrm{H}$. einige gleichfarbige Schüppchen.) Rand nach oben gebogen und etwas gefurcht (nur beim grossen Ex.) F. (grosses Ex.) $7 \times 7$, braun, kahl, Ring dauerhaft (hängend), oberhalb des Ringes heller und ganz oben gerieft, Basis weisslich und verdickt. L. bauchig, breit, beinahe frei. Sp. $6-7.5 \times 4-5$. Cyst. spärlich, kolbig (oben stumpf), unten etwas verdickt, z. B. $30-50 \times 5-3-11$, oben häufig etwas verdickt. Auf Holz (wohl Fichte).

G. graminea Vel. - 19.8. - H. bis 1 hoch und unausgebreitet bis 0.8 breit, gerieft, honigocker, trocken sehr hell. F. bis $5 \times 1$, sehr hell, nur unten fuchsig. L. intensiv ockergelb. Sp. sehr dünnwandig, $8 \times 5$ etc. Gyst. haarförmig, sichtbarer Teil $16 \times 5$ (unten). Im Grase. Sehr gebrechlich.

G. clavata Vel. - 7.7.

Phaeocollybia Fennyae Karst. ss. Langei - 17. 8.

Gymnopilus picreus Fr. - 28. 8.

G. sapineus Fr. - 31.7.

G. hybridus Fr. - 4.7.

Dermocybe cinnamomeobadia Hry - 10.9. - H. 2.5 breit, rot-bis kast.braun. F. bis $10 \times 6$, gelbbraun, faserig. L. gelb mit rötl. Ton. Sp. $6-7.5 \times 4-5$ $(-5.5)$.

D. cinnamomea L. var. conformis f. croceifolia Peck 10. 8.

D. cinnamomea L. var. cinnamome-fulva Hry - 11. 8.

D. semisanguinea Fr. - 25. 8.

D. phoenicea Mre ss. Moseri, Kühn. - 26. 8.

D. sanguinea Wulf. - 17.8.

Cortinarius raphanoides Pers. - 18. 8.

C. gentilis Fr. - 14.8.

Hydrocybe armilla ta Fr. - 12. 8. 
H. bovina Fr. ss. Rick. Moseri nec ss. Langei, Kühn. et Romagn. - 27. 8. - Die Mykologen behandeln unter diesem Namen mindestens zwei verschiedene Arten. Hier handelt es sich um einen Pilz mit ff. Merkmalen: H. bis 7 breit, nussbraun, mit dunklerer Mitte und braunen Fasern vom Velum am Rande. Nur schwach hygrophan und daher leicht für Phlegmacium gehalten. F. bis $8 \times 8-20(-30)$. Ziemlich hell mit braunen Velumresten. Knolle schwammig. Sp. 7-11x $4-6$, meist $8 \times 5$.

H. bovina Fr. Kleinsporige Var. - 21. 9. - H. bis 6 breit, braun, mit rotem Ton, eingewachsen faserig, mit breitem dunklerem Buckel, braune Velumreste. F. bis $9 \times 12-20$, ohne richtige Knolle, aber stark verdickt, gleichfarbig, unten hell, faserstreifig mit braunem Velumstreifen. L. kaffeebraun, vom F. abstehend. Sp. 6-7 $\times 4$ 4.75, erreichen nie $8 \times 5$. Keine Cyst. Der Pilz ist nur schwach hygrophan und wird leicht für Phlegmacium gehalten. Er nähert sich Mosers $H$. betulorum, hat aber keine Olivtöne.

H. psammocephala Bull. ss. OvS. - 12.9. - H. bis 1.5 breit, braun, mit bräunlichen Schüppchen dicht besetzt. Erinnert daher an $H$. hemitricha, der aber weisse Schüppchen hat. Dunklerer Buckel, meist spitz. F. bis $2 \times 3$ mit gelbbraunen Velumresten. L. ziemlich hell braun, angewachsen. Sp. 6-6.5 $\times 3-3.5$. Nadelwald. Typische Sammelart. Daher weit auseinandergehende Grössenangaben für die Sp. in der Lit.

H. paludosa Fr. ss. Moseri (Dermocybe cinnamomea L. var. paludosa Hry) - 26. 8. - H. bis 6.5 breit, trocken kaum hygrophan, anfangs grün mit Olivton, allmählich bräunend, Rand bleibt lange olivgrün, faserig (nicht glatt, aber auch nicht schuppig). F. bis $9 \times 6-8$, gleichdick, hohl, anfangs grün mit schwachem Olivton, dann schwach bräunend. Velum gelbgrün, Zone schnell verschwindend. Basis unbedeutend schuppig. L. anfangs ähnlich gefärbt wie H. und F. (grün), aber mit Safranton, der schnell dominierend wird, gesägt. Fl. besonders im F. grünoliv. Reaktion auf Lugol mehr od. weniger 0. Sp. $6-7.8 \times 4-5.2$. Mild. Geruchlos. Sehr nasser moosiger Nadelwald.

H. saniosa Fr. - 14. 8 .

H. bulbosa Sow. - 19. 8.

H. laniger Fr. - 22. 9.

H. bivela Fr. ss. Moseri (s. Karstenia III S. 22) nec Konr. Lge. - 7. 9. - Sp. 7-9 $\times 4-5$. Phenolanilin auf Fl. rot. Vielleicht identisch mit $H$. biveloides Hry.

H. triformis Fr. - 21.8.

H. privignoides Hry -8.9 . - $\mathrm{H}$. bis 4.5 breit, glockig, nass gelbbraun, trocken hell braungelb und glänzend, durch Velumreste besonders am Rande seidig. F. weisslich, oben bisweilen kaum sichtbar bläulich, bis $9 \times 13-25$ (Keule), meist viel schmächtiger, faserstreifig, hohl, gebrechlich. L. rostgelb, gezähnt. Sp. 6-6.75×4. Fl. weiss. Schwacher Rettichgeruch, aber auch ohne. Rasig, zusammengepresst.

H. melleo-pallens Fr. ss. Langei - 23.8. - Nur ein Ex. H. 3 breit, mit kleinem Buckel, honiggelb, wenig hygrophan, Rand mit flüchtigen weissen Velumresten. F. $7 \times 6-12$ (keulig), mehrfach ziemlich vergänglich weiss gegürtelt-gestiefelt.
L. gedrängt, honigfarben. Śp. nie über $7.5 \times 4.5$, meist $7 \times 4$.

H. melleo-pallens Fr. var. - 1.9. - Sp. nur 4.5$6 \times 3-4$. Sonst wie Hauptform.

H. biformis Fr. - 7.8.

H. armeniaca Schff. - 24.8.

H. sericeo-fulva Moser (jubarina Lge?) - 30. 8. - H. bis 3.5 breit, stumpf gebuckelt, rotbraun-fuchsig, sehr hygrophan. F. bis $8 \times 5$, sehr blass, kahl. L. gelbbraun, angewachsen. Sp. ziemlich hell, klein (nie über $8 \times 5$, meist $7 \times 4$ ). Fl. braun. Nadelwald.

H. pseudoduracina Hry - 25. 8.

H. damascena Fr. ss. Moseri - 3. 9.

H. rigens Pers. var. - 30.9. - Nicht identisch mit dem Pilze in Karstenia III S. 38 Nur ein Ex. (sehr klein). H. 2 breit, lederfarben, wenig hygrophan, Rand eingeknickt. F. $3 \times 5$ (kurze spindelige Wurzel), weisslich. L. zimtfarben, dicklich, eher entfernt. Sp. $7-8.25 \times 4.25-5$. Ziemlich geruchlos. Zäher Pilz. Nadelwald.

H. duracina Fr. - 8.9.

H. evernia Fr. - 12.9. - Phenolanilinreaktion purpurn.

H. csutulata Fr. - 29. 8.

H. saturnina Fr. var. Bresadolae Moser - 3.9.

H. castanea Bull. ss. OvS. (Karstenia III, S. 47). - 1.9.

H. tortuosa Fr. - 21.9. - H. bis 5 breit, hell schokoladenfarben, trocken hellbraun. F. bis $8 \times 10$, violettlich, silberglänzend, unten weisslich, auffallend verbogen. L. bauchig, eher von F. abstehend, hell kanel. Sp. 7-8 $\times 5-5.5$, dickwandig. Farbveränderung der L. die bei Druck eintreten soll und seit Fr. immer wieder von den Autoren behauptet, aber selten nachgeprüft worden ist, liess sich nicht feststellen. Übrigens sind Farbreaktionen, besonders wenn starke Fröste den Pilz angegriffen haben, n. m. Erfahrungen häufig ein ziemlich unsicheres Kennzeichen. Nadelwald.

H. erythrina Fr. ss. Langei - 4. 9. - H. 2-4 breit, kast.-braun, trocken mehr rötlich-fuchsig, Rand schwach weiss-seidig. F. rosa-viol. $3-5 \times 2-4$. L. rostfarben, schwach gesägt. Sp. $6-7.5 \times 3-4$. Cyst. auf der Schneide, 3-6 breit.

H. erythrina Fr. ss. Rick. - 20.8.

H. Adalberti Fav. - 23. 8.

H. glandicolor Fr. -27.7.

H. brunnea Fr. - 11.8.

H. brunneo-fulva Fr. - 13.8. - Sammelart. Die in Rasila gesehenen Ex. zeigten z. T. charakteristische eingewachsene Fasern auf der Huthaut und längs dem F. Andere Ex. (3.9.) zeigten diese Eigentümlichkeit nicht. Die Sp.-Masse waren in Rasila stets $7-9 \times 5-6$, grobwandig. Der Pilz steht $H$. brunnea sehr nahe, hat aber, besonders wenn trocken, hellere (und fuchsige) Töne. Ausserdem hat er gedrängtere L.

H. holophaea Lange - 26.8. - Hat mit Rickens milvina kaum etwas zu tun. $\mathrm{H}$. bis 4 breit, kast.braun, zuerst gewölbt, dann mit schwachem breitem Buckel, nur schwach hypgrophan. Trocken mit schwachem fuchsigem Ton. F. $7 \times 8-20$, keulenartig, Farbe des H., dunkel faserstreifig, Basis meist schief, weisslich. L. bis 8 breit, bauchig angewachsen. Sp. meist $7-8 \times$ $4.5-5$. 
H. hinnulea Fr. -24.8

H. helvola Fr. - 12.9.

H. himnuloides Hry - 23.8. - Nur ein Ex. H. 5 breit, rötlichgelb, schwarzstreifig, Rand weissfaserig. F. etwa $5 \times 7-10$, strohfarben mit rötlichem Ton. L. aderig-anastomisierend, vom F. abstehend. Sp. $7-5 \times 5.5$ etc. Fl. unten im F. auffallend safrangelb. Geruch angenehm.

H. safranopes Hry - 31.8. - Nur ein Ex. H. 6 breit, hellocker, mit vorstehendem Buckel, radialfaserig, mit weissen Flocken am Rande. F. $11 \times 7$, Farbe des H., mit weissen Resten des Velum universale. L. von F. sehr abstehend, breit, rotrostfarben. Sp. $7-9 \times 6-6.5$. Fl. im F., besonders unten, safran. $\mathrm{KOH}$-Reaktion daselbst schwarzviolett.

H. subbalaustina Hry - 26. 8.

H. balaustina $\mathrm{Fr}$. ss. Rick. - 10.9.

H. jubarina Fr. - 19. 9.

H. uracea Fr. ss. Hry - 14.8. - H. bis 3.5 breit, braun, flach gebuckelt, Rand lange durchscheinend gerieft, trocken ocker, so dass man Schwicrigkeiten hat den Pilz wiederzuerkennen. F. bis $10 \times 5$. gerieft, sehr dunkel braun, unten weissfilzig. L. dunkelschokoladenfarben, dicht, beinahe herablaufend. Rand bewimpert und weiss (Cyst.) Sp. $7-8 \times 4-5$, es kommen auch solche von $9.5 \times 5.5$ vor. Cyst. an der Schneide zahlreich. Sichtbarer Teil flaschenförmig, oben 5, unten 11 breit und 25 lang. F1. Geruch wie Cyst. carcharias, weiss, durch Phenolanilin gelbrot. Sehr gesellig, beinahe büschelig. Fichtenwald. Unsichere Bestimmung, da Geruch und Cyst. auf $H$. hinnulea Fr. f. robusta hinzuweisen scheinen. Die Abweichungen von dieser Art sind jedoch noch erheblicher.

H. uracea Fr. nec Hry, Lge, Karst, vielleicht = Kühners Pilz? - 10.9. - H. bis 4 breit, braun, nicht besonders hygrophan, wird fuchsig, konvex, ausgebreitet, ohne Buckel. F. $6 \times 6-10$, faserig, bräunlich, unten heller. L. horizontal. Sp. 7 $8 \times 5-5.5$. Phenolanilin \pm 0 . Überall schwärzend,

H. rubricosa Fr. - 30. 8.

H. crassifolia Vel. - 2. 9. - H. 3-6 breit, dunkelbraun, feinfaserig, trocken rehfarben. F. $8 \times 10$, gleichfarbig, bisweilen keulig verdickt, auch mit angedeutetem Ring (dunkel). L. nicht übertricben dick, sehr breit, abstehend, dunkel umbra. Sp. $10-12 \times 6-7.5$. Überall schwärzend und dann wie angebrannt aussehend. Eine andere Bestimmungist - wenn man keine neue Art annehmen will - nicht möglich. Völlig zufriedenstellend 1st sie nicht, da die L. nicht besonders dick sind.

H. alnetorum Vel. - 26. 8.

H. hemitricha Pers. nec ss. Moseri - 24. 8. - Sp. $7-8 \times 4-5$.

H. hemitricha Fr. ss. Moseri - 18. 9. - H. bis 2.5 breit, gebuckelt, fuchsig, dicht bedeckt mit weissen Schüppchen. F. bis $6 \times 5$, braun mit Ring und weissen Zonen. L. rostbraun, undicht. Sp. $8-10 \times 3.5-4.5$. Nadelwald.

H. hemitricha Fr. genabelte Form. - 19. 9. - H. bis 2.5 breit, dunkelkastanienbraun, nur schwach ausbleichend, ohne Buckel, meist genabelt, am Rande mit weisslichen Fasern dicht besetzt. F. bis $6 \times 5$, blassbraun, mit schwachem viol. Schimmer, mehrfach weiss gezont. L. dicht, horizontal, kanelbraun. Sp. sehr klein, 5.5-6 $(\max .7) \times 3.5-4$

H. incisa Pers. - 26.8

H. incisa Pers. ss. Moseri - 3.9. - Nicht identisch mit meinen früheren Funden. $H$. bis 2 breit, kast. braun, spitz gebuckelt, ungerieft, aber eingewachsen faserig, Rand etwas zackig. F. bis $3 \times 4$, braun, mit deutlicher weisser Ringzone. Sp. $10-11 \times 5-5.5$, mandelförmig.

H. incisa Pers. var. nec Moser - 18, 9. - H. bis 2 breit, kastanienbraun, ohne Buckel, ungerieft, geringe Velumreste, Rand etwas gezähnt. F. bis $3 \times 5$, braun, mehrfach weiss gegürtelt. L. horizontal angewachsen, sogar etwas herablaufend. Sp. $7-8 \times 4.5-5$. Könnte mit früheren Funden identisch sein.

H. striaepila Favre - 8.9.

H. stemmata Fr. Rick. - 14. 9.

H. stemmata Fr. ss. Hry - 29.9. - H. bis 3 breit, nass sehr dunkel schwarzbraun, trocken kast.braun, weisse Velumreste auf der Oberfläche, breit gebuckelt. F. bis $6 \times 6$, bräunlich, wiederholt unklar weiss gegürtelt. L. bauchig, abstehend. Sp. $8-9 \times 5-5.5$. Nadelwald.

H. stemmata Fr. ss. OvS. - 6.9. - H. bis 3 breit, gewölbt, dann breitgebuckelt, kast.braun mit braunen Vclumresten. F. bis $6 \times 6$, gleichfarbig, mir braunem Ring. L. ausgebuchtet angewachsen, gleichfarbig. Sp. $7.5-8.5 \times 4.5-5.5$.

$H$. stemmata wird ganz versch. aufgefasst. Meine Auffasung nähert sich am ehesten derjenigen von Karst. und Rick. Ich fand Rickens Pilz 1954 (s. Karstenia III S. 66). Dieser Pilz hat kleinere, insbesondere schmälere Sp. Moser hat seine Auffassung seit der ersten Auflage seines Buches modifiziert. Seine Beschreibung in der 2. Auflage deckt sich mit meiner, mit Ausnahme der weissen Zonen. H. stemmata ist eine typische Sammelart,

H. flexipes Fr. - 22.8.

H. sp. - 17.9. - Nur cin Ex. H. 4.8 breit, matt graubraun, schwach verfärbend, nicht klebrig, überall besetzt mit bräunlichen Fasern vom Velum, besonders am Rande, konisch-bucklig. F. 5 lang (incl. Wurzel). Breite 8 (oben) - 13 (dickste Stelle), dann spindelig verdünnend. Spindel 1.5 lang, braun, heller befasert. L. breit, dunkel milchkaffeefarben, abstehend. Sp. 7.5$8 \times 5-5.5$. Intensiver Pelargoniumgeruch.

H. paleacea Weinm. - 26. 8.

H. rigida Scop. ss. Kühn. - 8. 8. - Nur ein Ex. H. 3 breit, kast.-braun, ausblassend, deutlich gebuckelt, Rand weiss befasert. F. mit weisser Zone, $4.5 \times 6$, voll, hart, unten verdickt und weisswollig. L. dicht. Sp. $7-8 \times 5-5.5$, glatt, dickwandig. Pelargoniumgeruch.

H. rigida Scop. ss. OvS. - 10.9. - S. Karstenia III S. 66 .

H. scandens Fr. nec. ss. Moseri - 1.9. - S. Karstenia III S. 38.

H. scandens Fr. ss. Moseri - 12. 9. - H. bis 3 breit, nass beinahe orangebraun, trocken gelbbraun, stumpf gebuckelt, nass mit gerieftem Rand. F. bis $7 \times 5$, ziemlich gleichdick, jedenfalls nicht nach oben verdickt, fuchsig, Basis häufig weisslich. L. rostbraun. Sp. $6-8 \times 5.5$, häufig subglobar. Nadelwald.

H. obtusa Fr. nec Lange - 8. 9.

H. fulvescens Fr. - 29.8. - H. 1.5-3 breit, spitz 
gebuckelt, nass sehr dunkel, besonders der Buckel, trocken rötlichbraun, eher etwas gefurcht als gerieft. F. bis $10 \times 4.5$, weisslich, wird rostbräunlich. L. zimtorangebraun. Sp. 9.5-11× 5.5 - 6.5. Nasser Nadelwald.

H. fasciata Fr. ss. Langei (decipiens ss. Rick.) - 21. 8.

H. acuta Fr. ss. Hry - 5. 9.

Myxacium sp. - 15.8. - H. glockig, 4 breit, tiefocker (etwa wie $M$. collinitum), Rand gelblich, sehr klebrig. F. $7 \times 15$, weiss, bräunend, ganz kahl, keulig, sehr klebrig. L. tonblass, bogig herablaufend, mit zahlreichen sterilen Zellen auf der Schneide. Spp. intensiv rostfarben. Sp. mandelförmig, $10-11 \times 6-7$. Nirgends violett. Mild.

M. stillatitium Fr. Rick. - 17. 9 .

M. elatior Fr. - 3. 9. - Rand runzelig. F. violettlich, spindelig wurzelnd. L. queradrig, Schneide mit grossen blasigen Cyst. Sp. $13-14 \times 8$ etc.

M. mucosum Bull. - 16. 8 .

M. collinitum Fr. - 23.8.

M. collinitum Fr. var. subolivascens Hry - 23. 8. H. mit Olivton. L. zuerst violettlich. Sp. $11-$ $12 \times 6-7$.

M. causticum Fr. - 27.8. - Nur junge Ex. H. 2 breit, orange, Rand weiss befasert und behangen. F. $3 \times 6$, unten knollig (bis etwa 10), weisslich oder blassgelb, fest, trocken. Sp. $6-7 \times 3-4$. Fl. schmutzig mit rötlich-bräunlichem Ton. Nur Haut bitterlich.

Phlegmacium allutum Secr. Rick. - 2. 9. - H. bis 8 breit, orangefuchsig, bereift und mit weissen Velumresten am Rande. F. bis $8 \times 6$, oben weisslich, dann gelb und unten orangebraun, Knolle weisslich und klein. L. dunkeltonfarben, gesägt. Sp. c. $8 \times 4.5$. Fl. wird durch SF. blaugrün. Geruch nach Kunsthonig.

P. sebaceum Fr. Rick. - 11.9. - Keine Reaktion auf Phenol. Sonst genau wie $P$. turmale Fr. ss. Kühn, et Romagn.

P. serarium Fr. ss. Rick. - 5. 9 .

P. ferrugineum Fr. ss. Rick. - 23. 8.

$P$. aurantiacum Moser - 25. 8.

P. napus Fr. ss. Moseri - 21. 8.

P. pseudocrassum Joss. - 4.9. - H. bis 7 breit, schmutzigbraun-kanel, filzig. F. $10 \times 10-18$ (keulig), blass-bräunlich. L. sehr breit, blass, werden braun, mit blasser Schneide (Cyst.). Sp. 8-9(-10) × 4-4.5(-5). Cyst. verschiedener Form. Fl. mit Anilinöl \pm 0 , mit $\mathrm{NH}_{3}$ braun. (S. auch Karstenia III S. 58.)

P. turmale Fr. ss. Kühn. et Romagn. - 28. 8. (Vielleicht $=$ sericellum Moser und sebaceum Fr. Rick. nec turmale Fr. ss. Rick. den ich in Karstenia III, S. 48 beschrieb). H. bis 9 breit, dunkel gelbocker. F. bis 10-15, keulig, ohne Knolle, hell, bräunlich befasert. L. lehmfarben. Sp. 8-9 $\times 3-4$, doch kommen auch solche von $9 \times 5$ vor. Fl. weiss, wird im F. bräunlich, durch Phenol rot, mit SF \pm 0 . Schleierreste weiss. Nadelwald.

$P$. olidum Lange (cliduchum Fr. ss. Rick. Konr. et M.; cephalixum Hry.) -28.8

P. porphyropus Schw. - 5.8.

P. purpurascens Fr. f. eumarginatum Hry. - 26. 8. H. 5 breit, braun mit violett. Ton, sehr klebrig. F. $6.5 \times 6-12$ (Knolle), viol. durch Berührung purpurn fleckend. L. viol., purpurn fleckend. Sp. $8.5-9.5 \times 5.5-6$.

P. scaurum Fr. Rick. - 10. 8. - Ein Ex. H. 5 breit, völlig oliv(grün) braun, nur am Rande mit braunen Flecken. F. $6.5 \times 5$ (Knolle 15), nur oben schwach blau, abwärts grünlich, dann bräunlich. Knolle bleich. L. olivbraun. Sp. 9.5-11 $\times$ 7. Fl. mit Lugol weinrot.

P. fulmineum Fr. ss. Karst. - 20. 8 .

P. fulgens A. et S. ss. Langei - 14. 9.

$P$. visitatum Britz. (olivascens Batsch ss. Langei nec Moseri) - 13. 8. - H. gewölbt, bis 4 breit, olivockerbraun. F. $6 \times 7$, blass, oben bisweilen bläulich, keulig (Keule bis 10 breit). L. oliv. Sp. 7-8 $\times 5-5.5$. Geschmack rettich, bitterlich.

P. traganum Fr. - 20. 8.

P. alboviolaceum Pers. - 23.8.

P. camphoratum Fr. - 25.8.

$P$. argentatum Pers. - 7.9. - H. bis 5.5 breit weiss-seidig, trocken ledergelblich, breit gebuckelt. Viol. Töne nur am Rande. F. bis $9 \times 10$, aber auch ganz kurz und dick, z. B. $5 \times 15$, aussen und innen weiss, kahl. L. schon bei relativ jungen Ex. rostgelb, dicht, ausgebuchtet, schwach gesägt. Sp. meist $9 \times 5.5$, warzig. Geruch (Rettich?) schwach. Rasig. Dicht aneinandergepresst. Nadelwald.

P. cinereoviolaceum Fr. ss. Langei - 11. 9.

$P$. decoloratum Fr. ss. Langei - 18. 8.

P. pholideum Fr. - 21. 8 .

P. caninum Fr. - 21.9.

P. anomalum Fr. - 17. 8.

P. anomalum Fr. var. Lebretonii Quél. - 24. 8.

Leucocortinarius bulbiger A. et S. - 12.9.

Conocybe lactea Lange - 16.9. - Sp. 11-16 $\times 7$ 10.5 .

C. apala Fr. var. sphaerobasis Post - 29. 8. - H. 4 breit, bleich honigfarben, trocken nahezu weiss, kahl, nass schwach gerieft. F. $8 \times 4-8$ (knollenartige Verdickung), weiss, oben behaart, d.h. mit sehr flüchtigen haarförmigen Cyst. bedeckt, hohl, gebrechlich. L. dunkelolivgelb, angeheftet, beinahe frei. Sp. $11-13 \times 7-8$, mit Keimporus, glatt, dickwandig.

C. tenera Schff. var. subovalis Kühn. - 31.7.

C. tenera Schff. ss. Kühn. - 29.7.

C. tenera Schff. var. semiglobata Kühn. - 26. 7.

C. Rickeniana Sing. - 29.6. - Ergänzung der Beschreibung vom J. 1955: Der zellige Char. der Haut tritt nur schwach zutage. Sp. $8-9.5 \times$ 5.5-6. Köpfe der Cyst. bis 7 im Diam. Ammoniakreaktion sehr schwach.

C. siliginea Fr. var. ochracea Kühn. - 2.8. Angeblich $=$ C. plumbeitincta Atk. H. 1 breit und 0.8 hoch, ocker, stark gerieft, bleibend glockig. F. $2.5 \times 1.5$, gleichfarbig, stark behaart und sammetig. Sp. 8-10×5-6. Auf dem Rasen.

Pholiotina blattaria Fr. ss. Kühn. ss. Moseri - 7. 8. Ein Ex. H. 1.3 breit, konvex, sehr schwach gebuckelt, braun, wird trocken ockerlich, Haut zellig, Rand wenn nass gerieft. F. $2 \times 1.5$, rostbraun, Basis weissfilzig, Ring unbedeutend. L. breit angewachsen. Sp. 7-9 4-5.5. Sichtbarer Teil der Cyst. $23 \times 7$ (unten) -4 (oben). Auf Holzstückchen und neben solchen. Deckt sich mit $P$. filaris ss. Langei.

P. blattaria Fr. var. - 2. 10. - H. 1.2-1.5 breit, braun, gewölbt, sehr schwach gerieft, Haut 
zellig. F. $2-2.5 \times 2$, Ring wenig dauerhaft. Sp. 8-9 $\times 5-5.5$, warzig, mit schwachem Keimporus. Cyst. meist ganz ohne Kopf, klein, sichtbarer Teil 5-7 breit. Auf Holz,

P. sp. - 6.8. - H. bis 1.5 breit, Haut zellig, braun (etwa wie $K$. mutabilis), trocken gelbocker. F. bis $5 \times 2$, unten weissfilzig, sonst bräunlich, der dauerhafte Ring ganz oben. L. dicht und zahlreich. Sp. 5.5-6×4, glatt, sehr hell. Cyst. in der Art der Conocybe, d.h. mit dickem abstehendem Kopf, sichtbarer Teil 16 lang, Kopf auf dünnem Stiel 7 breit. Nasser Mischwald. Der Pilz steht zwischen der unklaren Gruppe filarisblattaria-togularis einerseits und $P$. brunnea Lange Kühn. andrerseits. Letztere hat Cyst. dieser Form, ist aber ohne Ring.

Bolbitius vitellinus Pers. var. typicus - 5. 8 .

B. vitellinus Pers. var. fragilis L. - 29.7. - Sp. bis $9.5 \times 6.5$.

Agrocybe praecox Pers. - 2. 7.

A. paludosa Lange (sphaleromorpha Bull.) - 27.6.

A. tabacina Cand. - 11.9.

Pholiota tuberculosa Schff. - 6. 8.

P. lenta Pers. Rick. - 1.9.

P. lubrica Pers. Rick. - 23.8.

P. sp. - 11.7. - Identisch mit dem Funde in Kasuri im J. 1955. Nicht $=P$. decussata Fr. ss. Moseri oder carbonaria Fr. var. gigantea Lange. F. bis 7 breit, leuchtend gelb- bis fuchsrot, bisweilen mit einigen blassen Schüppchen am Rande, Mitte dunkler, sehr klebrig. F. bis $8 \times 10$, weisslich, nach unten zu braunfaserig bis feinschuppig, Basis etwas verdickt und verbogen. Schleier weiss. aus $3-5$ breiten inkrustierten Fäden. L. weisslich, dann olivbraun, breit mit kurzem Zahn angewachsen. Spp. schmutzig. Sp. $5.5 \times 4$, aber auch $6 \times 4.5$ (zwei Rassen?). Cyst. dünnfleischig (ich fand nur eine dickwandige mit Schopf in der Art vieler Inocybe-Arten), 35-72 × 13-22, bald sackartig, meist in der bei der lubricalenta-Gruppe üblichen Flaschenform. Fl. dünn, gummiartig-zäh.

P. carbonaria Fr. - 28. 7

P. spumosa $\mathrm{Fr}$. - 3. 7 .

P. flavida Schff. - 28. 8.

P. abstrusa Fr. - 11.8. - H. bis 4 breir, wellig, Farbe etwa von $K$. mutabilis, trocken blass. F. bis $3 \times 3$, oben gelblich, sonst wie $H$. gefärbt, grobfaserig gestreift, knorpelig, nach unten verschmälernd, mit Velumresten. L. sehr breit (6 $\mathrm{mm}$ ), angewachsen. Sp. 6-7 $\times 4-4.5(-5)$. Gyst. schlecht sichtbar. Der sichtbare Teil etwa 3 (oben) -10 (unten) $\times 20$ (Länge). Fl. gelb. Geschmack mild. Büschelig an einem Wege. Ich fand diesen Pilz schon 1951 in Vaanila (Lohja), konnte ihn aber damals nicht bestimmen. Wenn auch diese Bestimmung nicht ideal ist, so liegt dies daran, dass die Lit. einen hier im Stich lässt. Kühn. et Romagn. werfen den Pilz mit $P$. inaurata zusammen. Lange und Moser trennen sie, doch zeigen die Abbildungen bei Lange, dass es sich hier mindestens um sehr nahe verwandte Pilze handelt.

P. myosotis Fr. f. typica -27.7 .

P. myosotis Fr. f. minor - 29. 7.

Kuehneromyces mutabilis Schff. - 27.6.

Naematoloma capnoides Fr. - 27.6.

N. elaeodes Fr. ss. Rick. - 6.9. - H. bis 7 breit, schwach gebuckelt, ziemlich trocken, gelbbraun mit braunen Velumresten. F. bis $6.5 \times 10-13$ (knollenartige, harte Basis), Farbe des H., unten dunkler befasert, Basis weissfilzig. L. grün, dann olivbräunlich. Sp. $6-7 \times 3.5-4$. Cyst. keulig (sichtbarer Teil z. B. $27 \times 10$ ) oder flaschenförmig (sichtbarer Teil z. B. $55 \times 15$ ). Fl. gelblich, mild, schwacher Geruch von C. carcharias. Auf Nadelholz. Steht $\mathcal{N}$. radicosum Lange ziemlich nahe.

N. sublateritium Fr. - 2C. 8.

$\mathcal{N}$. fasciculare Huds. - 2. 8 .

$\mathcal{N}$. radicosum Lange (epixanthum Rick. nec. Fr.) 8. 8. - Nur ein Ex. H. 2 breit, glockig, falb, Scheitel bräunlich, zum Rande zu blass-seidig überfasert, Rand besäumt. F. $7 \times 4$ (oben) -7 (Wurzel), oben mehlig, Farbe des oberen Teils falb, nach unten bräunend und mit dunkelbrauner Wurzel abschliessend. Auf dem F. Schleierreste. L. falb mit grünoliv Ton. Sp. 6-7 $\times 4$. Cyst. haarförmig. Stark riechend. Auf einer Wurzel wachsend.

N. dispersum Fr. Karst. ss. Moseri - 12.8. - H. bis 2 breit, gelb, mit fuchsigem Scheitel. F. $5.5 \times 2$, gelblich, abwärts bräunlich, weissfaserig. L. gelb bis oliv. Sp. $7-9.5 \times 4.5-5.5$. Bitter. Nadelwald.

N. polytrichi Fr. - 26. 7. - H. circa 1 breit, gelblich, nass gerieft. F. $4 \times 1.5$, oben gelblich, unten braunrot, Velumreste meist fehlend. L. weisslichgelblich, werden oliv. Sp. viclettlich, 8-9.5 $\times$ 4.5-6. Sumpf, unter Sphagnum.

N. elongatum Pers. - 8.8. - L. mit grünlichem Ton. Cyst. meist flaschenförmig, oben 6 unten 12 breit. Sp. $9.5-11 \times 5-6$.

Stropharia depilata Pers. - 3.9.

S. aeruginosa Curt. - 16. 8.

S. albo-cyanea (Desm.) Fr. - 5.9.

S. melasperma Bull. f. - 9. 7. - Nur ein Ex. H. 2 breit, ockergelb. F. $6 \times 3$, strohfarben. L. schmutzig, die durchgehenden, wie bei Agrocybe sphaleromorpha, bauchig vorstehend. Sp. violett, dickwandig, mit zentralem Tropfen und Keimporus, $8.5-10 \times 6.75-7.75$. Cyst. nur auf der Schneide, aufgeblasen (bis 19 breit). Im Moose. Sieht Agrocybe sphaleromorpha täuschend ähnlich, hat jedoch viel breitere und violette Sp. Eine volle Übereinstimmung mit den Beschreibungen von $S$. melasperma in der Lit. liegt nicht vor. Dieser Pilz wird überall als »untersetzt» gebaut beschrieben, d.h. mit relativ kurzem, dickem $\mathrm{F}$. Es handelt sich hier wohl um eine Form sehr moosiger Wälder.

S. semiglobata Batsch - 26. 6 .

S. semiglobata Batsch var. stercoraria Fr. - 28. 7.

S. semiglobata Batsch f. etiolata - 17. 8. - Mit einigen ganz blassen $15-16 \times 8-8.5 \mathrm{Sp}$.

Psilocybe merdaria Fr. - 30.6.

P. coprobia Bull. - 8. 7 .

P. atrobrunnea Lasch - 7. 8 .

P. turficola Favre - 11.7. - Nur ein Ex. Nicht identisch mit $P$. atrobrunnea Lasch. H. $1 \times 1$, dunkelrotbraun, konisch, mit anfangs eingebogenem Rand, stark gerieft, kahl. F. $3 \times 1$, hell, faserig, bereift. Sp. $10-13 \times 7-8$, grösser als bei $P$. atrobrunnea, dunkelpurpurn. Im Sphagnum-Moose.

Deconica crobula Fr. - 25.7.

D. inquilina Fr. f. - 29.7. - Ohne abziehbare 
Haut (s. Kühn. et Romagn.)

D. atrorufa Schaeff. - 25. 7 .

D. rhombispora Britz. - 27. 7 .

D. bullacea Bull. nec Langei - 9. 8. - L. braun mit schwachem Purpurton. Sp. 6-7 $\times 4.5-5$.

Panaeolus retirugis Fr. - 1.7. - Nicht hygrophan. H. lehmfarben etwas rötlich, deutlich netzigrippig, $15 \mathrm{~mm}$. hoch und $13 \mathrm{~mm}$. breit, Velumreste am Rande. F. $4 \times 2$, rötlichgrau, überall stark grob bereift. Sp. $14-16 \times 10.5-12$, citronförmig, schwärzlich, undurchsichtig. Cyst. nur auf der Schneide nachweisbar, cyl., z. B. $40 \times 8$. Im Grase, an einem Wege (gedüngter Boden?)

$P$. campanulatus L. (sphinctrinus Fr. ss. Kühn. et Romagn.) - 5. 7. - Dieser allgemein bekannte Pilz hat ff. Merkmale: glockiger, dazwischen etwas zugespitzter H., braungrau, ins Grünliche neigend, nicht hygrophan, behangen. L. sehr breit, bauchig angeheftet. Sp. citronförmig, 14-18 $\times 10.5-13$, schwärzlich, aber mit braunrotem Ton.

P. sphinctrinus Fr. - 21. 8. - Überall schwärzlich. Var. von campanulatus L.

P. acuminatus Schff. - 14. 8. - H. $18 \times 18 \mathrm{~mm}$, nur wenig höher als breit, nass dunkel schokoladenbraun, gerieft, trocken rehbraun, nicht behangen. F. $8 \times 2$, dunkel rotbraun, überall weissbereift. Sp. $10.5-14 \times 8.5-11$. beinahe subglobar. Cyst. 4-5 breit. Im Moos.

P. fimicola $\mathrm{Fr}$ - 3. 8. - H. 20 bis $25 \mathrm{~mm}$. breit und $10-12.5 \mathrm{~mm}$. hoch, nass beinahe rotschwarz und gerieft (Rand), hygrophan, trocken rötlichbraun und ungerieft, kleiner Buckel, Rand nicht behangen. $F$. bis $9 \times 2$, braunrot, nur oben bereift. L. ziemlich breit angewachsen, schwärzlich, Schneide heller. Sp. 11-12.5×7-9.5. Cyst. mit 4 breitem Köpfchen oder stumpf cyl. (4-6 breit), auch flaschenförmig, stets unbedeutend und schwer zu sehen. Auf Mist.

Anm. zur Gruppe campanulatus. Ausser der oben erwähnten typischen Art gehören hierher zahlreiche entweichende Formen. Ich habe mich in Rasila wenigstens etwas diesen Pilzen widmen können. Meine vorläufige Meinung ist die, dass ff. Unterscheidungsmerkmale von Bedeutung sind: 1) Form des H. glockig oder konisch zugespitzt (breiter als hoch oder Höhe $=$ oder $>$ Breite). 2) Farbe des H., der stets düster gefärbt ist, aber bald rötliche Töne zeigt, bald nicht. 3) Hygrophan oder nicht. 4) Behangen oder nicht. 5) Farbe des F. beinahe stets rotschwarz. Ausnahmen von Bedeutung. 6) L. angeheftet oder breit angewachen. 7) Sp.-Form citronförmig oder subglobar (mit Stielchen und breitem Keimporus). Eine sehr viel geringere Bedeutung kommt zu: 1) der Bereifung des F. 2) der Farbe der Sp. (meist schwärzlich mit rotbraunem Ton, dessen Intensität wohl stark von der Dicke der Sp. abhängt - je dicker die Sp. desto dunkler erscheint sie). 3) den Cystiden, die wohl stets da sind und nur geringe $\mathrm{Ab}-$ weichungen zeigen, 4) der Farbe der L.Schneide, 5) dem Habitat (vohl stets Mist oder gedüngter Boden). Davon ausgehend habe ich aus den 10 nicht bestimmbaren Funden vorläufig ff. 5 »Arten» gemacht.

$P$. sp. Hierher gehören die Funde vom 30. 7, 3.8, 5.8, $10.8,13.8,17.8$ (Exs. rote Nr. 114). H. glockig, breiter als hoch, hygrophan, graubraun, etc. mit rötlichem Ton, ungerieft oder kaum gerieft, unbehangen. F. lang, bis 3 breit, schwarzrot, überall bereift, Basis bisweilen weissfilzig. L. ziemlich schmal, angeheftet. Sp. $9-15 \times 8-12$, beinahe subglobal, schwärzlich mit rotbraunem Ton. Cyst. vorhanden, unbedeutend. Auf Mist oder gedüngtem Boden.

P. sp. - 17. 8. - H. weissgrau, Mitte gelblich, bis $10 \mathrm{~mm}$. breit und $6 \mathrm{~mm}$ hoch, konisch oder glockig, nicht behangen, nicht hygrophan. F. bis $5 \times 1$, gelbrötlich, oben verdickt und weissmehlig. L. sehr breit, Schneide schwach weisslich. Sp. $12-15 \times 8-9.5$, citronförmig, schwärzlich. Einige unbedeutende Cyst. a.d. Schneide bemerkt. Im Grase (auf Dünger?).

P. sp. - 17.8. - H. $25 \times 25$ mm., auch kleiner, aber Höhe stets = Breite, kast.braun, mit schwach gerieftem Rand, hygrophan, trocken rehbraun und ungerieft, Rand zackig-behangen. F. bis $12 \times 2$, schwarzrot, oben weissmehlig, unten weissfilzig. L. bis 5 breit (also schmal), angeheftet, relativ hell (schwärzlich), Rand gleichfarbig. Sp. $14-17 \times 11-12.5$. Staub beinahe schwarz. Cyst. zahlreich, haarförmig, breit und sichtbarer Tcil 32 lang.

P. sp. - 10. 9. - H. 10-19 mm. breit und 8-15 $\mathrm{mm}$. hoch, halbkugelig bis fingerhutförmig (stumpf), behangen, nass schmutzig dunkelbraun, trocken rehbraun mit rötlichem Ton. F. bis $5 \times 1.5$, dunkel, bereift, unten weissfilzig. L. breit, angewachsen, nicht bloss angeheftet. Sp. $11 \times 9.5$. etc. beinahe subglobal, schwarzbraun. Cyst. unbedeutend. Auf Mist.

P. sp. - 2. 10. - H. $15 \mathrm{~mm}$. breit und $12 \mathrm{~mm}$. hoch, nass schwarzgrau (sehr dunkel), trocken hellgrau, völlig ungerieft, behangen, anfangs beinahe kugelig mit stark eingebogenem Rand. F. $2 \times 2$, Farbe des H., fein bereift, Basis weisslich. L. angeheftet, ziemlich schmal. Sp. schwarzrotbraun, $11-13 \times 8-10$. Cyst. unbedeutend, sichtbarer Teil 5.5-6 breit. Auf Mist. Im Walde. NB. Dieser Pilz zeigte keinerlei rötliche Töne auf $\mathrm{H}$. und F.

Panaeolina foenisecii Pers. - 6. 7.

Anellaria separata L. - 28.6.

Psathyrella subatomata Lange - 8.7.

P. sphagnicola Mre - 28.6. - Nur ein Ex. H. 1 breit, flach, Rand gerieft, Mitte schwach gebuckelt, schmutzig braun, trocken ocker, Haut zellig. F. $3 \times 1$, Farbe des H., Ring sehr deutlich oben am F. L. breit, schmutzıg braun, mit viol. Ton. Sp. $8-10 \times 5.5-6.5$. Cyst. offenbar flaschenförmig, sichtbarer Teil $16 \times 10$ (unten). Sumpf.

P. coprobia Lange - 29.6. - H. bis 3 breit, halbkugelig, dann konvex, bisweilen mit kleinem Buckel, hygrophan, schwarzbraun, wird beginnend mit dem Scheitel lederfarben-ocker, besonders am Rande mit weissen Flocken besetzt, Rand gerieft. F. bis $7 \times 3$, weisslich. L. sehr breit, beinahe dreieckig. Sp. $10-11 \times 6-6.75$, durchsichtig, violettlich. Cyst. langhalsig, oben 3 breit, wenn mit Köpfchen dann etwas breiter, 60 lang und im bauchigen unteren Ende 15 breit. Auf Pferdemist, im Walde.

P. gossypina Bull. nec Lange - 5.8. - H. 2.5 breit, kastanienbraun, im Gegensatz zu $P$. noli 
tangere nur im nassen Zustande mit gerieftem Rand, trocken ockerbräunlich. F. $3.5 \times 4$, gebrechlich, oben weiss und nach unten zu sehr hell weisslich-bräunlich. L. dicht, ziemlich breit angewachsen, schokoladenfarben. Sp. c. $6-7 \times 4$. Cyst. nur wenige, c. 12 breit, flaschenförmig (sehr wechselnde Form), schlecht zu sehen. Der Pilz zeigt nur geringe Velumspuren.

P. frustulenta Fr. ss. Langei - 16. 8. - Nur ein Ex. H. 2 breit, braun, glockig, halb gerieft, behangen. F. $5 \times 2$, weiss, faserig. L. breit, schwach abgerundet angeheftet. Sp. etwa $7.5 \times 4.5$ (auch etwas kleiner). Cyst. spärlich, um 9-10 breit. Moor.

$P$. noli tangere Fr. - 4.8. - H. bis 2 breit, glockig; gerieft (trocken runzelig), schokoladenbraun, trocken blass. F. $4 \times 2$, unten bräunlich, gebrechlich. L. schokoladen braun, abgerundet angeheftet. Sp. c. $8 \times 5$. Cyst. wenige bemerkt, flaschenförmig; oben stumpf und 5 breit.

P. pseudocasca Romagn. (casca ss. Langei nec. Fr.) - 1. 8. - H. bis 3.5 breit, glockig, ockerbräunlich, trocken blass, weisse Velumreste auf der Obcrfläche und am Rand. F. bis $10 \times 7$, weisslich, flockig, Spitze bereift, ganz oben gerieft. L. weisslich-holzfarben, schmal, beinahe frei. Sp. 7-8 $8 \times 4.5$. Cyst. stumpfkonisch, z. B. $38 \times 12$ (Basis 19), oder sackförmig $12-14$ breit. Auf Holzstücken und dem Erdboden.

P. fibrillosa Pers. - 16.8. - Nur ein Ex. H. 3 breit, nass hochgerieft, graubraun, trocken blass, mit Velumresten. F. $7 \times 3$, weisslich, befasert. L. ziemlich breit angewachsen (nicht stark ausgebuchtet). Sp. 8-8.5 $\times 4.5-5$. Cyst. flaschenförmig, um 12 breit, mit langem Hals.

P. Candolleana Fr. ss. Langei - 2. 7.

$P$. egenula B. et Br. - 1.8.

P. fasciculata Bert. - 19.8. - H. bis 3.5 breit, kegelig-konvex, bleich, bis zur Hälfte gerieft, kahl. F. bis $9 \times 2$, strohfarben, gerieft, kahl, nur an der Spitze bereift. L. schmutzig-schokoladenfarben. Sp.-Grösse sehr schwankend: $6 \times 3.5,6 \times$ $4,6 \times 4.5,6.5 \times 5,7 \times 4.5$, dickwandig. Sichtbarer Teil der Cyst. 30 lang, 4 breit, oben etwas verdickt (6). In grossen Büscheln, Viehweide.

P. subnuda Karst. - 21. 7.

P. gyroflexa Fr. - 10.8. - Ein Ex. H. 1.7 breit, glockig, nass dunkel graubraun, hochgerieft, trocken rötlichgrau. F. $4 \times 1$, etwas verbogen, weiss-seidig, L.breit angewachsen, dunkelpurpurn. Sp. meist $7.5 \times 4.5$, höchstens $8 \times 5$. Einzeln. Im Grase (Wald).

P. obtusata Fr. - 3.8.

Coprinus atramentarius Bull. var, acuminatus Romagn. - 8. 8.

C. Friesii Quél. - 8. 7. - H. bis etwa $1 \times 1$, lederweisslich mit gelblichem Scheitel und gerieftem Rd. F. bis $3 \times 2$, weiss, staubig, mit verdickter etwas behaarter Basis. L. weiss, dann violettbraun. Sp. 8-10 × 7-9, etwas kantig, braun. Auf Gras.

C. phaeosporus Karst. - 28.6.

C. Rostrupianus Hansen - 6.7. - Nur ein Ex. H. 1 breit, dicht weissfilzig. Filz ablösbar. Nach Ablösung des Filzes im nassen Zustande dunkelgrau, wenn trocken bleich. Oberfläche nach Ablösung des Filzes stark gerieft. F. $6 \times 1$, steif, oben weisslich, nach unten zu allmählich bräunlich, kahl. L. bunt, mit hellem Rand, breit, mit
Zahn herablaufend. Spp. schwarz. Sp. mit deutlichem Keimporus, $12-14 \times 6.5-8$, schwach durchsichtig, schwärzlich mit rötlichem Ton. Cyst. $19-25 \times 5-11$ (unten), nur der sichtbare Teil gemessen, in der Form unregelmässig. Gedüngter Boden. Die Angaben in der Lit. weichen insofern etwas ab, als sie den Pilz als mehr untersetzt bezeichnen und (Lange) grössere Cyst. angeben, wobei allerdings festgestellt werden muss, dass ich nicht die Möglichkeit hatte die ganzen Cyst. zu sehen.

C. xanthothrix Romagn. (domesticus ss. Langei) - 3. 7 .

C. domesticus Pers. s. Métrod. - 29. 7. - Grösser als C. xanthothrix Romagn. F. über 10 lang, unten 5 breit, Basis gelblich, mit kleiner Knolle. Sp. braun, c. $8 \times 5$.

C. truncortum Quél. ss. Kühn. - 13,8.

C. niveus Pers. - 18. 8 .

C. velox God. - 6.8. - Auf Kuhmist im Waldc.

C. Patouillardi Quél. ss. Kühn. - 30.8. - H. 2.2 breit, 1.8 hoch, gelbbraun, schwach glimmerig, hoch gerieft-gefurcht, Scheibe glatt. F. $4 \times 4-5$, weisslich, hart, unten weissfilzig. Sp. nitraförmig in der Lage, wie man sie meist unter dem Mikroskop zu sehen bekommt, $5.5 \times 5$ etc. Auf Holz. Hat mit C. cordisporus Gibbs ss. Langei nichts zu tun.

C. cordisporus Gibbs - 27. 7.

C. Boudieri Quél. - 6.8.

C. impatiens Fr. - 25.7. - H. ausgebreitet bis 2 breit, Mitte schön ocker, 3/4 gefurcht. F. $6 \times 1$, unten ein wenig filzig-verdickt. L. ohne Scheibchen, nicht zerfliessend. Sp. beinahe schwarz (mit ganz schwachem braunem Ton), 11-12x 6-7. Sphagnum-Sumpf.

Russula delica Fr. - 1.8.

$R$. densifolia Secr. - 8.9.

R. adusta Pers. - 19.7.

R. foetens Fr. - 8. 8.

R. heterophylla Fr. - 20.7

$R$. aeruginea Lindbl. - 20.7.

R. lepida Fr. - 8.8.

R. rosea Quél. - 10.8.

$R$. lilacea Quél. - 20.7.

R. claroflava Grove - 20.7.

$R$. vinosa Lindbl. - 17. 8 .

$R$. xerampelina Schff, var. typica $=$ purpurata Crawsh. - 9.8.

R. xerampelina Schff. var. graveolens Romell (subrubens Lange) - 19.8.

R. Turci Bres. - 12.8.

$R$. alutacea $\mathrm{Fr}$. ss. M. et $\mathrm{Zv},-23.7$.

$R$. curtipes Møll. et Schff. - 1.8.

R. Romellii Mre - 4.8.

$R$. nauseosa Pers. (chamaeleontina ss. Langei) - 21. 7.

$R$. venosa Vel. ss. Melz. - 27. 7.

$R$. venosa Vel. var. subingrata Sing. - 15. 8.

R. puellaris Fr. - 4.7.

R. paludosa Britz. - 24.7.

R. Velenovskyi M. et Z. - 12.8.

R. betulina Burl. - 27.7. - Nähert sich R. Velenovskyi und $R$. venosa. H. 5 breit, rötlichgelb mit oliv Ton, matt, niedergedrückt und flach gebuckelt, Rand sehr dick, beinahe gefurcht. F. bis $7 \times 13$, schneeweiss, ziemlich schwammig. L. sehr breit, sahnefarben. Sp. isoliert-stachelig, Farbe E., Grösse 10-12.5 × 8-9.5. Mischwald. (Fichte und Birke). 
R. atropurpurea Krombh. - 26. 7. - Bisweilen beinahe mild.

R. emetica Schff. var. typica - 23. 7.

$R$. emetica Schff. var. silvestris f. pityophila Romagn. - 1.8 .

R. Mairei Sing. ss. lato Kühn. et Romagn. - 29. 7 .

R. fragilis Fr. - 12. 8 .

$R$. fragilis Fr. var. nivea Pers. Cke (anomala Peck.) -31.8 .

$R$. versicolor J. Schff. -7.8 .

R. sanguinea Bull. - 16.8.

R. Queletii Fr. - 8. 8 .

Lactarius torminosus Schff. - 13. 8.

L. uvidus Fr. - 24. 7.

L. deliciosus L. - 28.6.

L. necator Pers. - 5.9.

L. zonarioides Kühn. et Romagn. - 2. 9. - H. 3-4.5 breit, orangerot, etwa wie Russula decolorans, klebrig, Rand ziemlich kahl, eingebogen. F. bis $3 \times 9$, weiss, unten gelblich, hart. L. etwas heller als H. Milch unveränderlich weiss,- reichlich, scharf. Fl. weiss, KOH-Reaktion gelblich, unverkennbarer Apfelgeruch. Sp. ziemlich gross, bis $10 \times 8$, grobwarzig, ziemlich dunkel (bis Crawshay E.). Nadelwald. Der Pilz gehört sicher der Gruppe zonarius an. Von den 5 Arten dieser Gruppe scheiden zonarius, acerrimus und porninsis aus verschiedenen Gründen aus. In Betracht kommen nur zonarioides und insulsus Fr. ss. Neuhoff. Letztere Art ist jedoch nur in Laubwäldern heimisch und hat kleinere Sp. Der vorliegende Pilz stimmt mit den Beschreibungen von $L$. zonarioides ganz gut, jedoch nicht ideal überein, doch sind die Abweichungen (schwache Zonen und geringere Grösse) nicht genügend, um eine neue Art zu rechtfertigen. Zu berücksichtigen ist auch, dass meine Ex. offenbar nicht voll entwickelt waren. Ungeklärter Fall.

L. vietus Fr. - 16. 8.

L. trivialis Fr. -5.8 .

L. hysginus Fr. - 1.8. - H. bis 5 breit, sehr effektvoll rotbraun, mit schwachem violettlichem 'Гon, kahl, dazwischen mit kleinem Buckel. Erinnert an $L$. rufus. Im Gegensatz zu diesem sehr klebrig. F. bis $6 \times 10$, rötlichbraun, heller als $\mathrm{H}$., klebrig. L. gelblich, werden ockerlich. Sp. gewöhnlich $7 \times 6$, grobgestielt. Milch wässerig, wird langsam scharf. Nasser Mischwald.

L. picinus Fr. - 1.8 .

L. Hibbardiae (glyciosmus Neuhoff) - 6.8.

L. mammosus Fr. - 4.8. - Wie L. glyciosmus Fr. In der Jugend mit spitzem Buckel, alt niedergedrückt, 1.5-4 breit. Ohne Geruch.

L. glyciosmus Fr. - 4.8.

L. flexuosus Fr. - 30.7.

L. lilacinus Lasch 12.8.

L. spinosulus Quél. - 14.9.

L. mitissimus Fr. - 22.8.

L. cremor Fr. ss. Karst. Rick. - 19. 8.

L. obscuratus Lasch ss. Pears. (cyathula Rick.; obnubilis Lasch ss. Langei) - 23. 7.

L. cupularis Bull. Fr. - 20.8. - Dieser Pilz wird neuerdings von Moser von $L$. obscuratus abgetrennt. Unterschiede, so weit ich sehe, stärkere olivgrüne Töne (übrigens F. und L. ohne solche), meist mit Papille, Rand auch im trockenen Zustande gerieft. Ich fand vereinzeltes ein
Ex., das genau diese Merkmale zeigte. Trotzdem halte ich diese Abtrennung für ziemlich zwecklos.

L. helvus Fr. - 6. 8.

L. camphoratus Bull. - 20.8.

L. rufus Scop. - 20.7.

L. subdulcis Pers. - 28. 7.

L. sphagneti Fr. ss. Moseri (lacunarum Romagn. Lange) - 13.8. - H. 2-3 breit, orangerötlich, ungerieft, mit undeutlicher Papille, bald niedergedrückt. F. bis $3 \times 7$, wird gleichfarbig. L. zuerst weisslichocker, dann mit H. gleichfarbig. Sp. mit ziemlich groben, verbundenen Warzen, $8 \times 6$ etc. Milch weiss, mild (schwach bitter), gilbt selbst nicht, ruft aber auf dem Fl. schwache Gilbung hervor. Sumpf.

Calvatia caelata Bull. - 27.9.

C. saccata Vahl - 18. 8.

Lycoperdon molle Pers. - 11.9. - Angeblich identisch mit umbrinum ss. Hollos. Bis 3 breit und 2.3 hoch, breite Birnenform, gelblich-rehbraun. Stacheln sehr klein. Spp. rost- bis schokoladenfarben, nicht olivlich. Sp. 4-5.5, grobwarzig, beinahe sternförmig, mit langen (bis 19) Stielchen, die leicht abfallen. Auf verfaultem Balken, oder eher auf dem Moos, das den Balken bedeckte. Geruchlos.

L. gemmatum Batsch - 7.8.

L. umbrinum Pers. - 10.8 .

L. pyriforme Schff. -24.7 .

L. pedicellatum Peck (caudatum Schroet.) - 27. 8. Kreiselförmig, 2.5 breit, 2.4 hoch, davon 0.6 auf den F. entfallend. Stacheln zusammenneigend, büschelig, c. $2 \mathrm{~mm}$. lang, bräunlich, bald abfallend. Innere Peridie öffnet sich mit rundlicher Mündung und ist nach der Öffnung grünlich-gelblich (wohl verfärbt durch Sp.). Fruchtmasse oliv. Sp. etwa 4 im Diam., glatt, mit 8-25 langer Füsschen. Waldrand.

Bovista nigrescens Pers. - 19.9.

Cantharellus cibarius Fr. - 23.8.

Tremella encephala Willd. - 19. 9. - Frk. bernsteinfarben mit Orangeton, geschwulstartig, um 1 breit, gehirnartig gefaltet, mehlig. Sp. $7-9 \times$ 6 -8, schwach gefärbt (gelblich), schwach kantig. Auf Borke.

Exidia repanda $\mathrm{Fr} .-3.10$.

E. saccharina Fr. - 17.9. - Auf Nadelholzzaun.

Ditiola radicata Fr. - 23. 7. - Auf Nadelholzzaun. Calocera flammea Schff. - 29.8.

Corticium laeve Pers. - 2. 10.

Peniophora $s p$. vermutlich $=P$. tomentella Bres. f. depauperata s. Bourdot et Galzin No 474-30. 7. Nicht sehr gross, z. B. eine Fläche von $6 \times 2 \mathrm{~cm}$. bedeckend, weiss. Sp. sehr klein (um $3 \times 2$ ). Cyst. sichtbarer Teil $30-50 \times 3$, dünnwandig. Auf Birke.

Peniophora incarnata Pers. - 3. 10. - Fest angeklebt, rötlich, ausbleichend, sehr dünn, zusammenfliessend. Rand byssusartig. Trocken gepudert. Sp. 7-9 $\times 3.5-4.5$. Gyst. vorhanden. Auf trockenem Ellernast.

Mehrere Corticium- und verwandte Arten konnten nicht bestimmt werden.

Plicatura nivea Karst. - 6. 9. - 1.5 × 1, muschelartig, blass (weisslich auch gelblich), filzig, am Scheitel 
befestigt. Fruchtlager weiss, aderig-runzelig. Sp. weiss, sehr klein. Meist auf Ellernästen oder Blättern.

Stereum hirsutum Willd. - 4. 7.

S. rugosum Pers. - 1.10.

S. sanguinolentum Schw. - 18. 7.

S. purpureum Pers. - 29. 7.

Radulum orbiculare Fr. - 28. 6.

$R$. membranaceum A. et S. - 27.9. - Wie $R$. orbiculare, aber mir runden $\mathrm{Sp}$.

Sarcodon imbricatum L. - 11.9.

S. subsquamosum Batsch - 17.9.

S. violascens A. et S. - 26.8. - H. 6-10 breit, schmutzigviolett, Rand meist weisslich, Oberfläche wird bald sehr rauh und zerbricht schuppig. F. $5-10 \times 20-40$ (oben), abwärts verjüngt, etwa gleichfarbig, häufig verästelt. Stacheln weiss, 2-3 lang. Sp. warzig, 4-4.5 im Diam. Fl. violettlich, mild, riecht angenehm, etwa wie $L$. helvus und $L$. camphoratus.

Phylacteria terrestris Ehrh. - 26.6.

Polyporus confluens Fr. - 22.8.

Melanopus varius Pers. - 1.8 .

M. picipes Fr. - 3.8. - Sp. $8 \times 3$.

$M$. varius Pers. f. squamigerus Pil. (elegans Bull. ss. Rick.) - 23. 8.

M. melanopus Pers. - 12.9.

Leucoporus brumalis Pers. - 27. 6 .

L. arcularius Batsch $\mathrm{f}$. rigosus - 23, 8 .

$L$. arcularius Batsch f. scabellus - 23. 8 .

Leptoporus lacteus Fr. - 29. 8.

L. caesius Schrad. - 20.9.

L. floriformis Quél. - 26.7. - Meist dachziegelig. H. halbiert, 2-3.5, weiss, der Länge nach strahlig-runzelig. Röhren sehr kurz, weiss. Fl. lederig, nie hart. Sp. $4-5 \times 2-2.5$.

L. amorphus Fr. - 26. 6 .

L. adustus Willd. - 26. 6.

Coriolus pubescens Schum. - 9.7.

C. velutinus Pers. - 28.7.

C. hirsutus Wulf. 1.7.

C. fibula Fr. - 23.7.

C. zonatus Nees - 27.7.

C. versicolor L. - 26. 6 .

C. unicolor Bull. - 26.6.

C. abietinus Dicks. - 1.7.

C. Neesii Fr. var. alneus Fr. - 6.9.

Lenzites betulina L. -5.7 .

L. sepiaria Wulf. $-28,6$.

Trametes serialis Fr. -26.7.

Ungulina fomentaria L. - 26. 6.

U. marginata Fr. - 25. 6.

$U$. betulina Bull. - 2.7

Ganoderma applanatum Pers. - 6.7.

Phellinus igniarius L. - 27.6.

P. salicinus Pers. - 27.6.

$P$. nigricans $\mathrm{Fr}$. - 4.7. - Oberfläche schwarz, beinahe glänzend. Sonst wie $P$. igniarius L.

P. nigrolimitatus Romell - 6. 7.-Braun, im Umkreis hell, feinfilzig. P. circa 5 per $1 \mathrm{~mm}$. Röhren 1-2 mm. lang, doch kommen auch Längen von 4 vor, dunkeln beim Altern. Röhrenschichten getrennt durch schwarzi: Linie. Sp. $5 \times 2$. Cyst. dickwandig $19-45 \times 6-10$, sehr ungleich verteilt. Auf einer alten Wand (Fichte).
Xanthochrous perennis L. -2 2i. 6.

X. pini Brot. - 2. 7 .

\section{ASCOMTCE TES.}

Gyromitra infula Schff. - 23.8.

G. sp. - 20. 9. - Steht G. infula nahe. Bis 9 hoch. H. schwarzbraun mit viol. Ton. F. bis 30 breit, im Jugendstadium ausgesprochen dunkel violett. Im trockenen Zustande tritt die violette Farbe stark zurück, so dass der Pilz auf dem H. eine schwärzliche und auf dem F. eine dunkelgraue Farbe mit violettlichem Schimmer zeigt. Der F. ist unten meist weiss bereift. Sp. 18-24-28 $\times 9$, schief-einreihig, aber auch zweireihig. Die Sp. sind einseitig verdickt und haben meist 0 bis 1 , die in den Asci sitzenden häufig 2, sogar 3-4 Tropfen. Die Asci haben bei einreihiger Anordnung einen sporif. Teil von etwa $152 \times 9$. Bei zweireihiger Anordnung sind sie bis 21 breit. Par. bis 22 breit, bisweilen ästig. Geruchlos. Sumpfgebiet. Gegen Frost sehr widerstandsfähig. Cudonia circinans Pers. - 7.9.

C. confusa Bres. - 11.8.

Spathularia clavata Pers. - 9.9.

Macropodia macropus Pers. - 29. 8.

Aleuria aurantia Müll. - 13. 8. - Sp. 16-18×8-9, grob warzig.

Humaria fusispora Berk. - 13.9. - Bis 6 mm. breit, schalenförmig, ohne F. Rand häufig gezähnt. Fruchtscheibe orange. Aussenseite gleicher Ton, aber viel blasser, glatt. Sp. $19-20 \times 8$ mit 1 bis 2 Öltropfen. Asci blauen nicht, bis $240 \times 12$. Par. gelb, 5 breit. Rasig, im Walde, nicht auf Mist.

Plicaria echinospora Karst. - 10. 8. - Schüsselförmig, bis $8 \mathrm{~cm}$. breit, wellig verbogen, eingeschlitzt. Aussenseite braungelb, Innenseite rotbraun. Kurzer gelblicher F. Sp. warzig, $15 \times 8.5$ etc., ohne Öltropfen. Auf Holzabfall.

P. badia Pers. - 24. 7 .

P. Stevensonia Rehm (varia Hedw.) - 11.8. Halbkugelig, dann schüsselförmig, schiesslich umgeschlagen, bis 7 breit. Scheibe braun, aussen weiss, kleiig-schuppig. F. weiss, 6-10 $\mathrm{mm}$. lang, breitgedrückt, grubig. Sp. $14.5-16 \times 8-8.5$, ohne Öltropfen oder nur mit einem. Asci $230 \times$ 12, blauend. Auf Holzabfällen.

P. fimeti Fuck. - 23. 7. - Sp. 18-19×9-9.5.

Lachnea gregaria Rehm - 18. 7. - $3 \mathrm{~mm}$. breit, innen (Fruchtschicht) gelblich-weiss, aussen dicht braunbehaart. Haare 200-270 lang und unten bis 10 breit, nach oben nicht spitz, aber abschmälernd zulaufend, schwach septiert. Sp. (15-) $19-21 \times 9.5-11$, ziemlich glatt, mit einem grossen Öltropfen. Par. 5 breit, ebenso wie die Sp. hyalin. Asci etwa $200-280 \times 12-13$. An einem Waldwege im Nadelwalde, sehr gesellig bis gedrängt.

L. gemella Karst. - 10.8. - $2-8 \mathrm{~mm}$. breit, schüsselförmig, cinnober, Aussenseite hell behaart. Haare c. 14 breit. Asci $125-195 \times 9.5-13-15$, durch Jod bräunend. Die Sp. füllen nicht den ganzen Sack. Sp. $12-16 \times 7-8$, einreihig, glatt, ohne resp. mit einem Öltropfen. Auf Mist.

L. scutellata L. -27.6 .

Helotium citrinum Hedw. - 23.9. - H. bis $2 \mathrm{~mm}$. breit. Fruchtscheibe gelb, kahl, schüsselförmig vertieft. Aussenseite gelblich, unter schwacher 
Lupe schwaoh filzig-mehlig. F. bis $3 \mathrm{~mm}$. lang, unten dunkler und schuppig-behaart. Sp. um $17 \times 5.5$, spulenförmig, mit einem flachen seitlichen Öltropfen, hyalin. Asci um 8 breit. Auf verfaulter Birke.

Coryne sarcoides (Jacq.) Tu. - 1.9.

Nectria cinnabarina Tod. - 1.7.

Abschliessend bringe ich nun eine Liste der Pilze, die in Südfinnland sehr häufig sind und im Gebiete von Rasila entweder völlig fehlten oder nur selten nachweisbar waren. Bei Beurteilung dieser Liste ist zweierlei im Auge zu behalten. Erstens, war ich in diesem Gebiete volle 100 Tage tätig und habe in dieser Zeit bestimmt um 1000 Kilometer zurückgelegt. Zweitens, ist das Gebiet um Rasila - im Gegensatz zu dem fichtenlosen Rayon um Parikkala, den ich 1955 besuchte - ein sehr vielseitiges. Wenn also viele Arten in Rasila sehr selten oder garnicht nachgewiesen werden konnten, so mag dies in Ausnahmefällen gewiss auf ein Übersehen meinerseits oder auf für die fragliche Art nicht günstige Bodenverhältnisse und Wachstumsbedingungen zurückzuführen sein. Die Hauptursache wird man aber sicher beim klimatischen Faktor suchen müssen. Der Frühling ist spät, der schöne Sommer ist kurz und ab Anfang September setzen in der Regel starke Nachtfröste ein, die der Entwicklung von Fruchtkörpern häufig ein frühzeitiges Ende bereiten.

Boletus edulis sah ich hier nur zweimal (zusammen 4 Exemplare).

Tylopilus felleus fehlte völlig.

Hygrophoropsis aurantiaca sah ich nur in zwei kleinen Grüppchen.

Die Hygrophoraceae waren sehr schwach vertreten. Häufiger waren nur Hygrophorus olivaceo-albus und Verwandte, Hygrophorus hypothejus und agathosmus, endlich Hygrocybe miniata. Alle übrigen von mir aufgezählten Arten waren ganz ausgesprochen selten.
Glitocybe nebularis fehlte völlig.

Iricholoma war ganz schwach vertreten. Es fehlten völlig vaccinum, imbricatum, album, saponaceum, virgatum und terreum resp. myomyces. Dic im Süden des Landes höchst gemeine Art flavobrunneum, ferner equestre und portentosum sah ich nur je einmal.

Lentinus lepideus fehlte völlig.

Marasmius war sehr schwach vertreten. Häufiger waren eigentlich nur perforans, androsaceus und epiphyllus zu sehen. Scorodonius und oreades sah ich nur je zweimal.

Xeromphalina campanella sah ich nur zweimal, das eine Mal übrigens merkwürdigerweise auf Birke. wachsend.

Mycena rosella fehlte. Wohl Zufall?

Clitopilus prunulus. Nur ein Exemplar.

Amanita. Reichlich waren nur muscaria und regalis vorhanden. Vaginata war bisweilen in wenig ansehnlichen Exemplaren zu sehen. Von porphyrea und rubescens sah ich nur je ein Exemplar. Alle übrigen Arten fehlten.

Lepiota s. lat. Nichts ausser einigen, nicht gerade häufigen Vertretern der clypeolaria-Gruppe.

Agaricus. Ich sah nur je ein Exemplar von silvicola und abruptibulba und je ein Grüppchen campester und rusiophyllus.

Telamonia im alten Sinne war sehr stark vertreten im Gegensatz zu Hydrocybe ss. restr. Von den Hydrocybe-Arten waren acuta und obtusa besonders selten.

Es gab nicht sonderlich viele Phlegmacium-Arten und die Zahl der gefundenen Exemplare war unbedeutend. P. triumphans fehlte ganz.

Pholiota. Die schuppigen Baumbewohner fehlten.

Psathyrella ss. restr. im Sinne der grosssporigen Arten fehlten beinahe völlig.

Coprinus comatus fehlte völlig.

Von Russula foetens sah ich nur ein Exemplar, consobrina, vesca, decolorans und lutea fehlten.

Lactarius scrobiculatus aud repraesentaneus fehlten, deliciosus und necator waren hier 1956 Raritäten.

Cantharellus cibarius sah ich nur zweimal. Einige schlechte Exemplare.

Bovista plumbea fehlte.

Von den etwa 20 mir bekannten Clavaria-Arten sah ich nicht eine einzige.

Hydnum repandum fehlte und von Sarcodon imbricatum sah ich nur zwei Exemplare an einer Stelle. Ich sah nicht eine einzige Calodon-Art.

Polyporus ovinus fchlte völlig!

\section{Nachträge}

Ich habe das Gebiet von Lohja kaum systematisch untersucht, denn meine Beobachtungen von 1951 in Vaanila und Umgegend (Karstenia III, S. 30 - 32) brachten nur sehr schwache Resultate. Das Jahr 1951 war ein sehr schlechtes Pilzjahr. Meine Funde im Gebiete Lohja waren also Gelegenheitsfunde. Ich erwähne jedoch ergänzend einige v. Jahre 56, da sie allgemeineres Interesse haben könnten:
Calocybe Georgii Clus. ex Fr. - 10.6. - Äusserst selten auf dem Festlande Finnlands.

Exidia pitya Fr. - 18. 10. - $2.5 \times 2 \mathrm{~cm}$. und c. 1 $\mathrm{cm}$. hoch, weich, untere Seite runzelig-faltig, Fruchtlager schwarz, gehirnartig mit Papillen. Sp. $12 \times 5.5$, wurstförmig. Auf Fichtenstumpf. Steht E. Friesiana mindestens sehr nahe.

Ischnoderma benzoinum (Wahl) Karst. - 19.10. Dieser Pilz ist in den grossen Werken von Bourdot et Galzin, Overholts und Bondarzev nicht zu finden. Die Pilze dieser Forscher unter den Namen benzoinum, resinosum und fuliginosum haben 
viel schmälere $\mathrm{Sp}$. (meist bis 2, selten 2.5 gegen 3 bis 4 bei Karsten und 3.7 bei Prof. Kujala 1956).

Abschliessend noch einige Funde aus Mustila/Elimäki, obgleich sie eigentlich schon ins Jahr 1957 gehören.

Ich fand ff. Pilze, die ich früher in Mustila nicht sah:

Pleurotellus acerosus Fr. var. - 15. 4. - H. $2 \times 1$, braun, nierenoder schaufelförmig, gerieft und niedergebogen. Haut nicht abziehbar. F. sehr klein, bis höchstens 1 lang, aber ziemlich dick, gut sichtbar, hellbraun, unten ziemlich schwach weissflizig. L. sehr schmal, sehr dünn, sehr dicht, Farbe des H., abgegrenzt. Sp. um $8 \times$ $3-3.5$, weiss, einseitig etwas abgeplattet. Fl. weiss, angenehmer Geruch, ohne Geschmack. Auf Kiefer- oder Abies concolor-Stange (Unterlage für gestapeltes Papierholz), beinahe treppenförmig. Der Pilz ist braun, während die Hauptform eher grau sein soll. Er hat offenbar Ende März fruktifiziert. Damals gab es vielleicht 1 Woche richtiges Tauwetter. Als ich ihn fand, machte er einen ziemlich frischen Eindruck, trotz der schweren Fröste der ersten Hälfte des Monats. Er hatte noch recht viele Sp. Die ausgesprochen braune Färbung wird in der Lit. nur in Karstens Hauptwerk erwähnt.

Rhodophyllus dysthales Atk. Romagn. -6. 4.- (R. fumosellus Wint. ss. Lange ist nahe verwandt, aber nicht identisch). H. bis $8 \mathrm{~mm}$. breit, kegeligglockig, feinschuppig besonders in der Mitte, schwarzbraun, weisshaarig, Rand schliesslich gerieft. F. bis $2 \times$ höchstens 1 , unten breiter, faserig gestreift, hohl, schwarzbraun, weisshaarig. Haare sehr flüchtig. L. graubraun mit rötlichem Ton, dicklich, ziemlich entfernt, ausgebuchtet angewachsen. Sp. 11-16 $\times 7-10$, schwach kantig. Treibhaus, unter Asparagus Sprengeri.

Agrocybe praecox Pers. - 16.3. - Im Treibhaus, merkwürdigerweise auf einer Holzkiste (Nadelholz).
Deconica physaloides Bull. - 4. 3. - H. bis 1.5 breit, gewölbt, schliesslich niedergedrückt, nass mit gerieftem Rand, trocken ungerieft, schwarzbraun, trocken gelbbraun, kahl, glänzend, Huthaut nicht abziehbar. F. bis $4 \times 2$, oben hell, unten sehr dunkel, faserig. L. dunkelbraun, dicht, breit angewachsen. Sp. linsenförmig, von vorne gesehen 6-8 $8 \times 4-5$, mit deutlichem Endospor, sehr hell. Cyst. haar- bis spulenförmig, $20 \times 5$. Treibhaus, gedüngter Boden.

Coprinus roris Quél. - 8.3. - H. bis 5-10 mm. hoch, falb, strahlig gefaltet, Scheibe rostbraun, unter Lupe glimmerig. F. $2-3 \times 0.5-1.0$, bereift, Basis feinzottig. L. blass, nicht zerfliessend. Sp. $8.5-10 \times 5.3-5.7$, dunkel, aber nicht schwarz. Treibhaus, gedüngter Boden. Exs. leider missglückt. Die Hüte schrumpfen bis zur Unkenntlichkeit beim Trocknen zusammen und fallen ab. Der Pilz sieht äusserlich etwa so aus wie Langes C. miser, Tafel 157 B. Konrad und Maublanc irren sich, wenn sie ihn mit Langes C. cortinatus identifizieren.

Corticium lacteum Fr. - 16. 3. - Weit ausgebreitet, milchfarben, später gelblich, Rand weisslich, feinstens gefasert. Hyphen 2-4 breit, nur wenige Schnallen (Prof. Kujala fand solche, ich nicht). Sp. $7.5 \times 3$ Auf Birkenbrennholz. Karstens $C$. lacteum $=$ Peniophora subcremea v. Hoehn. et Lit.

C. roseum Pers. - 17. 3 .

Radulum membranaceum Bull. -2.4. - Makroskopisch und besonders mikroskopisch Corticium confluens Fr. sehr ähnlich. Fruchtlager mit deutlichen flachen Warzen. Hyphen mit seltenen Schnallen, $2-4.5$ breit. Sp. um $9 \times 6$. Cyst. nicht vorhanden. Auf Birkenbrennholz.

Über die Verwandtschaft mit C. confluens Fr. siehe Bourdot et Galzin, p. 213 und 403. Vielleicht nur Formen einer Art?.

Xanthochrous rheades (Pers.) Pat. (vulpinus Fr.?, dryophilus Berk.?) - 10.4. - Meist ziemlich klein (3-6 cm.), aber dick und fest, fuchsig, filzig, aber bald kahl, nicht gezont. R. sehr lang (bis $17 \mathrm{~mm}$.) P. rundlich, aber bald eckig, verlängert und schliesslich zerrissen. Sp. $5.5 \times 4.3$, braun. Ohne setae. Auf Espe. 
Ich bitte folgende Versehen und Fehler in Karstenia III zu korrigieren:

Seite 20, Spalte 2, Zeile 19 von unten: Xeromphalina statt Xerophalina.

\begin{tabular}{|c|c|c|c|c|c|c|}
\hline & 21 , & $\gg$ & 2 , & $19 \gg$ & oben : & 6.5 statt 6.6 . \\
\hline ») & 23 , & $»$ & 1 , & $16 \gg$ & $\gg$ : & Nach Fr. einfügen $\mathrm{H}$. \\
\hline 》) & 23, & $\gg$ & 1 , & $21 \gg$ & unten: & (Mairei Singer) streichen. \\
\hline 》) & 26. & $\gg$ & 2 , & $21 \gg$ & $» \quad:$ & Lyophyllum statt Fayodia \\
\hline i) & 26 , & $»$ & 2 , & $7 »$ & $\gg$ : & Kaum statt Viell. \\
\hline ע & 30 & $»$ & 1 , & $9 »$ & $\gg:$ : & subinvoluta statt involuta. \\
\hline & 31 & Spalte & 2, Zeile & 22 von & unten: & 4.5 statt 6.5 \\
\hline & 32 , & 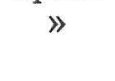 & 1, Zeilen & 31,32》 & oben : & $\begin{array}{l}\text { atropurpurea Krombh. var. depallens Maire, statt } \\
\text { fusco-vinacea Lange (depallens Fr.ex Pers. ss. Cke) }\end{array}$ \\
\hline 》 & 33 , & $»$ & 1 , & $1 »$ & oben : & streichen \\
\hline » & 35 & $\gg$ & 1 , & $20 \gg$ & oben : & nach »rosa» ein Punkt. \\
\hline$»$ & 35 , & $\gg$ & 2 , & $23 \gg$ & unten: & Komma nach »weiss» streichen. \\
\hline$»$ & 36 & $\gg$ & 2 , & $7 \gg$ & oben : & $9-9.5$ statt $9-5$ \\
\hline » & 37 , & $»$ & 1 , & $13 »$ & unten: & F. statt Fl. \\
\hline » & 37 & $\gg$ & 2 , & $27 »$ & oben : & $5-5.5$ statt $5 \times 5.5$ \\
\hline » & 37 , & $\gg$ & 2 , & $8 »$ & unten: & rostfarben statt rotfarben. \\
\hline 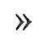 & 38 & $\gg$ & 2 , & $32 »$ & $\gg:$ & 15 statt 5 \\
\hline 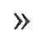 & 3 & $»$ & 1, & $15 »$ & unten: & Sp. statt S. \\
\hline 》» & & $»$ & $»$ & $16 »$ & $\gg$ : & $15 \times 12$ statt $15-12$ \\
\hline
\end{tabular}

$» 44, \quad 1, \quad 7$ »

unten: Komma nach »trocken» streichen und vor "mit» einistellen

» 45, Spalte 1 , Zeile 7 von oben : H. statt F.

$» 49, » 1, \quad 25$ » unten: $7.5 \times 5.5$ statt $7.5-5.5$.

$» 51, » 1, » 13$ » oben : non Fr. Quel. statt Quel., non Fr.

$» 54, » 2, » 6$ » unten: Komma nach »trocken» streichen.

$» 55, » 1, \gg 21 \gg$ » Micromphale statt Michromphale.

$\gg 56, \gg 1, \quad 20 \gg \gg$ : Hispidodermi statt Hispidoderni.

$» 57, \gg 1, \gg 24$ » $\gg$ ben : putilla statt pusilla

»59, »1, »25 $\gg$ oben : 17.8. statt 17.6.

»63, » 1, 4 » unten: Omphalina statt Omphaliella.

$» 63, » 2, » 8 \gg$ » $\quad$ ( nach »Metr.» einfügen - 14.9. -

$» 64, \gg 1, » 9$ » oben. Ich statt Iche.

$» 64, \gg 1, \gg 32 \gg$ » nach $\gg 7 »$ einfügen $\mathrm{mm}$.

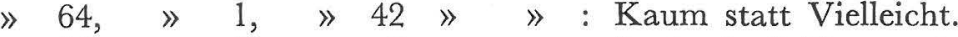

»64, 》 $1, \gg 5$ » unten: $3-4 \times 1-2.25$ statt $4-4.5 \times 2.5-3$.

$» 65, » 1$, Zwischen A. xanthodermus und abruptibulbus ist einzuschieben:

A. augustus Fr. - 28. 9. - H. bis 20 breit, blass, mit braunen Fäserchen bedeckt, gilbend. F. $10-20 \times 20-40$, weiss. L. nicht rosa, sondern zuerst weiss, schliesslich schokoladenfarben. Sp. 8-10 $\times 5-8$. Geruch angenehm, nicht nach Anis. Schaefferreaction positiv. Nadelwald.

»66, Spalte 1, Zeile 9 von oben : Nach »Maire»). einfügen - 1.10. - 